\title{
0 edeago na sistemática de passalídeos americanos (Coleoptera: Passalidae)
}

\author{
P. F. Bührnheim \\ Departamento de Zoologia \\ Instituto de Biologia \\ Universidade Estadual de Campinas \\ São Paulo
}

ACTA AMAZONICA Vol. 8(1): Suplemento 2 
BUHRNHEIM, P. F.

O edeago na sistemática de Passalídeos americanos (Coleoptera: Passalidae). Acta Amazônica, Manaus, 8(1): Suplemento 2 mar. 1978.

60 p. ilust.

1. Passalidae - Morfologia - Sistemática 2. Zoologia Sistemática 1. Título.

CDD 595.76

18.ed.

595.7

CDU 595.76

595.70

RESUMO: Estudo da morfologia da genitália mosculina dos Passalidae (Coleoptera) e da origem de seus somitos, resultando no ochado de uma provável rotoçăo do edeago, em caráter permanente, de $1800 \mathrm{em}$ torno do eixo longitudinal. Apresenta a descriçăo do edeago de 26 espécies de Passalidae, 14 das quais ocorrem no Amazônia, abrangendo os gêneros Odontotaenius, Popilius, Vełurius, Verres, Paxillus, Spasalus e Passalus. A discussäo do significado taxonômico dos edeagos demonstra que são capazes de caracterizar espécies e a maioria dos gêneros estudados. As variaçōes intraespecíficas encontradas permanecem dentro dos limites das espécies e algumos, com indicios de significado populacional, sugerem a possibilidade de uso do edeago em estudos de distribuiçāo. Sâo discutidas também as técnicas de preparo e representaçāo do edeago para fins taxonômicos. 
Introdução $\ldots \ldots \ldots \ldots \ldots \ldots \ldots \ldots \ldots \ldots \ldots \ldots \ldots \ldots \ldots \ldots \ldots \ldots \ldots$

Agradecimentos $\ldots \ldots \ldots \ldots \ldots \ldots \ldots \ldots \ldots \ldots \ldots \ldots \ldots \ldots \ldots \ldots \ldots$

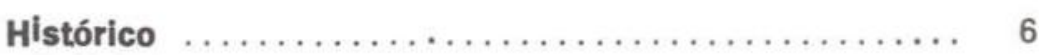

Material e Métodos $\ldots \ldots \ldots \ldots \ldots \ldots \ldots \ldots \ldots \ldots, 8$

Material estudado $\ldots \ldots \ldots \ldots \ldots \ldots \ldots \ldots \ldots, 8$

Métodos empregados $\ldots \ldots \ldots \ldots \ldots \ldots \ldots \ldots \ldots, 8$

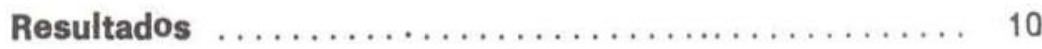

Morfologia da genitália masculina $\ldots \ldots \ldots \ldots \ldots \quad 10$

Morfologia do edeago nas espécies estudadas ..... 10

Variação do edeago em Passalus interruptus (Lin., 1758) ......................... 40

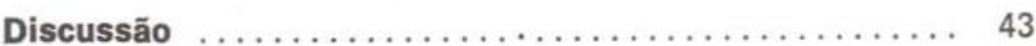

A genitália masculina e suas homologias ....... 43

O edeago na sistemática das espécies estudadas .. 44

Variação intra-específica do edeago ............ 49

Técnicas de preparo e representação do edeago ... 50

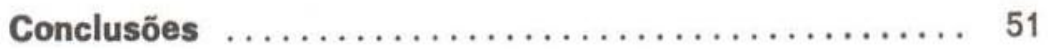

Summary $\ldots \ldots \ldots \ldots \ldots \ldots \ldots \ldots \ldots \ldots \ldots \ldots \ldots \ldots \ldots \ldots \ldots \ldots, \quad 53$

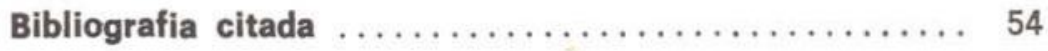

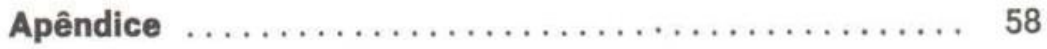

Material examinado $\ldots \ldots \ldots \ldots \ldots \ldots \ldots \ldots \ldots \ldots \ldots$

Indice das espécies estudadas que ocorrem na Amazônia $\ldots \ldots \ldots \ldots \ldots \ldots \ldots \ldots \ldots \ldots, 60$ 


\section{INTRODUÇ ÃO}

A sistemática dos Coleópteros Passalidae, está baseada exclusivamente na sua morfologia, principalmente a externa. Apesar da extensa bibliografia que se ocupa desses insetos, desde a descrição de Passalus interruptus (Lin., 1758), pouco se tem feito além de descrevê-los incompletamente e agrupá-los segundo caracteres de preferência geralmente não justificada.

Mesmo tratando-se de uma família de ocorrência pantropical, estudos faunísticos também são raros e pouco conclusivos, pois pode-se dizer que apenas Percheron (1835), Kaup (1871), Kuwert $(1896,1897, .1898)$ e Gravely (1918), se ocuparam dos Passalídeos de todo o mundo, demorando-se os demais autores de trabalhos de conjunto, em faunas locais, como o fizeram em relação à região neotropical, Bates (1886), Moreira $(1922,1925)$, Luederwaldt (1931) e Reyes-Castillo (1970a).

Gravely (1918) foi o único autor que chegou a tecer considerações mais significativas sobre a evolução e a distribuição dos Passalídeos, principalmente indo-australianos. As demais discussões sobre problemas de distribuição e taxonomia, restringem-se a casos isolados como em Bührnheim (1962), e Reyes-Castillo (1970).

Até agora, mesmo os caracteres externos de uso mais freqüente, carecem de esiudos sobre o seu valor taxonômico, nada se sabendo sobre sua variabilidade intra-específica.

Os únicos autores que especuiaram sobre a validade taxonômica de caracteres internos, foram Sharp \& Muir (1912), Gravely (1914, 1918) e Reyes-Castillo (1970a), ocupando-se da genitália masculina, e Pereira \& Kloss (1966), comparando os divertículos do intestino posterior de diferentes espécies. Apesar da preocupação sobre o valor diferencial daqueles caracteres, já superar muito o cuidado que tem merecido a maioria dos caracteres externos em uso, poucas espécies foram exa- minadas e nada foi escrito sobre a variação das partes estudadas. Em relação à genitália, mais especialmente ao edeago, conclusōes e generalizações prematuras de Sharp \& Muir (1912) e Gravely $(1914,1918)$, resultaram no descrédito do seu valor taxonômico entre todos os especialistas mais modernos, só desmentido recentemente por Reyes-Castillo (1970a).

Verificando a diversidade do edeago entre espécies de Passalídeos neotropicais, ao contrário da uniformidade que the era atribuída, propomo-nos agora a demonstrá-la, com atenção ao significado taxonômico de suas partes e à sua variação intra-específica, contribuindo para ampliar os estudos sobre esse caráter, ultimamente reforçados pelos trabalhos de Reyes-Castillo (1970, 1970a, 1973), que estendidos às demais regiōes faunísticas e associacios a outros caracteres internos e externos, seguramente permitirão um embasamento sólido da sistemática dos Passalidae.

\section{AGRADECIMENTOS}

O autor agradece a Benedicto Abilio Monteiro Soares pela orientação e apoio durante a realização deste trabalho, ao Pe. Francisco Silvério Pereira pela inestimável ajuda na identificação do material estudado, a Catarina da Silva Motta, Pierre Charles Georges Montouchet, Mohamed Ezz El-Din Moustafa Habib e Jocélia Grazzia, pela leitura dos originais e valiosas sugestões na redação, a Maria Izabel Agnello pelo acabamento a traço e aguada de todos os desenhos, a Flora Maria Panza pelo cuidado às coleções, a Rita de Cássia Pires da Silva pela datilografia dos originais, ao Instituto Oswaldo Cruz, Museu de Zoologia da Universidade de São Paulo, Museu Paraense Emílio Goeldi e Instituto Nacional de Pesquisas da Amazônia, pelo acesso às coleções e empréstimo de exemplares. 


\section{HISTÓRICO}

As primeiras considerações sobre o valor taxonômico do edeago nos Coleópteros Passalídeos, são de Sharp \& Muir (1912). Percheron (1835) esquematizou sucintamente a "armadura copuladora" de Passalus interruptus (Lin., 1758), mas năo chegou a compará-la com a de outras espécies, nem mencionu qualquer possibilidade de seu uso como caráter diferencial.

Sharp \& Muir (1912) não só estudaram dez espécies diferentes de cinco gêneros de Passalidae, como representaram e descreveram o edeago de três delas, dividindo as formas examinadas em dois grupos distintos, um com tégmen único, no qual se enquadravam dois Aulacocyclus estudados, e outro com os lobos laterais e a peça basal distintos, constituído pelas demais espécies estudadas. Dentre as espécies neotropicais citadas, constam Proculus opacipennis, P. mnizechi? e Neleus sp., cujos edeagos não descreveram nem figuraram, o que faz crer que pertençam ao segundo grupo.

Tendo examinado o edeago de representantes de quase todas os familias de Coleópteros, Sharp \& Muir, ainda no mesmo trabalho, aventam uma correlação filogenética dos Passalidae com os Lucanidae e os Scarabaeidae, através dos Trogidae, aos quais se acham mais diretamente relacionados pelo caráter em questão.

Gravely (1914) estendeu o tipo descrito por Sharp \& Muir para Aulacocyclus, aos Aulacocyclinae em geral, o que retificou em 1918, por verificar que ambos os tipos ocorriam na mesma subfamília. Ainda afirmou o mesmo autor em 1918, que nos demais Passalídeos por ele estudados, os resultados não se prestavam a" qualquer investigação mais ampla, desde que todas as genitálias examinadas provavam ser muito parecidas.
Desde então, não mais apareceram menções ao caráter na bibliografia especializada, até que Reyes-Castillo (1970), na descrição original de Spurius halffteri, representou e descreveu sucintamente o edeago desta espécie, sem comentar seu significado taxonômico.

Crowson (1967), em trabalho geral sobre a classificação das famílias de Coleópteros, baseando-se no aspecto globoso do lobo médio e nos lobos laterais reduzidos do edeago dos Passalidae, distinguiu-os, em chave analítica de identificação, dos Lucanidae, que referiu com lobos laterais distintos e separados, e lobo médio não globoso.

Reyes-Castillo (1970a) retornou ao assunto num tópico em que historia o estudo da genitália masculina dos Passalidae, afirmando que apesar da opinião corrente entre os autores modernos sobre a uniformidade e as poucas características taxonômicas do edeago, verificou ser de importância na separação das espécies. O autor se ocupou ainda da descrição geral da genitália masculina, figurando o edeago de Odontotaenius zodiacus e Pticopus angulatus, comentando também o reduzido tamanho do lobo médio de $P$. angulatus em relação ao tégmen e o achado, nesta última espécie e em Verres cavicollis, de longo flagelo no saco interno, como em espécies de Lucanidae. No mesmo trabalho, Reyes-Castillo descreveu pela primeira vez Pseudarrox karreni, de cujo edeago também se ocupou, dizendo não apresentar diferenças notáveis do holótipo para o parátipo, ambos da mesma procedência e data de coleta.

Reyes-Castillo (1973), ao estudar material coletado na Guiana Francesa, descreveu e representou os edeagos, secos e semi-reidratados de Popilius marginatus, Verres furcilabris, Veturius cephalotes, Veturius charpentie- 
rae, Paxillus leachi, Spasalus crenatus, Spasalus balachowski, Passalus convexus, Passalus epiphanoides, Passalus latifrons então revalidado, Passalus rhodocanthopoides, Passalus spinifer, Passalus abortivus, Passalus glaberrimus, Passalus bucki, Passalus coniferus, Passalus elfridae, Passalus interstitialis e Passalus punctiger. Nesta oportunidade, o autor não mencionou o número de edeagos examinados de cada espécie, dispondo na maioria dos casos de vários exemplares sobre cujo sexo também silenciou, por vezes até de localidades diferentes, nem chamou a atenção sobre nenhuma variação intra específica. Sete das espécies estudadas neste trabalho de Reyes-Castillo, também merecem nossa atenção e não deixamos de redescrever-lhes os edeagos, tanto pelo valor de sua comparação em indivíduos de populações diferentes, quanto pela possibilidade de avaliação da eficiência obtida corn emprego de técnicas diferentes. 


\section{MATERIAL E METODOS}

\section{MATERIAL ESTUDADO}

O material estudado, pertence às coleções entomológicas do Instituto Oswaldo Cruz, no Rio de Janeiro, na qual está incluída a antiga coleção do Sr. J. F. Zikan, e do Museu de Zoologia da Universidade de São Paulo, que são as maiores e mais representativas do Brasil, contando com exemplares estudados por todos os autores que se dedicaram ao estudo dos Passalidae no Brasil (Moreira, Luederwaldt, Pereira e Bührnheim). Espécimes da coleção entomológica do Museu Paraense Emílio Goeldi, também foram examinados. Os exemplares daquelas coleções, passarão a ser referidos neste trabalho, acompanhados respectivamente das iniciais IOC, IOCZ, MZSP e MPEG.

Os exemplares coletados durante a realização do trabalho, estão depositados na coleção entomológica do Departamento de Zoologia do Instituto de Biologia da Universidade Estadual de Campinas, que passará a ser referida pelas iniciais ZUEC.

As amostras de cada espécie estudada, estão caracterizadas pelos dados de seus rótulos e são provenientes do Brasil, Estados do Amazonas ( $A M)$, Acre ( $A C)$, Pará (PA), Mato Grosso(MT), Goiás (GO), Bahia (BA), Minas Gerais (MG), Espírito Santo (ES), Rio de Janeiro (RJ), São Paulo (SP) e Território do Amapá (AP); dos Estados Unidos da América (EUA) e do Paraguai.

\section{MÉTODOS EMPREGADOS}

Foram utilizados principalmente insetos fixados e conservados em álcool $70 \%$, e alguns fixados por dessecação e espetados em alfinetes entomológicos. Os exemplares dessecados," convenientemente reidratados, serviram ao estudo para complementar a representação dos gêneros examinados ou para com- parar edeagos de indivíduos de populações diferentes daquelas de que dispúnhamos em líquido.

Sempre que possivel, foram examinadas séries de indivíduos da mesma população e representantes de populações provavelmente diferentes de uma mesma espécie.

As tentativas de expor o edeago por compressão abdominal, mesmo em exemplares recém-mortos e ainda não fixados, nem sempre deram bons resultados e só raros casos terminaram pela extroversão do saco interno também (Est. I, fig. 4).

Para não danificar os espécimes estudados, passamos a extrair-lhes o tergito e o esternito do oitavo seymento abdominal, juntamente com o edeago e demais segmentos genitais. Esta técnica foi empregada logo após a morte do inseto ou mesmo depois de já fixado e conservado em álcool $70 \%$ ou ainda, excepcionalmente, depois de macerado à quente em água com detergente doméstico a $10 \%$, quando dessecado.

As dissecções consistiram no rompimento, com o bisel de agulha hipodérmica, da membrana de articulação do sétimo com o oitavo urotergito e do sétimo com o oitavo uroesternito, permitindo a extração de todo o pigídio (Est. I, fig. 1) com os segmentos da genitália no seu interior. Em seguida o pigídio era manipulado em solução fisiológica ou água, conforme se tratasse de material fresco ou fixado, para a passagem do edeago por entre o nono e o décimo uroesternitos (Est. l, fig. 2).

Os edeagos livres, foram então desenhados com câmara clara, sob microscópio estereoscópio, com iluminação direta; nas posições ventral, lateral e dorsal.

Todos os pigídios dissecados, com a respectiva genitália, foram conservados em álcool glicerinado a $20 \%$, acondicionados em 
tubinhos fechados com tampa plástica, guardados dentro de frascos maiores também fechados com tampa plástica, que contêm a mesma solução conservadora para diminuir a evaporação.

Técnicas de diafanização foram dispensadas por apresentarem as desvantagens de tornar pouco visíveis as áreas esclerosadas, pontuações e demais acidentes superficiais, assim como os limites e linhas de articulação das partes do edeago.

Cada exemplar cujo edeago foi documentado, teve também desenhados a topografia de sua cabeça, o labro e as mandíbulas, caracteres de uso mais freqüente na sistemática vigente, para facilitar a elucidação de qualquer dúvida futura sobre sua identificação.

Os desenhos para documentar a anatomia da genitália em geral, foram obtidos de dissecções de abdomens de Paxillus pentaphylloides recém-mortos.

A terminologia empregada nas descriçōes dos edeagos, é a mesma de Sharp \& Muir (1912), ainda em uso entre os coleopterologistas modernos e que não discorda de Lindroth \& Palmén in Tuxen (1970). 


\section{RESULTADOS}

\section{MORFOLOGIA DA GENITÁLIA MASCULINA}

O oitavo urotergito dos Passalidae é móvel e quando em repouso, encaixa-se num arco formado pelo oitavo uroesternito (Est. I, fig. 1), cobrindo a genitália e o orifício anal. O tubo digestivo abre-se sob o oitavo urotergito e sobre dois escleritos, que provavelmente correspondem ao décimo uroesternito (Est. I, fig. 2). O nono uroesternito, semelhante a uma ferradura, e o décimo, reduzido a duas placas trapezoidais, formam um arco, que abriga o edeago e através do qual ele passa quando se expõe (Est. I, figs. 2 e 5).

O nono uroesternito mostra-se como se houvesse sofrido um arqueamento em ferradura para dentro do abdome. carregando suas membranas de conexão com os segmentos vizinhos.

A membrana que liga o nono ao duplo décimo uroesternito, fica em posição dorsal e forma uma bolsa em cujo fundo está preso o edeago. Esta membrana tem, no trecho abaixo do edeago, um esclerosamento em forma de botão (Est. I, fig. 2).

$O$ edeago mesmo em repouso, apresenta-se voltado para cima, com o poro genital ou ostium, abrindo-se no dorso do lobo médio (Est. l, figs. 4 e 6 ).

O lobo médio é globoso, bem vísivel e geralmente esclerosado na superfície ventral, lateral e distal, mostrando-se membranoso na maior parte da superfície dorsal. Possui dois apodemas cilíndricos, um de cada lado de sua base, escondidos no interior do tégmen (Est. I, fig. 3).

O tégmen é curto e robusto, esclerosado na superfície ventral e lateral, e membranoso na maior parte da superfície dorsal.

Os tobos laterais são reduzidos, laterais. ventro-laterais ou latero-dorsais e soldados entre si na base ventral.
A peça basal costuma estar soldada com os lobos laterais, destacando-se apenas em espécies que têm sulcos transversais divisórios entre ambos.

Uma dilatação distal do canal deferente forma o saco interno, que em repouso, só é visível no material diafanizado como uma mancha no interior do lobo médio (Est. I, fig. 3). Quando evaginado, geralmente mostra ornamentos esclerosados em toda volta, mais freqüentes e abundantes na superfície ventral (Est. I, fig. 4). O saco interno expõe-se no sentido dorso-anterior do inseto.

As dissecçôes efetuadas para o estudo da genitália, mostram que o canal deferente, antes de penetrar no edeago, faz um percurso helicoidal, semelhante ao de um tubo flexível torcido $180^{\circ}$. Visto do dorso do inseto, logo depois da fusão dos canais eferentes, situada junto ao ventre e ao eixo médio longitudinal, o canal diferente dirige-se para o lado direito dorsal do abdome, retorna para diante, passando sob si mesmo para o lado esquerdo ventral, por onde continua para atrás, sobe para o dorso até a altura da margem anterior do oitavo tergito, de onde volta sobre o edeago, em cuja base se dobra para nele penetrar.

\section{MORFOLOGIA DO EDEAGO NAS ESPÉCIES ESTUDADAS}

\section{Gênero Popilius Kaup, 1871}

Popilius marginatus (Percheron, 1835)

(Est. II, fig. 7, 8 e 9; Est. XII, fig. 3)

Passalus Marginatus Perch., 1835: 89, est. VII, fig. 1 Passalus marginatus; Perch., 1841: 37 Passalus marginatus; Burm., 1847: 507 Pertinax marginatus; Kaup, 1869: 26 Popilius marginatus; Kaup, 1871: 77 Popilius Marginatus; Kuwert, 1891: 172 Popilius marginatus; Kuwert, 1897: 299 

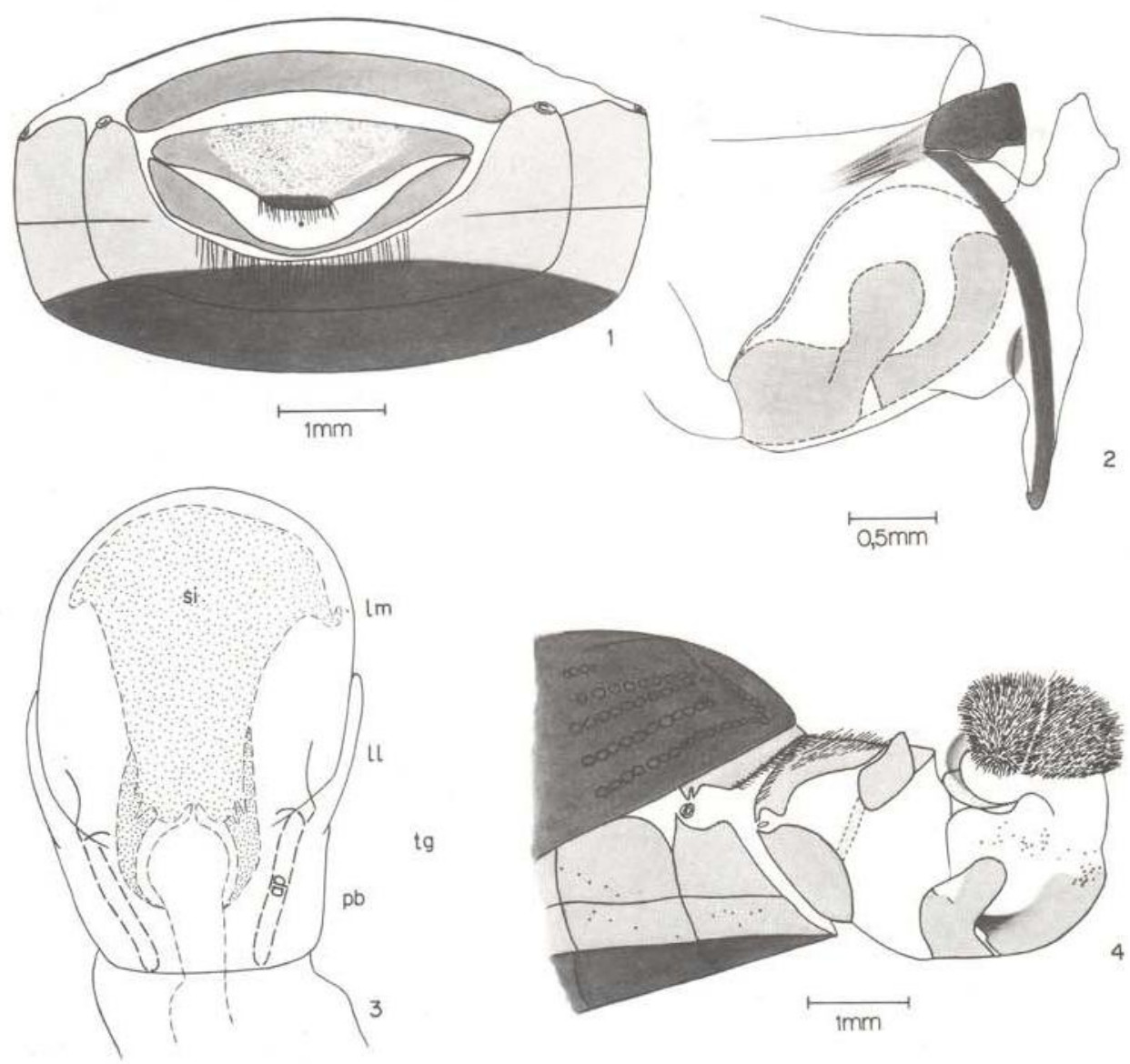

$0,5 \mathrm{~mm}$
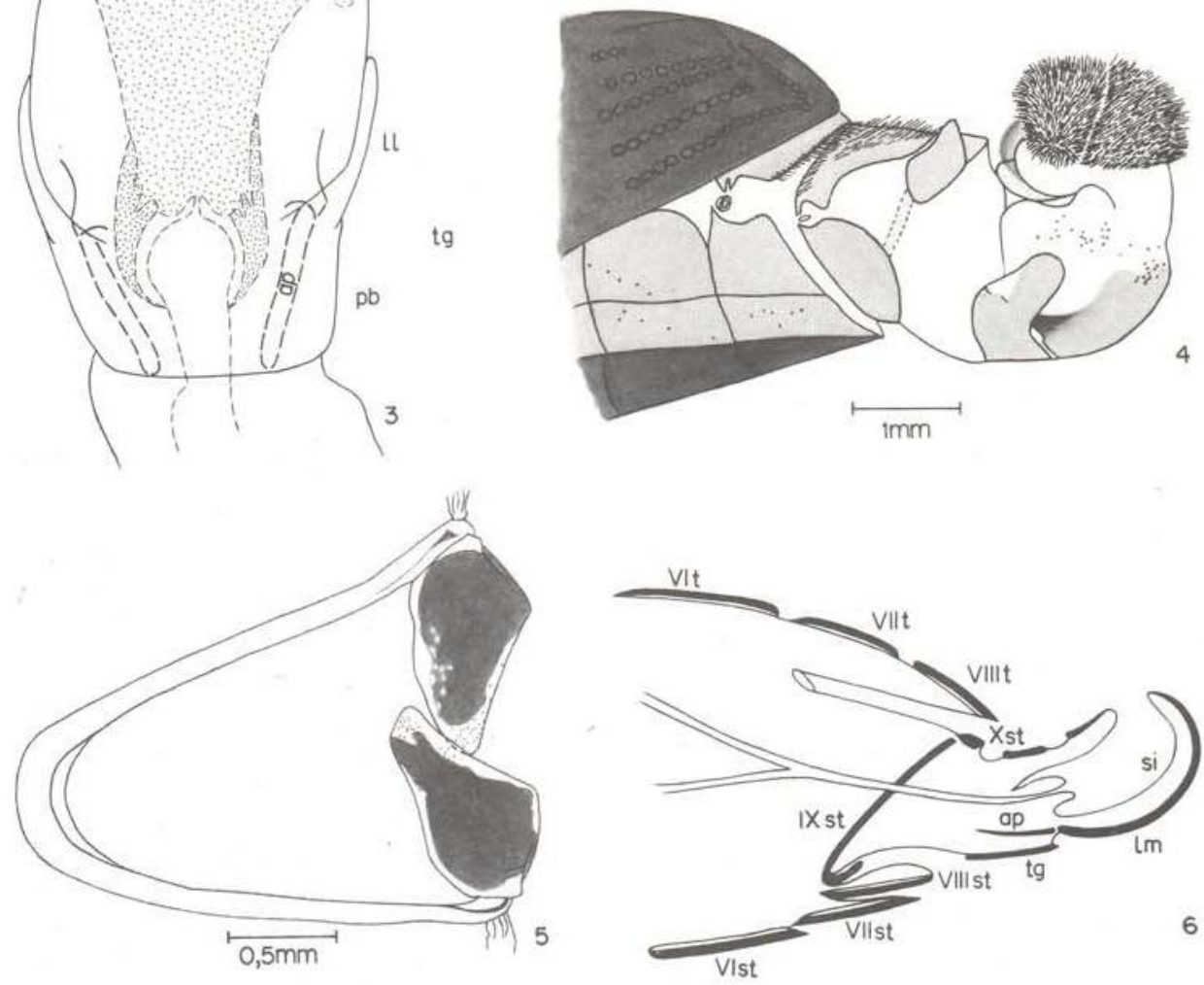

ESTAMPA I - Paxillus pentaphylloides Luederw., 1931: Fig. 1 - Pigídio; Fig. 2 - Genitália masculina; Fig. 3 - Edeago diafanizado, vista ventral; Fig. 4 - Extremidade do abdome com edeago e saco interno extrovertidos (Exemplar ZUEC n. 331); Fig. 5 - Nono e décimo uroesternito.

Passafidae: Fig. 6 - Esquema da extremidade abdominal dos Passalidae com o edeago exposto (Orig.). Para as figuras 3 e 6: -ap, apodema; -1l, lobo lateral; -pb, peça basal; -si, saco interno; -st, uroesternito; -t, urotergito, -tg, tégmen e $\mathbf{l m}$, lobo médio. 
Popilius marginatus; Gravely, 1918: 27, 29, fig. IV-6, p. 24

Popilius marginatus; Moreira, 1921 (1922): 257, fig. 3 p. 258 , fig 7 p. 267

Popilius marginatus; Moreira, 1925: 17, 18, fig. 2, p. 2 , fig. p. 12 , est. I, fig. 1

Popilius marginatus; Luederw., 1931: 21, 23, 213, est. 1 , fig. 1,6

Popilius marginatus; Hincks \& Dibb, 1935: 18

Popilius marginatus; Dibb, 1940: 77

Popilius marginatus; Luederw., 1941: 78, 82

Popilius marginatus; Blackwelder, 1944: 189

Popilius marginatus; Hincks \& Dibb, 1958: 9

Popilius marginatus; Bührnheim, 1962: 303, 308, 309, fig. 1, 3, tabs. II, III

Popilius marginatus; Vulcano \& Pereira, 1967: 535 Popilius marginatus; Reyes-Castillo, 1970: 107, 108

Popilius marginatus; Reyes-Castillo, 1973: 1545. fig. 1 (Edeago)

\section{DESCRIÇÃO DO EDEAGO}

Lobo médio globoso, com diâmetro maior que a largura do tégmen. Superfície esclerosada nas áreas ventro-laterais junto à base. Areas ventro-laterais distais com bastonetes escuros dispostos longitudinalmente.

Tégmen curto, com metade do comprimento do lobo médio. Superfície inteiramente esclerosada no ventre e parcialmente nos lados. A área esclerosada alcança o dorso nos cantos basais. Na metade distal, de cada lado apresenta um pequeno sulco transversal, sugerindo os limites entre os lobos laterais e a peça basal.

Lobos laterais muito curtos, mostrando-se apenas por lıgeira convexiclade da margem distal lateral.

Peça basal mais longa do que os lobos laterais e estreitando-se em direção à base.

MATERIAL ESTUdAdo - Três exemplares do Pará e dois de Mato Grosso. Um macho de cada procedência.

VARIAÇÃo OBSERVADA - No edeago do indivíduo do Pará, a região membranosa ao meio da borda distal da superfície ventral do tégmen, não passa de uma ligeira reentrância, bem como o sulčo lateral do tégmen avança mais para dentro da superfície ventral e as medidas são ligeiramente maiores.
Popilius refugicornis Bührnheim, 1962

(Est. II, fig. 10, 11 e 12; Est. XII, fig. 4)

Popilius refugicornis Bührnheim, 1962: 303-30S, fig. 2, 4, tabs. I, III

Popilius refugicornis; Reyes-Castillo, 1970: 107, 108

\section{DESCRIÇÃO DO EDEAGO}

Lobo médio globoso, com o diâmetro bem maior que a largura do tégmen. Superfície quase toda esclerosada no ventre e nos lados. As áreas esclerosadas alcançam o dorso nos cantos junto à base.

Tégmen curto, com menos da metade do comprimento do lobo médio. Superfície esclerosada no ventre e nos lados. A área esclerosada alcança o dorso como duas faixas transversais que não chegam a se encontrar no meio.

Lobos laterais muito curtos mostrando-se apenas por ligeira convexidade da margem distal latero-dorsal.

Peça basal apesar de pouco distinta dos lobos laterais, parece ser quase tão longa quanto $\epsilon$ les. Estreita-se em direção à base.

MATERIAL ESTUdAdo - Cinco exemplares do Espírito Santo, quatro do Rio de Janeiro e um de São Paulo. Dois machos da primeira procedência (mesma amostra) e um da segunda.

VARIAÇÃo OBSERVADA - Mesmo os edeagos de indivíduos provenientes de localidades diferentes, mostram-se bastante uniformes.

Popilius tetraphyllus (Eschscholtz, 1829) (Est. II, fig. 4, 5 e 6; Est. XII, fig. 2)

Passalus tetraphyllus Eschsch., 1829: 23 (sep. p. 11) Passalus tetraphyllus; Perch., 1841: 43 Passalus tetraphyllus; Burm., 1847: 518, 533 Tetraracus tetraphyllus; Kuwert, 1898: 197 Popilius quinquelamellatus; Luederw., 1927: 37 Popilius tetraphyllus; Luederw., 1927a: 65-66 Popilius quinquelamellatus; Luederw., 1927a: 65 Popilius tetraphyllus; Luederw., 1931: 21, 25, 214, est. 1 , fig. 8

Popilius tetraphyllus; Hincks \& Dibb, 1935: 19

Popilius tetraphyllus; Dibb, 1940: 77

Popilius tetraphyllus; Luederw., 1941: 78

Passalus tetraphyllus; Blackwelder, 1944: 190

Popilius tetraphyllus; Hincks \& Dibb, 1958: 9

Popillus tetraphyllus; Vulcano \& Pereira, 1967: 534 Popilius tetraphyllus; Reyes-Castillo, 1970: 107, 108 Popilius tetraphyllus; Reyes-Castillo, 1973: 1545.1547 


\section{DESCRIÇÃO DO EDEAGO}

Lobo médio ovalado, mais largo que o tégmen. Superfície com as áreas ventro-laterais esclerosadas e com bastonetes mais escuros dispostos longitudinalmente na metade apical.

Tégmen curto, com metade do comprimen. to do lobo médio. Superfície inteiramente esclerosada no ventre e parcialmente nos lados. $\mathrm{Na}$ metade apical, de cada lado, apresenta um pequeno sulco transversal, sugerindo os limites entre os lobos laterais e a peça basal.

Lobos laterais curtos, mostrando-se apenas por convexidade da margem distal latero-dorsal, que avança sobre os lados do quinto basai do lobo médio.

Peça basal mais longa que os lobos laterais e estreitando-se em direção à base.

MATERIAL ESTUDADO - Dois exemplares do Amazonas. Um macho.

\section{Gênero Odontotaenius Kuwert, 1896}

Odontotaenius disjunctus (IIliger, 1800)

(Est. II, fig. 1, 2 e 3; Est. XII, fig. 1)

Scarabeus interruptus; Lin., 1764: 35

Lucanus interruptus; Olivier, 1789: 25, cst. 3, fig. 5

Lucanus interruptus; Herbst, 1790: $306^{\circ}$

Passalus disjunctus mlliger, 1800: 78

Passalus cornutus Fabr., 1801: 256

Passalus distinctus Weber, 1801: 79

Passalus cornutus; Latr., 1804: 255*

Passalus cornutus; Palis, 1805: 1, est. I, fig. $1^{\circ}$

Passalus cornutus; Schoenh., 1817: 332

Passalus cornutus: Lamark, 1817: 597

Passalus cornutus; Latr., 1818: $571^{\circ}$

Passalus cornutus; Lepeletier \& Serv., 1825: 20

Passalus cornutus; Eschsch., 1829: 28 (sep. p. 16)

Passalus distinctus; Perch., 1835: 99, est. VII, fig. 6 Passalus cornutus; Cast., 1840: 178

Passalus distinctus; Perch., 1841: 38

Passalus cornutus; Burm., 1847: 454 (Biol.)

Passalus cornutus; Burm., 1847: 510

Passalus distinctus; Chapius \& Candèze, 1853: 467-468, est. 14, fig. 5-5c (Biol.)

Passalus distinctus; Truqui, 1857: 261, 314 (sep. p. $4,17)$

Passalus distinctus; Candèze, 1861: 343-344 (Biol.) ${ }^{\circ}$

Passalus cornutus; Leconte, 1862: $119^{\circ}$

Passalus cornutus; Kaup, 1869: 3

Passalus distinctus; Kaup, 1871: 106, est. VII, fig. 1 Passalus cornutus; Riley, 1872: 139-141, fig. 62a-d (Biol.) $)^{\circ}$
Passalus cornutus; Schiödte., 1874: 356 , est. XV, fig. 16 , est. XVIII, fig. $12 \cdot 19$, est. XIX, fig. 17 (Biol.) ${ }^{*}$

Passalus cornutus; Fuchs, 1882: 60 , fig. 13, $14^{*}$ Passalus cornutus; Leconte \& Horn, 1883: 236** Passalus cornutus; Bates, 1886: 21

Passalus Stanleyi Kuwert, 1890: 99

Passalus Cornutus var. distinctus; Kuwert, 1891: 171

Passalus Cornutus ab. Dollei Kuwert, 1891: 171

Passalus Bos Kuwert, 1891: 171

Passalus cornutus; Casey, 1896-97 (1897): 648

Passalus cornutus ab. distinctus; Kuwert, 1897: 286

Passalus bos; Kuwert, 1897: 286

Passalus cornutus; Kuwert, 1897: 286

Passalus cornutus ab. Stanleyi; Kuwert, 1897: 287

Passalus cornutus; Wickham, 1899: 21 *

Passalus cornutus; Babb, 1904: 279-281, fig. (Biol.)

Passalus distinctus; Zang., 1904: 181

Passalus cornutus ab. Stanleyi; Zang., 1904: 181

Odontolaenius disiunctus; Zang., 1905: 225

Passalus cornutus; Heyne \& Taschenberg, 1908: 58, est. 8, fig. 37

Popilius cornutus; Blatchley, 1910: 909

Popilius disjunctus; Blatchley, 1910: 908 (Biol.)

Passalus cornutus; Schaffer, 1917: 407-434 (Espermatogenese)

Popilius cornutus; Gravely, 1918: 28, 29

Popilius cornutus; Luederw., 1931: 21, 27, 214, est. 1, fig. $2,7,9$

Popilius cornutus ab. stanleyi; Luederw., 1931a: 62 Passalus cornutus; Miller, 1932: 709-712 (Biol.)

Passalus cornutus; Park, 1935: 36-37 (Ecol.) -•

Popilius disjunctus; Hincks \& Dibb, 1935: 16

Passalus cornutus; Patterson, 1937: 619-640, figs. (Tubo Digestivo)

Passalus cornutus; Pearse, Patterson, Rankin \& Wharton, 1936: 455-490 (Ecol.)

Passalus cornutus; Anderson, 1936: 21, est. 6, fig. 5 (Labium larval) **

Passalus cornutus; Park, 1937: 239-253, figs. (Ecol.)

Popilius disjunctus; Dibb, 1938: 98, 99

Popilius disjunctus; Dibb, 1940: 76

Popilius disjunctus; Luederw., 1941: 77

Popilius disjunctus; Blackwelder, 1944: 189

Passalus cornutus; Gray, 1946: 728-746 (Biol.)

Passalus cornutus; Krause, 1946: 193-206 (Gonad.)

Passalus cornutus; Paulian, 1947: 19, fig. 1-6

Passalus cornutus; Allec, Park, Emerson \& Schmidt, 1949: 188 (Ecol.)

Popilius disjunctus; Arrow, 1951: 31, 32

Popilius disjunctus; Hincks, 1951: 12

Popilius disjunctus; Krause \& Ryan, 1953: 1-20, 4 tab. (Embriol.) $\cdots$

Passalus cornutus; Lewis, 1956: 11-21, fig. (tubo Digestivo)

Popilius disjunctus; Hincks \& Dibb, 1958: 8

(*) apud Hincks \& Dibb, 1935

(*) apud Hincks \& Dibb, 1958 

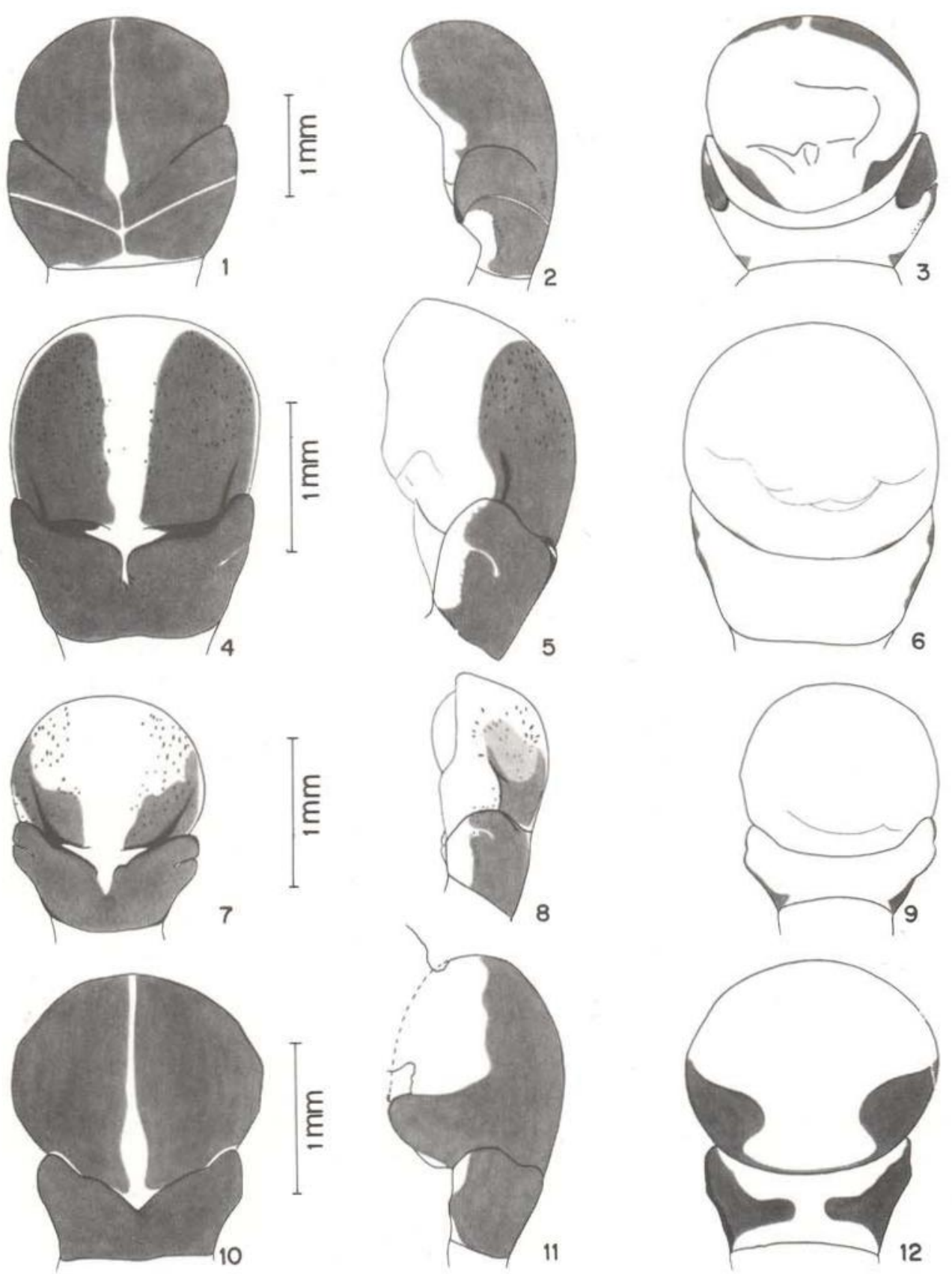

ESTAMPA II - Odontotaenius disjunctus (Illiger, 1800). Edeago do exerplar IOCZ n. 6789: Fig. 1 - Vista ventral; Fig. 2 - Vista lateral; Fig. 3 - Vista dorsal.

Popilius tetraphyllus (Eschscholtz, 1829). Edeago do exemplar MZSP, AM, Manaus, IX/1963: Fig. 4 - Vista ventral; Fig. 5 - Vista lateral; Fig. 6 - Vista dorsal.

Popilius marginatus (Percheron, 1835), Edeago do exemplar MZSP, MT, Utiariti, VII-VIII/1961: Fig. 7 - Vista"ventral; Fig. 8 - Vista lateral; Fig. 9 - Vista dorsal.

Popilius refugicornis Bührnheim, 1962. Edeago do exemplar IOC n.॰ 9515, Holótipo: Fig. 10 - Vista ventral; Fig. 11 - Vista lateral (saco interno evagınado, não representado); Fig. 12 - Vista dorsal. 
Popilius disjunctus; Robertson, 1961: 245-263 (Ovaríolos)

Odontotaenius disjunctus; Reyes-Castillo, 1970: 149, $150,151,152,153$

Odontotaenius disjunctus; Reyes-Castillo \& Ritcher, 1973: 478, 479 (Ovaríolos)

\section{DESCRIÇÃO DO EDEAGO}

Lobo médio globoso, com diâmetro um pouco menor que a largura do tégmen. Superfí. cie quase toda esclerosada no ventre e nos lados. As áreas esclerosadas alcançam os quatro cantos do dorso.

Tégmen com mais da metade do comprimento do lobo médio. Superfície esclerosada no ventre e nos lados. "Arreas esclerosadas alcançando o dorso nos lobos laterais e nos cantos basais. Na margem distal ventral, de cada lado da linha média, há um grupo de puncturas. Na metade distal, apresenta um sulco transversal que corta toda a área esclerosada, sugerindo os limites entre os lobos laterais e a peça basal.

Lobos laterais curtos, mostrando-se apenas por leve convexidade da margem distal lateral. Suas extremidades afilam-se das áreas laterais para o dorso, ficando voltadas para a base, sem chegar a serem livres.

Peça basal um pouco mais longa do que os lobos laterais e formando com eles um conjunto globoso.

MATERIAL ESTUDADO - Quatro exemplares de Michigan, dois da Carolina do Norte e dois de Illinois, todos dos EUA. Dois machos da primeira procedência (mesma amostra), um da segunda e um da terceira.

VARIAÇÃo OBSERVADA - Mesmo os edeagos de indivíduos provenientes de localidades diferentes, mostram-se bastante uniformes.

\section{Gênero Veturius Kaup, 1871}

Veturius libericornis Kuwert, 1891

(Est. III, fig. 1,.2 e 3; Est. XIII, fig. 1)

Veturius Libericornis Kuwert, 1891: 174

Veturius libericornis; Kuwert, 1898: 171

Veturius libericornis; Luederw., 1931: 13, 31, 38, 217

Veturius libericornis; Hincks, 1934: 154

Veturius libericornis; Hincks \& Dibb, 1935: 25

Veturius libericornis; Blackwelder, 1944: 190

Veturius libericornis; Vulcano \& Pereira, 1967: 535

Veturius libericornis; Reyes-Castillo, 1970: 165

\section{DESCRIÇÃo DO EDEAGO}

Lobo médio globoso, um pouca mais longo do que largo. Maior que o tégmen, que só o ultrapassa em largura ao nível dos lobos laterais. Superfície esclerosada nas áreas ventro-laterais junto à base.

Tégmen um pouco mais curto do que o lobo médio. Superfície parcialmente esclerosada no ventre e nos lados. As áreas esclerosadas alcançam o dorso apenas nos cantos distais. Logo adiante da metade basal, apresenta um largo sulco transversal dividindo toda a área esclerosada, sugerindo os limites entre os lobos laterais e a peça basal.

Lobos laterais curtos, mostrando-se por convexidade da margem distal lateral, que avança lateralmente sobre o terço basal do lobo médio.

Peça basal um pouco mais longa do que os lobos laterais, formando com eles um conjunto globoso.

MATERIAL ESTUdAdo - Cinco exemplares do Pará. Dois machos (mesma amostra).

VARIAÇÃo OBSERVADA - Os dois edeagos não mostram diferenças notáveis entre si.

Veturius assimilis (Weber, 1801)

(Est. III, fig. 4, 5 e 6; Est. XIII, fig. 2)

Passalus assimilis Weber, 1801: 81

Passalus assimilis; Schoenh., 1817: 333

Passalus semicylindricus Eschsch., 1829: 27 (sep. p. 15)

Passalus Assimilis; Perch., 1835: 96, est. VII, fig. 5

Passalus assimilis; Perch., 1841: 38

Passalus semi-cylindricus; Perch., 1841: 45

Passalus assimilis; Burm., 1847: 511

Passalus semicylindricus; Burm., 1847: 511, 518, 532

Passalus assimilis; Kaup, 1868: 26

Veturius assimilis; Kaup, 1871: 111

Veturius pumilio Kuwert, 1890: 102

Veturius Gabonis Kuwert, 1890: 103

Veturius Gabonis; Kuwert, 1891: 173

Veturius Pumilio; Kuwert, 1891: 173

Veturius Assimilis; Kuwert, 1891: 173

Veturius assimilis; Kuwert, 1898: 166

Veturius gabonis; Kuwert, 1898: 167

Veturius pumilis; Kuwert, 1898: 167

Passalus assimilis; Heyne \& Taschenberg, 1908: 58 est. 8 , fig. 38

Veturius assimilis; Gravely, 1918: 38,39 , fig. V-8, p. 34 
Veturius assimilis; Moreira, 1921 (1922): 261, 268-269, fig. 15, p. 274

Veturius pumilis; Moreira, 1921(1922): 261, 269, fig. 16, p. 274

Veturius assimilis; Moreira, 1925: 19-20, fig. p. 20, est. 1, fig. 4

Veturius pumilis; Moreira, 1925: 19, 23-24, fig. p. 23, est. II, fig. 1

Veturius assimilis; Luederw., 1931: 31, 39-42, 205, 218 , est. 1 , fig. 4

Veturius pumilis; Luederw., 1931: 41, 42

Veturius gabonis; Luederw., 1931: 41

Veturius assimilis; Hincks \& Dibb, 1935: 23-24

Veturius assimilis; Blackwelder, 1944: 190

Veturius assimilis; Doesburg, 1957: 22-23

Veturius assimilis; Pereira \& Kloss, 1966: 44, 46, fig. 7 (Intest. post.)

Veturius assimilis; Reyes-Castillo, 1970: 165

\section{DESCRIÇÃO DO EDEAGO}

Lobo médio globoso, com diâmetro menor que a largura do tégmen. Superfície esclerosada nas áreas ventro-laterais, junto à base. Margens das áreas esclerosadas e vizinhanças com pontuação mais escura.

Tégmen quase tão longo quanto $\sigma$ lobo médio. Superfície parcialmente esclerosada no ventre e nos lados. A área esclerosada alcança o dorso como um estreito traço em cada canto.

$\mathrm{Na}$ metade do seu comprimento, apresenta um fino sulco de cada lado da área esclerosada, também visivel nas margens ventro-laterais, sugerindo os limites entre os lobos laterais, e a peça basal.

Lobos laterais curtos, mostrando-se por convexidade da margem distal lateral, que avança lateralmente sobre o terço basal do lobo médio.

Peça basal quase tão longa quanto os lobos laterais e um pouco mais estreita do que eles.

MATERIAL ESTUDADO - Dois exemplares de Minas Gerais e quatro de São Paulo. Um macho da primeira procedência e dois da segunda (localidades diferentes).

VARIAÇÃ O OBSERVADA - Apesar dos edeagos pertencerem a indivíduos de proveniências diferentes, mostram-se bastante uniformes.
Veturius punctatostriatus Arrow, 1907

(Est. III, fig. 7, 8 e 9; Est. XIII, fig. 3)

Veturius punctatostriatus Arrow, 1906(1907): 454

Veturius punctatostriatus; Hincks, 1934: 153

Veturius punctatostriatus; Blackwelder, 1944: 190

Veturius punctatostriatus; Reyes-Castillo, 1970: 165

\section{DEscriçÃo Do EDEAGo}

Lobo médio globoso, mais longo do que largo. Mais estreito que o tégmen. Superfície esclerosada nas áreas ventro-laterais junto à base. Areas ventro-laterais com pontuação mais escura.

Tégmen quase tão longo quanto o lobo médio. Em vista ventral e dorsal, mostra uma leve concavidade ao meio de cada lado. Superfície esclerosada no ventre, lados e parte do dorso. A área esclerosada alcança o dorso ao longo das margens laterais.

Lobos laterais com saliência latero-dorsal, que avança sobre a metade basal do lobo médio.

Peça basal, apesar de pouco distinta dos lobos laterais, parecendo mais curta do que eles.

MATERIAL ESTUdADO - Três exemplares do Amapá. Um macho.

\section{Gênero Verres Kaup, 1871}

Verres furcilabris (Eschscholtz, 1829)

(Est. III, fig. 10, 11 e 12; Est. XIII, fig. 4)

Passalus furcilabris Eschsch., 1829: 25 (sep. p. 13) Passalus Furcilabris; Perch., 1835: 92, est. VII, fig. 2 Passalus furcilabris; Perch., 1841: 37 Passalus furcilabris; Burm., 1847: 513 Passalus furcilabris; Kaup, 1868: 25 Verres furcilabris; Kaup, 1871: 116, est. VII, fig. 8 Verroides Tuberculilabris Kuwert, 1891: 175 Verroides Labrifissus Kuwert, 1891: 175 Verres Furcilabris; Kuwert, 1891: 175 Verres Deficiens Kuwert, 1891: 175 Verres furcilabris; Kuwert, 1898: 176 Verres deficiens; Kuwert, 1898: 176 Verroides furcatilabris Kuwert, 1898: 177 Verroides kolbei Kuwert, 1898: 177 Verroides labrifissus; Kuwert, 1898: 177 Verres furcilabris; Zang, 1905: 227 Verroides furcilabris; Arrow, 1906(1907): 451

Verres furcilabris; Gravely, 1918: 40, 41, fig. V-11, p. 34 

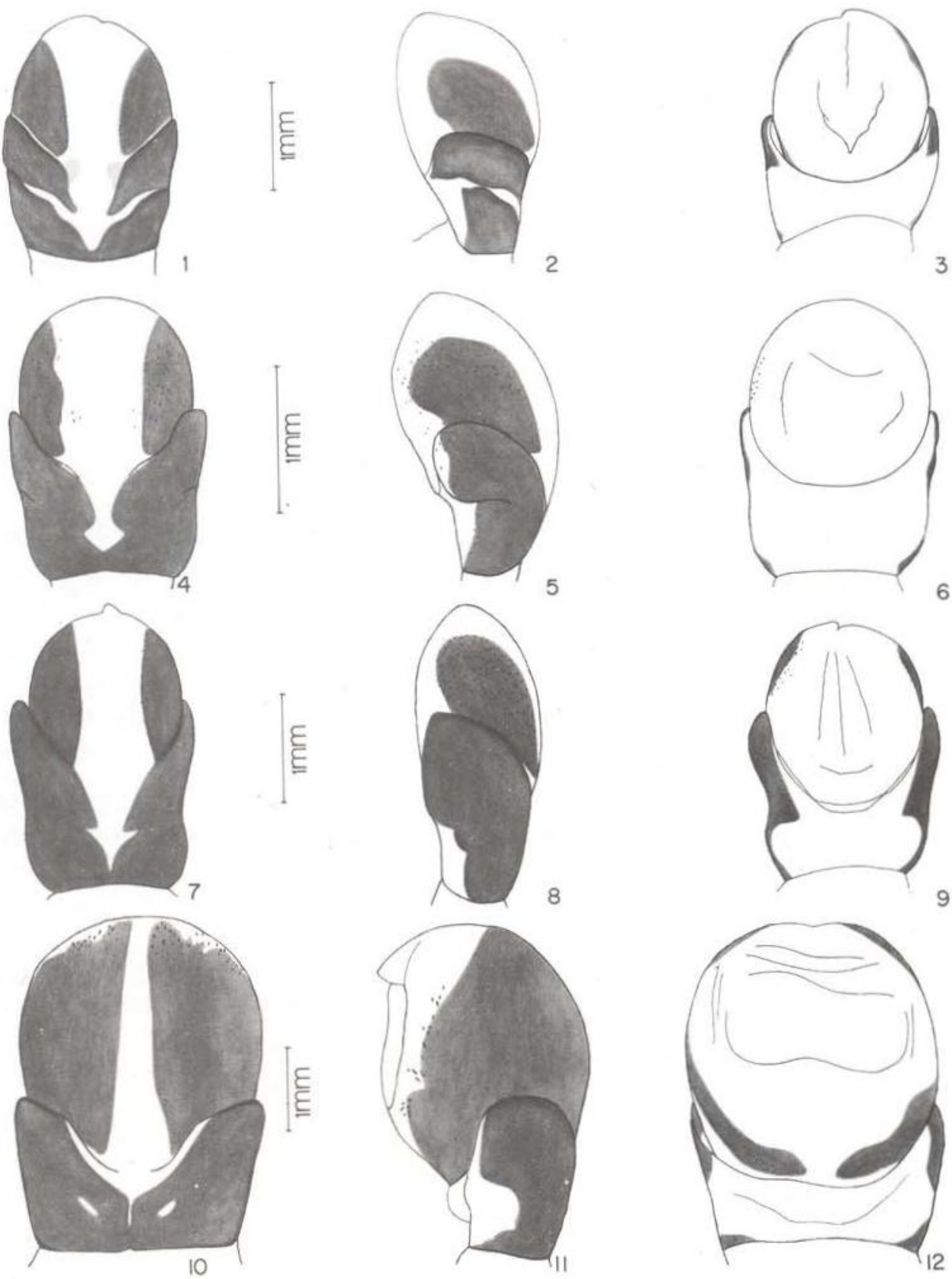

ESTAMPA III - Veturius libericornis Kuwert, 1891. Edeago do exemplar IOC n. 14.761: Fig. 1 - Vista ventral; Fig. 2 - Vista lateral; Fig. 3 - Vista dorsal. Veturius assimilis (Weber, 1801). Edeago do exem. plar ZUEC n. 199: Fig. 4 - Vista ventral; Fig. 5 - Vista lateral; Fig. 6 - Vista dorsal.

Veturius punctatostriatus Arrow, 1907. Edeago do exemplar IOC n. 14.760: Fig. 7 - Vista ventral; Fig. 8 - Vista lateral; Fig. 9 - Vista dorsal.

Verres furcilabris (Eschscholtz, 1829). Edeago do exemplar IOC n.॰ 14.758: Fig. 10 - Vista ventral; Fig. 11 - Vista lateral; Fig. 12 - Vista dorsal. 
Verres furcilabris; Moreira, 1921(1922): 270

Verres furcilabris; Moreira, 1925: 27, fig.

Verres furcilabris; Luederw., 1931: 52-56, 199, 220, est. 1 , fig. 12,13

Verroides furcatilabris; Luederw., 1931: 55

Verroides kolbei; Luederw., 1931: 55

Verroides labrifissus; Luederw., 1931: 55, 199

Verres furcilabris; Luederw., 1931a: 62

Verres furcilabris; Hincks, 1934: 56, 57

Verres furcilabris; Hincks \& Dibb, 1935: 29

Verres furcilabris; Blackwelder, 1944: 191

Verres furcilabris; Hincks, 1950: 1035

Verres furcilabris forma Hincks, 1950: 1035

Verres furcilabris; Hincks \& Dibb, 1958: 11

Verres furcilabris; Vulcano \& Pereira, 1967: 535

Verres furcilabris; Reyes-Castillo, 1970: 161

Verres furcilabris; Reyes-Castillo, 1973: 1547, fig. a (Edeago)

\section{DESCRIÇÃo DO EDEAGO}

Lobo médio globoso e bem maior que o tégmen, que só o ultrapassa em largura ao nível dos lobos laterais. Superfície quase toda esclerosada no ventre e nos lados. As áreas esclerosadas alcançam o dorso na base, como duas faixas que não chegam a se encontrar no meio. Na margem distal e latero-dorsal da área esclerosada, há pontuação mais escura.

Tégmen com um pouco mais da metade do comprimento do lobo médio. Superfície quase toda esclerosada no ventre e nos lados. Area esclerosada alcançando os quatro cantos do dorso.

Lobos laterais curtos, mostrando-se por convexidade da margem distal lateral, que avança ventro-lateralmente sobre o terço basal do lodo médio.

Peça basal, apesar de pouco distinta dos lobos laterais, parece quase tão longa quanto eles. Estreita-se um pouco em direção à base e tem, de cada lado da linha média ventral, um bastão membranoso oblíquo.

MATERIAL ESTUDADo - Dois exemplares do Amapá, um do Amazonas e quatro de Mato Grosso. Um macho da primeira procedência, um da segunda e três da terceira (mesma amostra).

VARIAÇÃo OBSERVADA - Todos os edeagos dos indivíduos provenientes do Mato Grosso são mais curtos, tem o lobo médio mais embutido no tégmen, o tégmen mais curto $\mathrm{e} a$ área mem- branosa média distal com aspecto de um triân. gulo, ao invés do aspecto da letra $Y$ dos demais (Fig.) .

\section{Gênero Paxilus Mac Leay, 1819}

Paxillus pentaphylloides Luederwaldt, 1931 (Est. V, fig. 1, 2 e 3; Est. XV, fig. 1)

Paxillus nudihumerus Luederw., 1927: 37 Paxillus pentaphylloides Luederw., 1931: 76, 225

Paxillus pentaphyllus Luederw., 1931 (nec Beauv.): $63,73,74-76.206,225$

Paxillus pentaphyllus var. nudihumerus; Luederw., 1931: 63, 76-77, 206, 225, 226

Paxillus philippinensis (phillippensis err.) Luederw., 1931 (nec Kuwert): 74

Paxillus pentaphylloides; Luederw., 1934a: 9, 14

Paxillus pentaphylloides var. nudihumerus; Luederw., 1934a: 01 (err.) $=10$, 14 (sep.)

Paxillus pentaphylloides forma a Luederw., 1934a: 01 (err.) $=10,14$ (sep.)

Paxillus pentaphylloides; Luederw., 1934a: 4, 5 (sep.) Paxillus pentaphylloides var. nudihumerus; Luederw., 1934b: 3 (sep.)

Paxillus pentaphylloides; Hincks \& Dibb, 1935: 36 Paxillus pentaphylloides; Blackwelder, 1944: 191

Paxillus philippinensis; Hincks, 1949: 58

Paxillus pentaphylloides; Hincks \& Dibb, 1958: 15

Paxillus pentaphylloides; Vulcano \& Pereira, 1967: 537

Paxillus pentaphylloides; Reyes-Castillo, 1970: 185-186 Paxillus pentaphylloides; Reyes-Castillo, 1973: 1553

\section{DESCRIÇÃO DO EDEAGO}

Lobo médio globoso, só superado em lar. gura pelo tégmen ao nível dos lobos laterais. Superfície esclerosada nas áreas ventro-laterais. Nas margens distais das áreas esclerosadas, existe uma pontuação mais escura. As áreas esclerosadas alcançam o dorso como quatro traços, dois nos cantos distais e dois nos cantos basais.

Tégmen um pouco mais curto do que o lobo médio. Superfície esclerosada no ventre, lados e parte do dorso. A área esclerosada alcança o dorso nos quatro cantos, apresentando pontuações mais escuras na margem da metade basal. Na metade distal, apresenta um pequeno sulco transversal, que corta a margem lateral do esclerosamento e é pouco visível ventralmente. 
Lobos laterais bem destacados, com a extremidade arredondada, avançando lateralmente sobre quase toda a metade basal do lobo médio.

Peça basal aparentemente mais curta que os lobos laterais e mais estreita do que eles.

MATERIAL ESTUDADO - Trinta exemplares de São Paulo e um do Espírito Santo. Dezesseis machos da primeira procedência (mesma amostra) e um da segunda.

VARIAÇÃo OBSERVADA - Mesmo os edeagos de indivíduos de proveniências diferentes, mostram-se bastante uniformes. Dentro da mesma população, há uma pequena variação no aspecto da área membranosa do meio da margem distal ventral do tégman.

Paxillus forsteri Luederwaldt, 1927

(Est. V, fig. 4, 5 e 6; Est. XV, fig. 2)

Paxillus forsteri Luederw., 1927: 38

Paxillus pentaphyllus var. Forsteri; Luederw., 1931: $57,63,77,205,221,226$

Paxillus forsteri; Luederw., 1934a: 01 (err.) = 10, 15 (sep.)

Paxillus Forsteri; Hincks, 1934: 270

Paxillus Forsteri; Hincks \& Dibb, 1935: 36

Paxillus forsteri; Blackwelder, 1944: 191

Paxillus Forsteri; Hincks \& Dihb, 1958: 13

Paxillus forsteri: Reyes-Castillo, 1970: 185

Paxillus forsteri; Reyes-Castillo, 1973: 1553

\section{DESCRIÇÃO DO EDEAGO}

Lobo médio globoso, só superado em largura pelo tégmen, ao nível dos lobos laterais. Superfície esclerosada nas áreas ventro-laterais. Na margem distal das áreas esclerosadas, existe pontuação mais escura. As áreas esclerosadas são um pouco deprimidas e mais escuras, no sentido longitudinal e junto à margem lateral.

Tégmen um pouco mais longo que o lobo médio. Superfície esclerosada no ventre, nos lados e em parte do dorso. A área esclerosada alcança as margens laterais do dorso. $\mathrm{Na}$ metade distal, apresenta um sulco transversal muito fino e curto, junto às margens laterais do ventre.

Lobos laterais bem destacados, com a extremidade arredondada, avançando latero-dor- salmente sobre quase todos os três quartos basais do lobo médio.

Peça basal aparentemente mais curta que os lobos laterais e um pouco mais estreita do que eles. Estreita-se em direção à baśe.

MATERIAL ESTUDADO - Três exemplares de Goiás. Um macho de uma amostra e outro de outra.

VARIAÇÃo OBSERVADA - Apesar dos edeagos pertencerem a indivíduos de localidades diferentes, mostram-se bastante uniformes.

Paxillus lanei Pereira, 1939

(Est. V, fig. 7, 8 e 9; Est. XV, fig. 3)

Paxillus lanei Pereira, 1939: 79

Paxillus lanei; Blackwelder, 1944: 191

Paxillus Lanei; Hincks \& Dibb, 1958: 13

Paxillus lanei; Reyes-Castillo, 1970: 185

Paxillus lanei; Reyes-Castillo, 1973: 1553

\section{DESCRIÇÃO DO EDEAGO}

Lobo médio globoso, mais curto do que largo, só superado em largura pelo tégmen, ao nível dos lobos laterais. Superfície esclerosada nas áreas ventro-laterais. As áreas esclerosadas são deprimidas e mais escuras, ao longo de uma linha que vai do meio da margem distal para o lado basal. Na margem distal, na lateral e na ventro-basal, existe densa pontuação mais escura.

Tégmen ligeiramente mais longo do que o lobo médio. Superfície esclerosada no ventre e em parte dos lados e dorso. A área esclerosada alcança o dorso como duas faixas anteriores, que cobrem a base dos lobos laterais, e duas manchas nos cantos basais. Na metade distal, apresenta um sulco transversal muito fino e curto, que corta a margem lateral do esclerosamento e é pouco visível nas margens ventrais.

Lobos laterais bem destacados, com a extremidade arredondada, avançando latero-dorsalmente sobre a metade basal do lobo médio.

Peça basal aparentemente pouco mais curta do que os lobos laterais e mais estreita do que eles.

MATERTAL ESTUdAdo - Um exemplar do Mato Grosso. 
Gênero Spasalus Kaup, 1869

Spasalus crenatus (MacLeay, 1819)

(Est. IV, flg. 1, 2 e 3; Est. XIV, fig. 1)

Paxillus crenatus MacLeay, 1819: 106

Passalus puncticollis; Lepeletier \& Serv., 1825: 21

Passalus crenatus; Eschsch., 1829: 24 (sep. p. 12)

Passalus crenatus; MacLeay, 1833: 20

Passalus Crenatus; Perch., 1835: 38, est. III, fig. 3

Passalus crenulatus; Dejean, 1837: 195

Passalus crenatus; Perch., 1841: 10

Passalus Hopei; Perch., 1844: 7

Passalus robustus (nec Perch.), Burm., 1847: 495

Passalus Hopei; Burm., 1847: 518

Spasalus robustus; Kaup, 1869: 28

Spasalus robustus; Kaup, 1871: 81

Passalus crenatus; Fleutiaux \& Sallé, 1889: 43

Spasalus Robustus; Kuwert, 1891: 182

Spasalus Abnormalis Kuwert, 1891: 182

Spasalus crenatus; Kuwert, 1898: 182

Spasalus magnus Kuwert, 1898: 183

Spasalus abnormalis; Kuwert, 1898: 183

Spasalus robustus; Kuwert, 1898 (nec Perch.): 183 (pars)
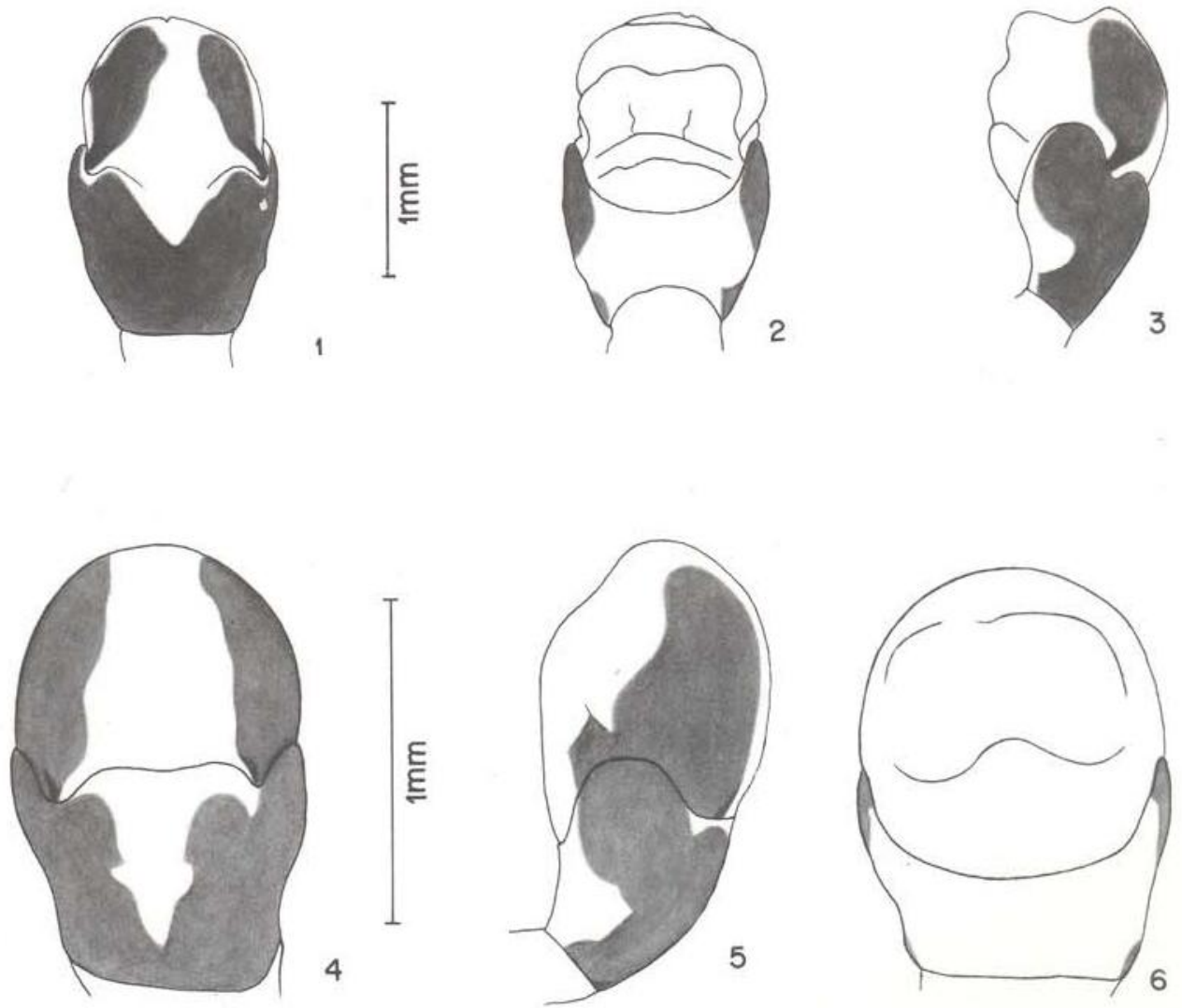

ESTAMPA IV - Spasalus crenatus (Mac Leay, 1819). Edeago do exemplar MZSP, AM, Benjamin Constant, 18-28/IX/1962: Fig. 1 - Vista ventral; Fig. 2 - Vista dorsal (saco interno semi-evaginado); Fig. 3 - Vista lateral.

Spasalus robustus (Percheron, 1835), Edeago do exemplar IOCZ n.॰ 7215: Fig. 4 - Vista ventral; Fig. 5 - Vista lateral; Fig. 6 - Vista dorsal. 

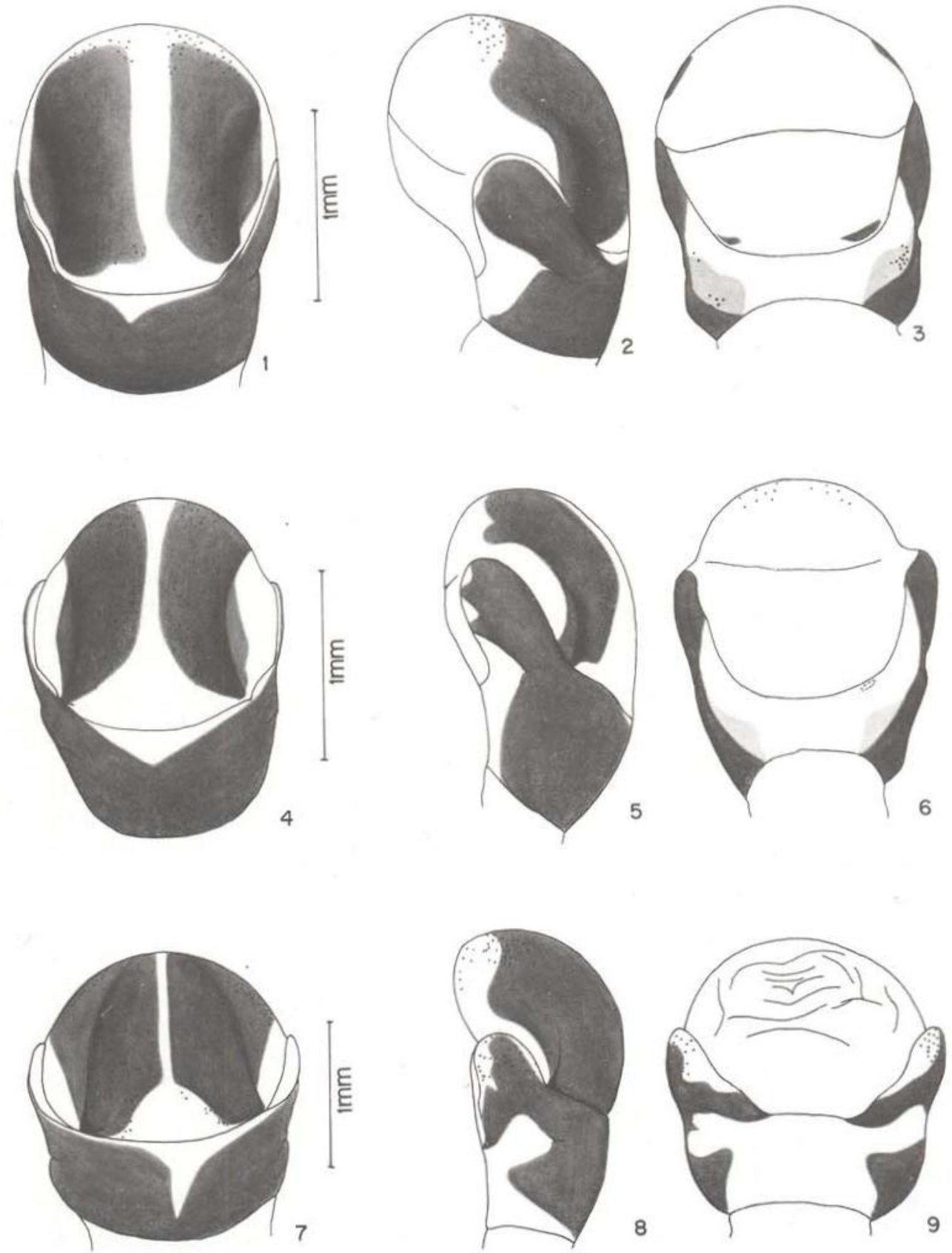

ESTAMPA V - Paxillus pentaphylloides Luederw., 1931. Edeago do exemplar ZUEC n. 332: Fig. 1 Vista ventral; Fig. 2 - Vista lateral; Fig. 3 - Vista dorsal.

Paxillus forsteri Luederw., 1927. Edeago do exemplar MZSP, GO, Campinas, VIII/1927, Parátipo: Fig. 4 Vista ventral; Fig. 5 - Vista lateral; Fig. 6 - Vista dorsal.

Paxillus lanei Pereira, 1939. Edeago do exemplar MZSP, MT, Salobra, 18-29/X/1938, Holótipo: Fig. 7 Vista ventral; Fig. 8 - Vista lateral; Fig. $9-$ Vista dorsal. 


\section{DESCRIÇÃO DO EDEAGO}

Lobo médio alongado e estreito, cuja projeção de tơpo é elíptica; só é superado em largura pelo tégmen, ao nível dos lobos laterais. Superfície esclerosada nas áreas ventro-laterais.

Tégmen um pouco mais longo do que o lobo médio. Superfície esclerosada no ventre, nos lados e em parte do dorso. A área esclerosada alcança o dorso como uma faixa de cada lado da metade distal, e como uma pequena mancha nos cantos basais.

Lobos laterais curtos, que avançam lateralmente sobre o terço basal do lobo médio. Apresentam-se como uma sinuosidade da margem distal, que se inicia com pequena convexidade ventral, seguida de reentrância ventro-lateral e terminando numa proeminência lateral.

Peça basal indistinta dos lobos laterais e ligeiramente maior do que eles. Estreita-se em direção à base.

MATEIAL ESTUDADO - Dois exemplares do Amazonas. Dois machos de amostras diferentes.

VARIAÇÃO OBSERVADA - Apesar dos edeagos pertencerem a indivíduos provenientes de localidades diferentes, mostram-se bastante uniformes.

Spasalus robustus (Percheron ,1835)

(Est. IV, fig. 4, 5 e 6; Est. XIV, fig. 2)

Passalus Robustus Perch., 1835: 35, est. III, fig. 1 Passalus robustus; Perch., 1841: 10

Passalus crenatus; Burm. (nec MacLeay), 1847: 496

Spasalus crenatus; Kaup, 1869: 28

Spasalus crenatus; Kaup, 1871: 81

Passalus robustus; Fleutiaux \& Sallé, 1889: 44

Spasalus Crenatus; Kuwert, 1891: 182

Spasalus crenatus; Kuwert, 1898: 182

Spasalus silvarum Kuwert, 1898: 182

Spasalus crenatus; Pangella, 1905: 4

Paxillus robustus; Gravely, 1918: 50, 51, fig. VI-10, p. 45

Paxillus robustus; Moreira, 1921(1922): 271, fig. 17, p. 274

Paxillus robustus; Moreira, 1925: 27, 30, fig. p. 31, est. II, fig. 4

Spasalus sivanus (err.), Moreira, 1925: 31

Paxillus robustus; Luederw., 1931: 61, 64, 67, 206, 223

Paxillus robustus; Luederw., 1934: 5, 12 (sep.)

Paxillus robustus; Hincks \& Dibb, 1935: 37
Paxillus robustus; Blackwelder, 1944: 192

Paxillus robustus; Paulian, 1947: 21

Paxillus robustus; Hincks, 1950: 1043

Paxillus robustus; Hincks \& Dibb, 1958: 15

Paxillus robustus; Pereira \& Kloss, 1966: 49-50, fig. 20 (Intest. post.)

Paxillus robustus; Reyes-Castillo, 1970: 185, 186, 187 Spasalus robustus; Reyes-Castillo, 1973: 1557

(*) apud Fincks \& Dibb, 1958

\section{DESCRIÇÃo DO EDEAGO}

Lobo médio globoso, quase tão largo quanto o tégmen, que só é ligeiramente mais largo ao nível dos lobos laterais. Superfície esclerosada nas áreas ventro-laterais.

Tégmen ligeiramente mais curto que o lobo médio. Superfície esclerosada no ventre e nos lados. A área esclerosada alcança um pouco o dorso nos cantos distais e basais.

Lobos laterais curtos, que avançam lateralmente sobre o terço basal do lobo médio. Apresentam-se como uma sinuosidade da margem distal, que se inicia com uma discreta convexidade ventral, seguida de reentrância ventro-lateral e terminando numa proeminência lateral.

Peça basal apesar de pouco distinta dos lobos laterais, aparenta ser mais curta e mais estreita do que eles.

MATERIAL ESTUDADo - Um exemplar do Rio de Janeiro e dois de São Paulo. Um macho da primeira procedência e dois da segunda (amostras diferentes).

VARIAÇÃo OBSERVADA - Apesar dos edeagos serem de indivíduos provenientes de localidades diferentes, mostram-se bastante uniformes, apenas variando ligeiramente no aspecto da área membranosa ao meio da margem distal ventral do tégmen.

\section{Gênero Passalus Fabricius, 1792}

Passalus rhodocanthopoides (Kuwert, 1891) (Est. VI, fig. 1, 2 e 3; Est. XIV, fig. 1)

Neleuops Rhodocanthopoides Kuwert, 1891: 179 Neleuops rhodocanthopoides; Kuwert, 1898: 143 Passalus rhodocanthopoides; Gravely, 1918: 53, fig. VII, 3, p. 65

Passalus rhodocanthopoides; Luederw., 1931: 82, 91, 205, 209, 229

Passalus Taunayi Luederw.; 1931: 82, 57, 86, 205, 209, 221,229 , est. 2 , fig. 29 
Passalus rhodocanthopoides; Hincks \& Dibb, 1935: 48

Passalus rhodocanthopoides; Blackwelder, 1944: 194

Paxillus tumupasae Hincks; 1949: 58-59, fig. 1

Passalus rhodocanthopoides; Hincks, 1950: 1041

Passalus rhodocanthopoides; Hincks \& Dibb, 1958: 17

Passalus rhodocanthopoides; Vulcano \& Pereira, 1967: 539

Passalus rhodocanthopoides; Reyes-Castillo, 1970: 204, 205, 212

Passalus rhodocanthopoides; Reyes-Castillo, 1973: 1569, fig. 15 , fot. 6 (Edeago)

\section{DESCRIÇÃO DO EDEAGO}

Lobo médio mais curto do que largo, cuja projeção de topo assemelha-se a um pentágono de pontas arredondadas. Ligeiramente mais largo do que o tégmen ao nivel dos lobos laterais. Superfície esclerosada nas áreas lateroventrais. As áreas esclerosadas são um pouco deprimidas e mais escuras no sentido longitudinal, junto à base, assim como marcadas em toda sua extensão for pontuações mais escuras que podem ultrapassar seus limites.

Tégmen um pouco mais curto do que o lobo médio. Superfície esclerosada no ventre, nos lados $e$ em partes do dorso. A área escle. rosada alcança as margens do dorso, apresentando pontuações escuras sobre os lobos laterais. Na margem distal do dorso, junto ao meio há duas faixas esclerosadas independentes.

Lobos laterais destacados por proeminência da margem distal lateral de ponta arredondada, que avança latero-dorsalmente sobre a metade basal do lobo médio.

Peça basal indistinta dos lobos laterais, parecendo mais curta do que eles.

MATERIAL ESTUDADO - Vinte e sete exemplares do Amapá. Onze machos (mesma amostra) .

VARIAÇÃo OBSERVADA - Os edeagos não mostram diferenças notáveis entre si, a não ser pequena variação nos limites das áreas esclerosadas.

Passalus morio Percheron, 1835 (Est. VI, fig. 4, 5 e 6; Est. XVI, fig. 2)

Passalus Morio Perch., 1835: 83, est. VI, fig. 4 Passalus morio; Perch., 1841: 33

Passalus longulus Perch., 1841: 35, est. 79, fig. 3
Passalus morio; Burm., 1847: 506

Passalus longulus; Burm., 1847: 505

Pertinax longulus; Gemminger \& Harold, 1868: 976

Pertinax morio; Kaup, 1869: 22

Pertinax longulus; Kaup, 1869: 24

Rhodocanthopus morio; Kaup, 1871: 91

Passalus longulus; Kaup, 1871: 92

Rhodocanthopus morio; Bates, 1886: 16

Pertinax Mancus; Kuwert, 1891: 178

Pertinax Epiphanoides Kuwert, 1891: 178

Pertinax Ruehli Kuwert, 1891: 178

Morosophus morio; Kuwert, 1898: 155

Morosophus mancus; Kuwert (nec Burm.), 1898: 158

Morosophus venerabilis Kuwert, 1898: 155

Morosophus morioides Kuwert, 1898: 156

Morosophus epiphanoides; Kuwert, 1898: 157

Morosophus cubanus Kuwert, 1898: 157

Morosophus rühli; Kuwert, 1898: 158

Morosophus epiphanoides; Rosmini, 1902: 3

Morosophus cubanus; Rosmini, 1802: 3

Morosophus rühli; Rosmini, 1902: 3

Passalus morio; Gravely, 1918: 54, 65, fig. VII-4, p. 53

Passalus morio; Moreira, 1921(1922): 276, 279, fig. 20, p. 274

Passalus morio; Moreira, 1925: 32, 39, fig., est. III, fig. 2

Passalus morio; Luederw., 1931: 84, 101-104, 207, 233

Passalus longulus; Luederw., 1931: 103

Passalus morio var. triangularifrons Luederw., 1931: $85,104,205,233$, est. 2 , fig. 27

Passalus morio var. triangularifrons forms a Luederw., 1931: 85, 104, 234

Passalus morio; Hincks, 1934: 271

Passalus morio; Hincks \& Dibb, 1935: 45-46

Passalus morio; Blackwelder, 1944: 193

Passalus morio; Pereira, 1944: 81-82

Passalus morio; Hincks \& Dibb, 1958: 16

Passalus morio; Pereira \& Kloss, 1966: 46, 47, fig. 13 (Intest. post.)

Passalus morio; Vulcano \& Pereira, 1967: 539

Passalus morio; Reyes-Castillo, 1970: 204, 205, 212

Passalus morio; Reyes-Castillo, 1973: 1568

\section{DESCRIÇÃO DO EDEAGO}

Lobo médio piriforme, de maior curvatura distal e mais largo que o tégmen. Superfície esclerosada nas áreas latero-ventrais. As áreas esclerosadas clareando e marcadas por pontuação esparsa mais escura na parte anterior. $\mathrm{Na}$ área membranosa latero-basal, junto aos limites das áreas esclerosadas, há alguns pontos mais escuros.

Tégmen um pouco mais longo do que o lobo médio. Superfície esclerosada no ventre e nos lados. As áreas esclerosadas alcançam 
a dorso ao longo dos lados, avançando mais para dentro nos lobos laterais e menos nos cantos basais. Pouco adiante da metade do seu comprimento, apresenta um sulco transversal, que corta toda a área esclerosada e é alargado ao meio do ventre.

Lobos laterais com a margem distal lateral reta, inclinada para a frente no sentido latero-dorsal e avançando mais dorsalmente sobre quase todo terço basal do lobo médio.

MATERIAL ESTUdAdo - Seis exemplares de Minas Gerais, um do Rio de Janeiro e quatro de São Paulo. Um macho da primeira procedência. um da segunda e três da terceira (mesma amostra) .

VARIAÇÃo OBSERVADA - Apesar dos edeagos pertencerem a indivíduos de diferentes proveniências, mostram-se bastante uniformes. A área esclerosada distal do tégmen, em indiví. duos da mesma amostra, pode ser ou não interrompida ao meio do ventre.

Passalus punctatostriatus Percheron, 1835 (Est. VI, fig. 7, 8 e 9; Est. XVI, fig. 3)

Passalus punctato-striatus Perch., 1835: 78, est. VI, fig. 1

Passalus punctato-striatus; Perch., 1841: 29

Passalus contractus Perch., 1841: 34 , est. LXXIX, fig. 2

Passalus punctato-striatus; Burm., 1847: 497

Passalus contractus; Burm., 1847: 498

Passalus punctato-striatus; Truqui, 1857: 261, 308 (sep. p. 3, 12)

Phoroneus puntatostriatus; Kaup. 1869: 18 Rhodocanthopus puntatostriatus; Kaup, 1871: 18 Rhodocanthopus puntatostriatus; Bates, 1986: 16-17 (pars)

Rhodocanthopus curtus Bates, 1886: 17

Rhodocanthopus Maillei Bates, 1886: 15 (pars)

Rhodocanthopus Punctatostriatus; Kuwert, 1891: 180

Rhodocanthopus Punctatostriatus var, contractus; Kuwert, 1891: 180

Rhodocanthopus Mundus Kuwert, 1891: 180 Rhodocanthopus Hoffmanni Kuwert, 1891: 180 Rhodocanthopus Ignavus Kuwert, 1891: 180 Rhodocanthopus Laticollis Kuwert, 1891: 180 Aponelides punctatostriatus; Kuwert, 1898: 151 Aponelides contractus; Kuwert, 1898: 150 Rhodocanthopus curtus; Kuwert, 1898: 142 Aponelides=laticollis; Kuwert, 1898: 150 Aponelides sincerus Kuwert, 1898: 150 Aponelides superfluus Kuwert, 1898: 151 Aponelides parabolicus Kuwert, 1898: 151
Aponelides ignavus; Kuwert, 1898: 151 Aponelides singularis Kuwert, 1898: 152

Aponelides hofmanni; Kuwert, 1898: 152

Aponelides mundus; Kuwert, 1898; 152

- Aponelides nescio Kuwert, 1898: 153

Aponelides praestans Kuwert, 1898: 153

Aponelides hofmanni; Pangella, 1905: 5

Neleides punctatostriatus; Arrow, 1906(1907): 449

Neleides curtus; Arrow, 1906(1907): 449

Rhodocanthopus maillei; Arrow, 1906(1907): 447

Passalus punctato-striatus; Gravely, 1918: 52, 65, fig. VI1-2, p. 53

Passalus punctatostriatus; Moreira, 1921(1922): 276, 281 , fig. 23 , p. 282

Passalus punctato-striatus; Moreira, 1925: 32, 42, fig. Passalus punctatostriatus; Luederw., 1931: 86, 110$-112,207,235$

Passalus parabolicus; Luederw., 1931: 83, 94, 230

Passalus punctatostriatus; Hincks, 1934: 272

Passalus curtus; Hincks, 1934: 272

Passalus superfluus; Hincks, 1934: 272

Passalus parabolicus; Hincks, 1934: 272

Passalus punctatostriatus; Hincks \& Dibb, 1935: 46

Passalus punctatostriatus; Blackwelder, 1944: 194

Passalus punctatostriatus; Hincks, 1950: 1044

Passalus punctatostriatus; Hincks, 1953: 34

Passalus punctatostriatus; Hincks \& Dibb, 1958: 16

Passalus punctatostriatus; Vulcano \& Pereira, 1967: 537

Passalus punctatostriatus; Reyes-Castillo, 1970: 204, 205

Passalus punctatostriatus; Virkki \& Reyes-Castillo, 1972: 52 , 55, fig. 35,39 (Citotaxonomia)

Passalus punctatostriatus; Reyes-Castillo \& Richter, 1973: 479 (Ovariolos)

\section{DESCRIÇÃO DO EDEAGO}

Lobo médio oval, com a maior curvatura distal e mais largo do que o tégmen. Superfície esclerosada nas áreas latero-ventrais que são mais escuras junto à base e mais claras do meio para diante. As áreas esclerosadas encontram-se na parte distal e são densamente pontuadas em marrom escuro numa faixa longitudinal ventro-lateral.

Tégmen mais curto do que o lobo médio e com quase $2 / 3$ do seu comprimento. Superfície esclerosada no ventre e em parte dos lados. A área esclerosada alcança as margens laterais distais e basais do dorso. $\mathrm{Na}$ margem da superfície dorsal, há dois traços esclerosados. laterais e independentes.

Lobos laterais curtos, mostrando-se apenas por uma convexidade mais dorsal da margem distal dos lados. 

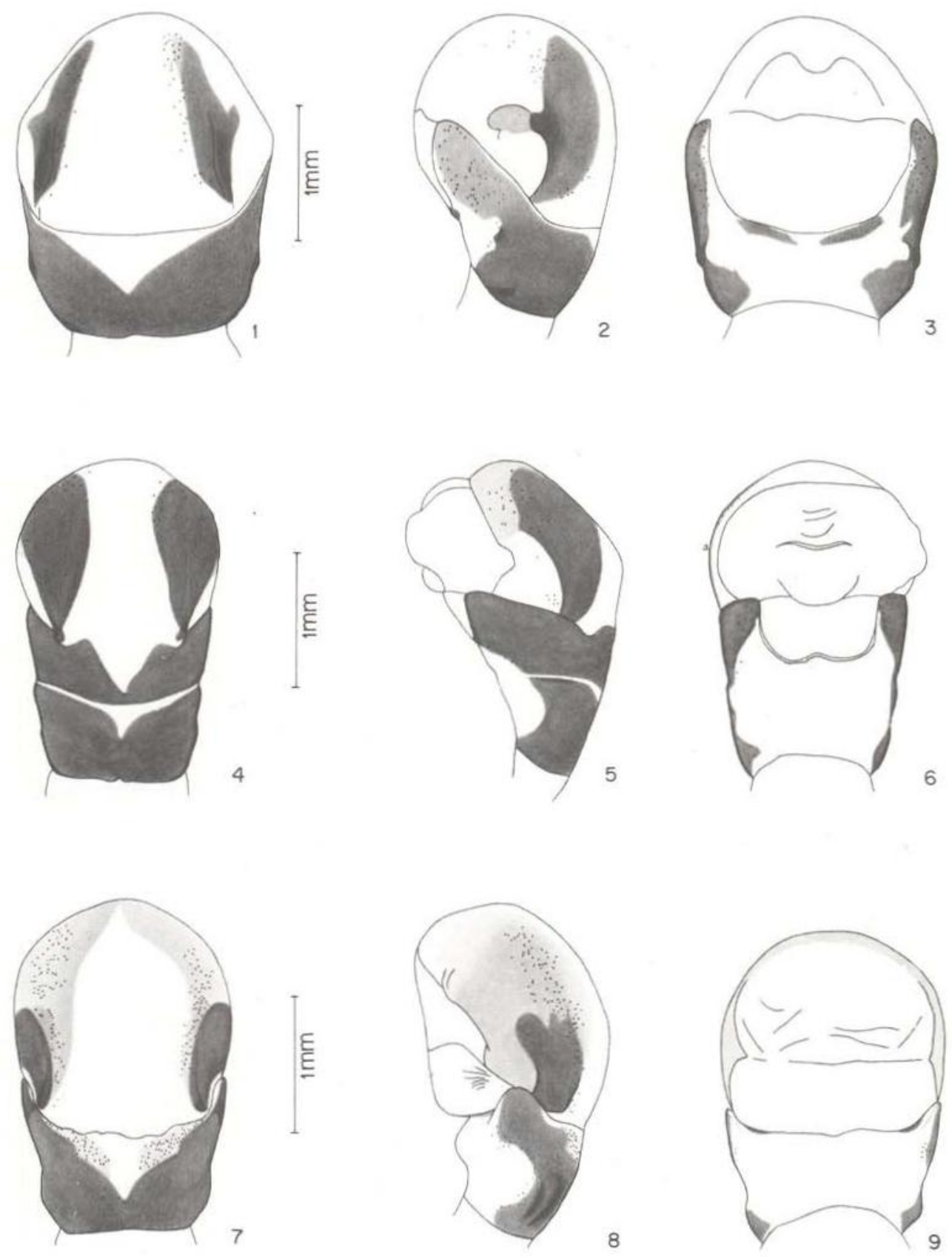

ESTAMPA VI - Passalus rhodocanthopoides (Kuwert, 1891). Edeago do exemplar IOC n.॰ 14.780: Fig. 1 - Vista ventral; Fig. 2 - Vista lateral; Fig. 3 - Vista dorsal.

Passalus morio Percheron, 1835. Edeago do exemplar ZUEC n. 340 : Fig. 4-Vista ventral; Fig. 5 - Vista lateraf; Fig. 6 - Vista dorsal (saco interno semi-evaginado).

Passalus punctatostriatus Percheron, 1835. Edeago do exemplar ZUEC n. 202: Fig. 7 - Vista ventral; Fig. 8 - Vista lateral; Fig. 9 - Vista dorsal. 
Peça basal pouco distinta dos lobos laterais, parecendo mais curta e mais estreita do que eles.

MATERIAL ESTUDADO - Cinco exemplares de São Paulo. Três machos (mesma amostra).

VARIAÇÃo OBSERVADA - Os edeagos não mostram diferenças notáveis entre si.

Passalus convexus Dalman in Schoenherr, 1817 (Est. VII, fig. 1, 2 e 3; Est. XVII, fig. 2)

Passalus convexus Dalm. in Schoenh., 1817: 333, app. p. 142

Passalus pelliculatus Perty, 1830: 55, est. 11, fig. 16 Passalus Convexus; Perch., 1835: 86, est. VI, fig. 6 Passalus convexus; Perch., 1841: 37

Passalus convexus; Burm., 1847: 503

Passalus convexus; Kaup, 1869: 21

Pertinax convexus; Kaup, 1871: 95

Pertinax Banghaasi Kuwert, 1891: 179

Pertinax Convexus var. Nickerli Kuwert, 1891: 179

Pertinax Convexus var. Stolli Kuwert, 1891: 179

Pertinax convexus; Kuwert, 1898: 159

Pertinax nickerli; Kuwert, 1898: 160

Pretinax sulcifrons Kuwert, 1898: 160

Pertinax convexus ab. banghaasi; Kuwert, 1898: 159

Pertinax convexus; Rosmini, 1902: 3

Passalus convexus; Gravely, 1918: 55, 66

Passalus convexus; Moreira, 1921(1922): 276, 280, fig. 21, p. 282

Passalus convexus; Moreira, 1925: 32, 33, fig. p. 34, est. III, fig. 1

Passalus convexus; Luederw., 1931: 86, 114, 207, 236

Passalus convexus forma a Luederw., 1934b: 3 (sep.)

Passalus convexus; Hincks, 1934: 271

Passalus convexus; Hincks \& Dibb, 1935: 43

Passalus convexus; Luederw., 1941: 86

Passalus convexus; Blackwelder, 1944: 192

Passalus convexus; Hincks, 1949: 60, 61

Passalus convexus; Hinks, 1950: 1040

Passalus convexus; Hincks \& Dibb, 1958: 16

Passalus convexus; Pereira \& Kloss, 1966: 49, 50, fig. 23 (Intest. post.)

Passalus convexus; Vulcano \& Pereira, 1967: 538

Passalus convexus; Reyes-Castillo, 1970: 203, 205, 212

Passalus convexus; Reyes-Castillo, 1973: 1561-1562, fig. 10 (Edeago), fot. 4

\section{DESCRIÇÃo DO EDEAGO}

Lobo médio com projeção de topo elíptica alongada e mais estreito do que o tégmen. Superfície esclerosada nas áreas ventro-laterais. As áréas esclerosadas são cobertas de pontos mais escuros e alcançam o dorso nos lados da margem distal.
Tégmen longo, com mais de três quartos do comprimento do lobo médio. Superfície esclerosada no ventre e nos lados. A área esclerosada alcança as margens laterais do dorso, como uma faixa contínua, mais larga ao nivel dos lobos laterais. No quarto basal, apresenta um sulco fino transversal, que corta toda a área esclerosada e está voltado da parte distal para a dorsal nos lados, retornando ao sentido transversal pouco antes de suas extremidades.

Lobos laterais grandes e bem destacados, formam ponta que ultrapassa a margem dorsal dos lados, avançando latero-dorsalmente sobre quase todos os três quartos basais do lobo médio.

Peça basal curta em relação aos lobos la. terais e um pouco mais estreita do que eles.

MATERIAL ESTUdAdo - Cinco exemplares do Pará e cinco do Rio de Janeiro. Dois machos da primeira procedência (mesma amostra) e dois da segunda (mesma amostra).

VARIAÇÃo OBSERVADA - Apesar dos edeagos pertencerem a indivíduos de diferentes proveniências, mostram-se bastante uniformes.

Passalus gravelyi Moreira, 1922 (Est. VII, fig. 4, 5 e 6; Est. XVII, fig. 1)

Passalus Gravelyi Moreira, 1922: 276 (parvulus lapsus), 278-279, 274, fig. 19

Passalus Gravelyi; Moreira, 1925: 32, 36, fig.

Passalus gravelyi; Luederw., 1931: 86 (Gravelyi), $116-118,236$

Passalus gravelyi; Luederw., 19340: 20

Passalus Gravelyi; Hincks et Dibb, 1935: 44

Passalus gravelyi; Blackwelder, 1944: 193

Passalus gravelyi; Zikan et Wygodzinsky, 1948: 26

Passalus gravelyi; Bührnheim, 1963: 313, 316-320, fig. 2 tab. I

Passalus gravelyi; Reyes-Castillo, 1970: 204

\section{DESCRIÇÃo DO EDEAGO}

Lobo médio oval, com a maior curvatura distal, só superado em largura pelo tégmen, ao nivel da extremidade dos lobos laterais. Superfície esclerosada nas áreas ventro-laterais. As áreas esclerosadas clareiam latero-dorsalmente e possuem pontuação mais escura nos lados, no terço apical ventral. 

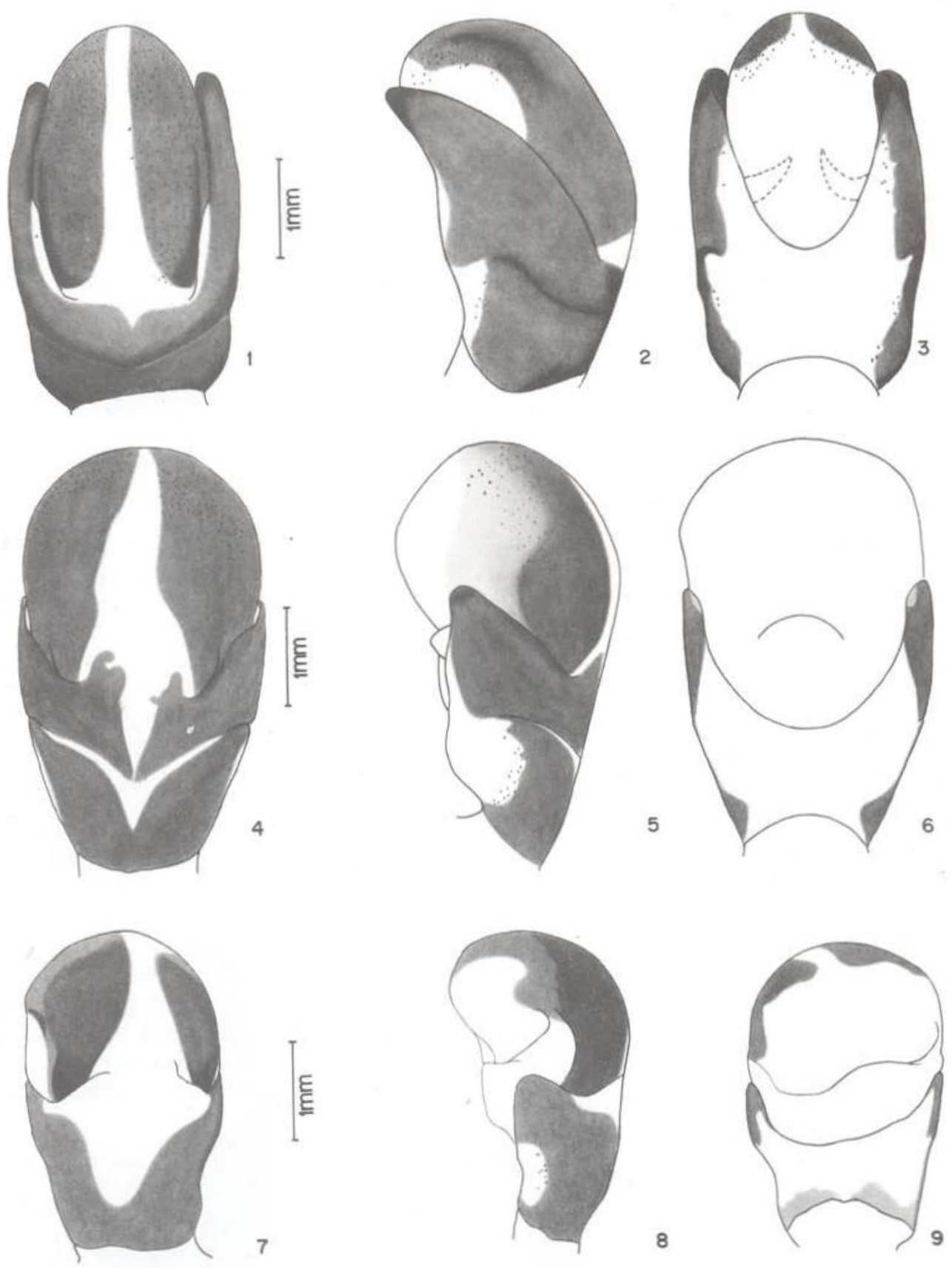

ESTAMPA VII - Passalus convexus Dalman, 1817. Edeago do exemplar IOO n. ${ }^{\circ}$ 14.771: Fig. 1 - Vista ventral; Fig. 2 - Vista lateral; Fig. 3 - Vista dorsal.

Passalus gravelyi Moreira, 1922. Edeago do exemplar IOCZ n.॰ 7985: Fig. 4 - Vista ventral; Fig. 5 - Vista lateral; Fig. 6 - Vista dorsal.

Passalus zikani Luederw., 1929. Edeago do exemplar IOCZ n.॰ 7669: Fig. 7 - Vista ventral; Fig. 8 - Vista lateral; Fig. 9 - Vista dorsal. 
Tégmen tão longo quanto o lobo médio e estreitando-se progressivamente em direção à base. Superfície esclerosada no ventre e em parte dos lados. As áreas esclerosadas tem pontuação mais escura nos seus limites laterobasais. As margens laterais do dorso, ao nível dos lobos laterais e nos cantos basais, são alcançadas pelos esclerosamentos. Um pouco adiante da metade do seu comprimento, apresenta um sulco transversal, que corta toda a área esclerosada e é mais largo ao meio do ventre.

Lobos laterais bem destacados, apontados para o dorso e avançando latero-dorsalmente sobre a metade basal do lobo médio.

Peça basal um pouco mais longa do que os lobos laterais.

MATERIAL ESTUDADO - Dois exemplares do Rio de Janeiro. Um macho.

Passalus zikani Luederwaldt, 1929

(Est. VII, fig. 7, 8 e 9; Est. XVII, fig. 3)

Passalus Zikani Luederw., 1929: 31

Passalus Zikani; Luederw., 1931: 203-204

Passalus Zikani; Hincks \& Dibb, 1935: 50

Passalus zikani; Blackwelder, 1944: 195

Passalus zikani; Bührnheim, 1961: 251-258, fig. 1-27

Passalus zikani; Reyes-Castillo, 1970: 204, 212

Mitrorhinus zikani; Reyes-Castillo, 1973: 1560

\section{DESCRIÇÃO DO EDEAGO}

Lobo médio globoso, tão largo quanto o tégmen e deformadio por uma torção no sentido horário. Superfície esclerosada nas áreas ventro-laterais. Areas esclerosadas alcançando o dorso na parte distal e parte de um dos lados, devido à torção da peça.

Tégmen um pouco mais curto do que o lobo médio e também torcido no sentido horário. Superfície esclerosada no ventre e nos lados. A área esclerosada alcança o dorso nas margens laterais distais e em toda a margem basal, onde é mais clara.

Lobos laterais curtos, mostrando-se apenas por proeminência dorsal da margem distal lateral e avançando latero-dorsalmente sobre o terço basal do lobo médio.

Peça båsal apesar de pouco distinta dos lobos laterais, parecendo mais longa e mais estreita do que eles.
MATERIAL ESTUDADO - Dois exemplares do Rio de Janeiro. Dois machos da mesma amostra.

VARIAÇÃo OBSERVADA - Os edeagos não mostram diferenças notáveis entre si, apresentando ambos a torção mencionada.

Passalus occipitalis Eschscholtz, 1829

(Est. VIII, fig. 1, 2 e 3; Est. XVIII, fig. 1)

Passalus occipitalis Eschsch., 1829: 21 (sep. p. 9)

Passalus Quadrifrons Perch., 1835: 64, est. IV, fig. 8 Passalus occipitalis; Mannernheim, 1838: $65^{*}$

Passalus occipitalis; Perch., 1841: 45

Passalus quadrifrons; Perch., 1841: 19

Passalus tetragonus Westwood, 1845: 28

Passalus occipitalis; Burm., 1847: 518, 532

Passalus quadrifrons; Burm., 1847: 472

Passalus rugifrons Kaup, 1869: 15

Phoroneus rugifrons; Kaup, 1871: 100, est. VI, fig. 5 Didimus quadrifrons; Kaup, 1871: 30

Manlius Rugifrons; Kuwert, 1891: 182

Manlius rugifrons; Kuwert, 1898: 161

Didimus quadrifrons; Kuwert, 1898: 306

Manlius rugifrons; Pangella, 1905a: 2

Epiphoroneus occipitalis; Arrow, 1906(1907): 445, $459-460$

Passalus tetragonus; Arrow, 1906(1907): 445

Passalus quadrifrons; Arrow, 1906(1907): 445

Passalus occipitalis; Gravely, 1918: 61, 68, fig. VII1-18, p. 53

Passalus occipitalis; Moreira, 1921(1922): 277, 286

Passalus occipitalis; Moreira, 1925: 32, 41, fig.

Passalus occipitalis; Luederw., 1931: 80, 127, 131, 134, 207, 226, 239, 244, est. 1, fig. 14-15

Passalus oecipitalis (err.); Luederw., 1934b: 373 (sep. p. 3)

Passalus occipitalis; Hincks \& Dibb, 1935: 52

Passalus occipitalis; Blackwelder, 1944: 193

Passalus occipitalis; Hincks \& Dibb, 1958: 17

Passalus occipitalis; Pereira \& Kloss, 1966: 46, fig. 11 (Intest. post.)

Passalus occipitalis; Reyes-Castillo, 1970: 204, 205, 212.

(•) opud Hincks \& Dibb, 1935

\section{DESCRIÇÃO DO EDEAGO}

Lobo médio globoso, mais largo que o tégmen. Superfície esclerosada nas áreas ventro-laterais. As áreas esclerosadas alcançam o dorso como duas pequenas manchas laterais, junto às pontas dos lobos laterais. Em torno dos limites laterais das áreas esclerosadas, existe pontuação mais escura.

Tégmen um pouco mais curto do que o lobo médio e ligeiramente mais estreito do que 

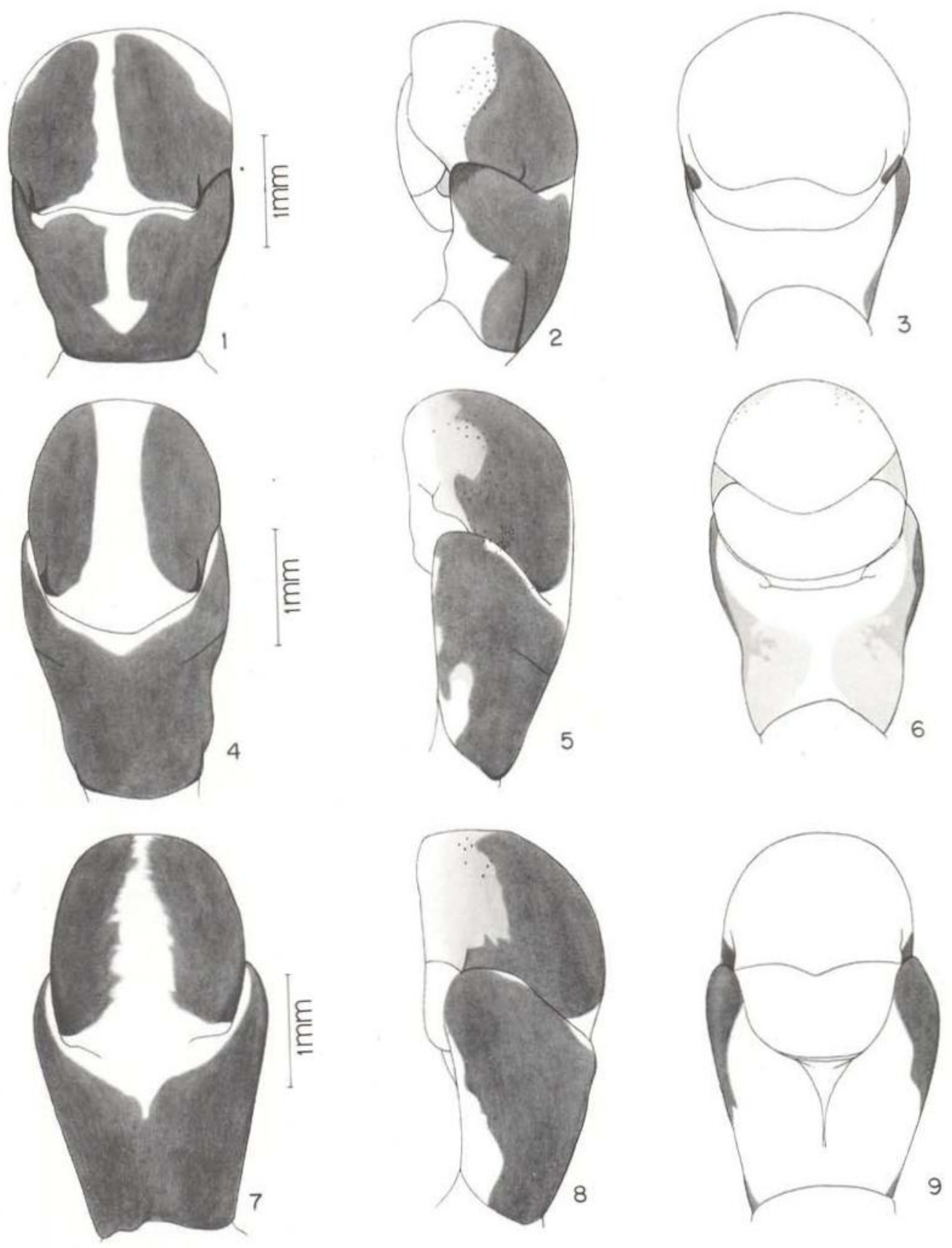

ESTAMPA VIII - Passalus occipitalis Eschscholtz, 1829. Edeago do exemplar IOC n.॰ 14.776: Fig. 1 - Vista ventral; Fig. 2 - Vista lateral; Fig. 3 - Vista dorsal.

Passalus alius (Kuwert, 1898). Edeago do exemplar IOC n. 14.779: Fig. 4 - Vista ventral; Fig. 5 - Vista lateral; Fig. 6 - Vista dorsal.

Passalus quadricollis Eschscholtz, 1829. Edeago do exemplar IOC n. 14.775: Fig. 7 - Vista ventral; Fig. 8 - Vista lateral; Fig. 9 - Vista dorsal. 
ele. Suparfície esclerosada no ventre e nos lados. Área esclerosada alcançando a margem lateral dorsal ao nível dos lobos laterais e do quarto basal. Na metade do seu comprimento, apresenta um fino sulco de cada lado, que acompanha os limites basais do esclerosamento dos lobos laterais.

Lobos laterais curtos, mostrando-se por uma proeminência da margem distal apontada para o dorso, avançando lateralmente sobre o terço basal do lobo médio.

Peça basal com o mesmo comprimento dos lobos laterais e mais estreita que eles. Estreita-se em direção à base.

MATERIAL ESTUdAdo - Cinco exemplares do Rio de Janeiro. Dois machos de uma amostra e dois de outra.

VARIAÇÃo OBSERVADA - Os edeagos não mostram diferenças notáveis entre si, mesmo pertencendo a indivíduos de amostras diferentes.

Passalus alius (Kuwert, 1898)

(Est. VIII, fig. 4, 5 e 6; Est. XVIII, fig. 2)

Phoroneus alius Kuwert, 1898: 191

Phoroneus caulifer Kuwert, 1898: 192

Passalus quadricollis; Gravely, 1918 (nec Eschsch.): 61,67 , fig. VII, 17, p. 53

Passalus quadricollis; Moreira, 1921(1922): 277, 290 Passalus quadricollis; Moreira, 1925: 33, 43, fig. Passalus alius; Luederw., 1931: 132, 138, 206, 244 Passalus alius; Hincks \& Dibb, 1935: 50

Passalus alius; Blackwelder, 1944: 192

Passalus alius; Reyes-Castillo, 1970: 203, 205, 211

\section{DESCRIÇÃo DO EDEAGO}

Lobo médio um pouco mais longo do que largo, cuja projeção de topo é elíptica. Só é ultrapassado em largura pelo tégmen, ao nível dos lobos laterais. Superfície esclerosada nas áreas latero-dorsais. As áreas esclerosadas clareiam à medida que se estendem para o dorso, alcançando-o nos lados da margem distal e ao meio das margens laterais. Há pontuações mais escuras nos lados e junto à margem dorso-distal.

Tégmen um pouco mais longo do que o lobo médio." Superfície esclerosada no ventre, nos lados e em parte do dorso. A área esclerosada clareia progressivamente das margens laterais do dorso para o meio, onde suas bordas não chegam a se encontrar. Um pouco adiante da metade do seu comprimento, apresenta um sulco fino e curto, que se estende transversalmente entre o ventre e cada um dos lados.

Lobos laterais curtos, mostrando-se por proeminência da margem distal, com ponta voltada para o dorso e que avança lateralmente sobre a metade basal do lobo médio.

Peça basal aparentemente mais longa que os lobos laterais e estreitando-se em direção à base.

MATERIAL ESTUDAdo - Seis exemplares de Minas Gerais. Dois machos de uma amostra e dois de outra.

VARIAÇÃo OBSERVADA - Os edeagos dos indivíduos provenientes de uma das amostras (Ja. boticatubas, Serra do Cipó), não têm sulcos que se estendem transversalmente entre o ventre e cada lado do tégmen, enquanto os da outra (Barreira do Piquete), os têm como mostra a figura. Quanto aos demais aspectos não apresentam diferenças notáveis entre si.

Passalus quadricollis Eschscholtz, 1829 (Est. VII, fig. 7, 8 e 9; Est. XVIII, fig. 3)

Passalus quadricollis Eschsch., 1829: 21 (sep. p. 9)

Passalus Quadricollis; Perch., 1835: 59, est. IV, fig. 5

Passalus quadricollis; Perch., 1841: 15

Passalus quadricollis; Burm., 1847: 501

Passalus quadricollis; Kaup, 1869: 14

Phoroneus quadricollis; Kaup, 1871: 102

Phoroneus quadricollis; Kuwert, 1898: 192

Phoroneus aequalis Kuwert, 1898: 192

Phoroneus aequus Kuwert, 1898: 192

Phoroneus obscurus Kuwert, 1898: 193

Passalus quadricollis; Luederw., 1931: 132, 139, 208, 233 , est. 1 , fig. 18

Passalus quadricollis; Hincks \& Dibb, 1935: 53

Passalus quadricollis; Blackwelder, 1944: 194

Passalus quadricollis; Pereira \& Kloss, 1966: 49, 50, fig. 24 (Intest. post.)

Passalus quadricollis; Reyes-Castillo, 1970: 204, 205, 211

\section{DESCRIÇÃO DO EDEAGO}

Lobo médio mais longo do que largo, com projeção de topo elíptica e mais estreito que o tégmen. Superfície esclerosada nas áreas ven. tro-laterais. As áreas esclerosadas alcançam o 

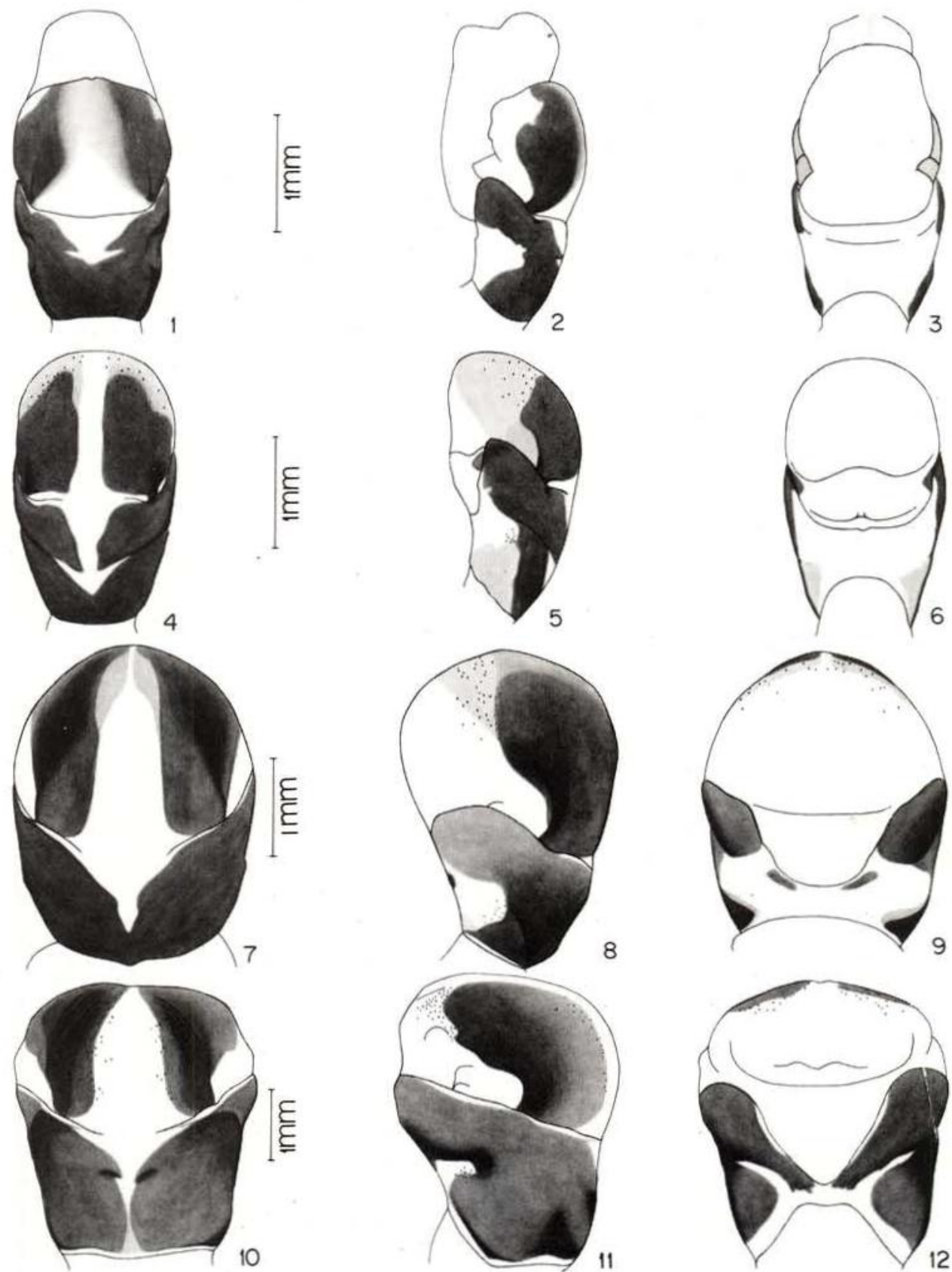

ESTAMPA IX - Passalus glaberrimus Eschscholtz, 1829. Edeago do exemplar IOC n. 14.773: Fig. 1 - Vista ventral; Fig. 2 - Vista lateral; Fig. 3 - Vista dorsal.

Passalus plicatus Percheron, 1835. Edeago do exemplar IOC n. 14.778 : Fig. 4 - Vista ventral; Fig. 5 Vista lateral; Fig. 6 - Vista dorsal.

Passalus coniferus Eschscholtz, 1829. Edeago do exemplar ZUEC n.॰ 01: Fig. 7 - Vista ventral; Fig. 8 - Vista lateral; Fig. 9 - Vista dorsal.

Passalus interruptus (Lin., 1758). Edeago do exemplar ZUEC n.॰ 290: Fig. 10 - Vista ventral; Fig. 11 - Vista lateral; Fig. 12 - Vista dorsal. 
dorso como uma pequena mancha ao meio da margem de cada lado. Há alguns pontos mais escuros nos limites laterais distais das áreas esclerosadas.

Tégmen mais longo que o lobo médio, estreitando-se regularmente em direção à base. Superfície esclerosada no ventre e nos lados. A área esclerosada alcança as margens laterais do dorso como uma faixa larga, ao nível dos lobos laterais, e como um traço, junto à base .

Lobos laterais com extremidade arredondada, voltada para o dorso e avançando laterodorsalmente até um pouco adiante do terço basal do lobo médio.

Peça basal apesar de quase indistinta dos labos laterais, aparenta ser mais curta que eles. MATERIAL ESTUDADO - Dois exemplares do Rio de Janeiro. Dois machos (mesma amostra).

VARIAÇÃo OBSERVADA - Os edeagos não mos. tram diferenças notáveis entre si.

Passalus glaberrimus Eschscholtz, 1829

(Est. IX, fig. 1, 2 e 3; Est. XIX, fig. 1)

Passalus glaberrimus Eschsch., 1829: 20 (sep. p. 8) Passalus Glaberrimus; Perch., 1835: 81, est. VI, fig. 3 Passalus bidentatus Dejean, 1837: 195

Passalus glaberrimus; Perch., 1841: 24

Passalus glaberrimus; Burm., 1847: 499

Phoroneus glaberrimus; Kaup, 1869: 20

Phoroneus paxilloides Kaup, 1869: 19

Epiphanus glaberrimus; Kaup, 1871: 98, est. VI, fig. 8

Epiphanus paxilloides; Kaup, 1871: 98

Epiphanus Simulator Kuwert, 1891: 184

Epiphanus glaberrimus; Kuwert, 1898: 197

Epiphanus paxilloides; Kuwert, 1898: 196

Epiphanus glaberrimus ab. simulator; Kuwert, 1898: 197

Epiphanus glaberrimus; Pangella, 1905a: 5

Passalus glaberrimus; Gravely, 1918: 58, 67

Passalus parvulus Moreira, 1921(1922): 277, 288, fig. 25 , p. 282 , fig. 3 , p. 288

Passalus glaberrimus; Moreira, 1921(1922): 277, 288-289

Passalus parvulus; Moreira, 1925: 33, 41-42, fig., est. III, fig. 3 , p. 12 , fig. 3

Passalus glaberrimus; Moreira, 1925: 33, 35, fig.

Passalus glaberrimus; Luederw., 1931: 133, 145, 246

Passalus glaberrimus ab. simulator; Luederw., 1931: 147

Passalus parvúlus; Luederw., 1931: 147, 202

Passalus glaberrimus; Hincks \& Dibb, 1935: 51

Passalus glaberrimus; Blackwelder, 1944: 193
Passalus glaberrimus; Hincks, 1950: 1044

Passalus glaberrimus; Bührnheim, 1964: 56-58, figs. 1-6

Passalus glaberrimus; Pereira \& Kloss, 1966: 46, fig. 9 (Intest. post.)

Passalus glaberrimus; Vulcano \& Pereira, 1967: 543

Passalus glaberrimus; Reyes-Castillo, 1970: 204, 205, 213

Passalus glaberrimus; Reyes-Castillo, 1973: 1574, fig. 18

\section{DESCRIÇÃO DO EDEAGO}

Lobo médio globoso, mais largo que o tégmen. Superfície com as áreas latero-ventrais esclerosadas e unidas ao meio do ventre, onde são mais claras. A área esclerosada alcança o dorso numa faixa marginal clareada, que vai de uma a outra extremidade dos lobos laterais passando pela margem distal.

Tégmen de comprimento aproximadamente igual ao do lobo médio. Estreita-se em direção à base, sofrendo ainda um estrangulamento entre os lobos laterais e a peça basal. Superfície esclerosada no ventre e nos lados. A área esclerosada alcança o dorso como quatro estreitos traços marginais laterais, dois anteriores e dois basais.

Lobos laterais formando extremidade arredondada, voltada para o dorso $e$ avançando lateralmente sobre o terço basal do lobo médio.

Peça basal aparentando ser quase tão larga quanto os lobos laterais.

MATERIAL ESTUdAdo - Dois exemplares do Amazonas. Um macho.

Passalus plicatus Percheron, 1835

(Est. IX, fig. 4, 5 e 6; Est. XIX, fig. 2)

Passalus Plicatus Perch., 1835: 54, esĩ. IV, fig. 2

Passalus plicatus; Perch., 1841: 13

Passalus plicatus; Burm., 1847: 486

Passalus plicatus; Kaup, 1869: 35

Vatinius plicatus; Kaup, 1871: 83

Tryptocerus fracticornis Kuwert, 1898: 200

Passalus plicatus; Luederw., 1931: 154, 162, 252, est. 1 , fig. 19

Passalus plicatus forma a Luederw., 1931: 164

Passalus plicatus forma b Luederw., 1931: 164

Passalus plicatus; Hincks \& Dibb, 1935: 55

Passalus plicatus; Hincks, 1940: 493

Passalus plicatus; Luederw., 1941: 87, 89

Passalus plicatus; Blackwelder, 1944: 194

Passalus plicatus; Hincks \& Dibb, 1958: 18

Passalus plicatus; Reyes-Castillo, 1970: 204, 212 

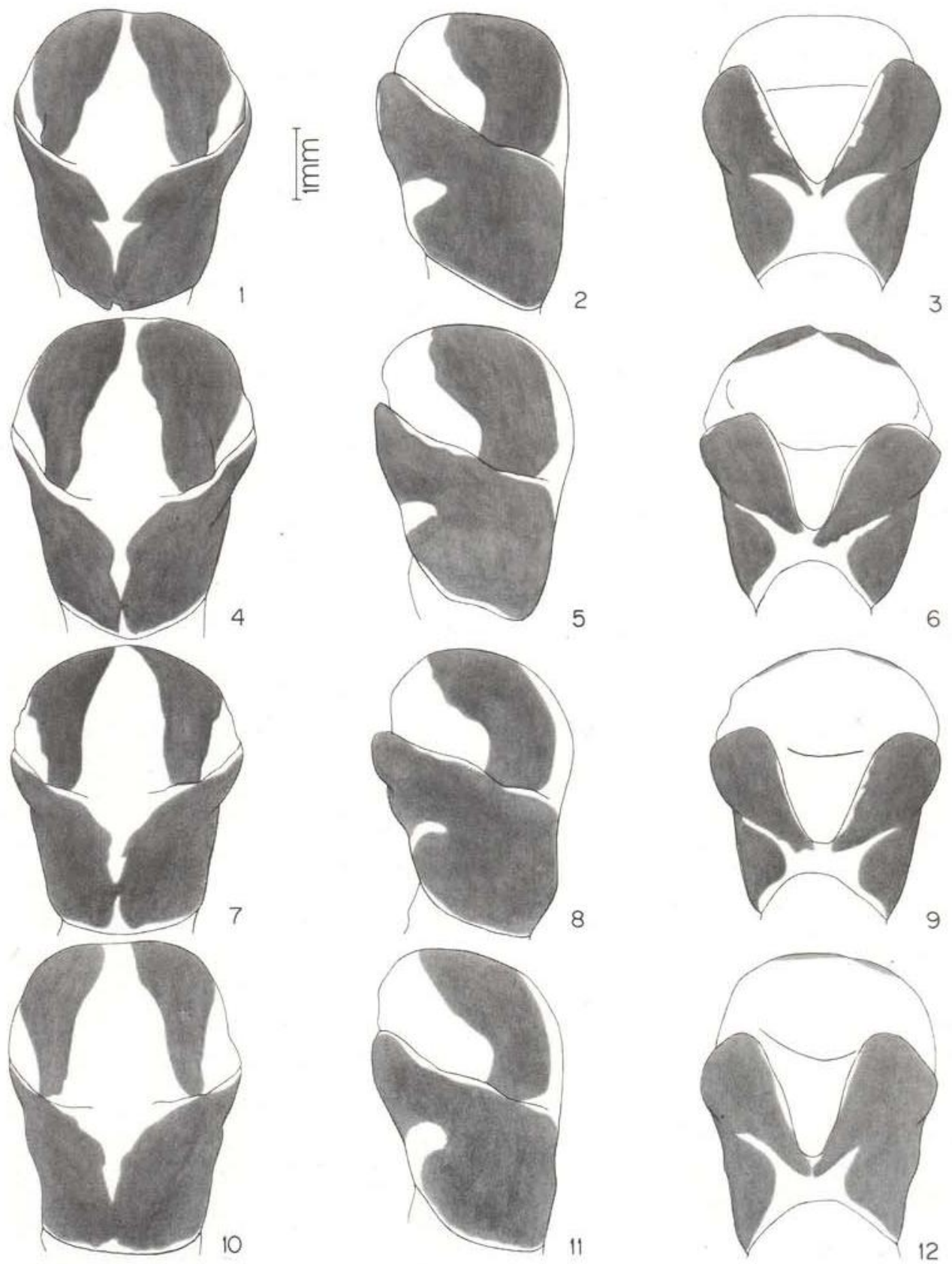

ESTAMPA X - Passalus interruptus (Lin., 1758): Fig. 1 a 3 - Edeago em vista ventral, lateral e dorsal de individuo proveniente do Amapá. Exemplar IOC n. 14.792; Fig. 4 a 6 - Edeago em vista ventral, lateral e dorsal de indivíduo proveniente do Pará. Exemplar IOC n. 14.830; Fig. 7 a 9 - Edeago em vista ventral, -lateral e dorsal de indivíduo proveniente de Mato Grosso. Exemplar IOC n.॰ 14.292; Fig. 10-12 Edeago em vista ventral, lateral e dorsal de indivíduo proveniente de São Paulo. Exemplar ZUEC n. 194. Para todas as figuras: Mesma escala. Áreas esclerosadas sem detalhes, apenas aspecto de seus contornos. 


\section{DESCRIÇÃo DO EDEAGo}

Lobo médio globoso, ligeiramente mais longo do que largo e quase tão largo quanto o tégmen. Superfície esclerosada nas áreas ventro-laterais, que são mais claras e pontuadas junto à margem distal. As áreas esclerosadas alcançam o dorso como duas pequenas manchas nas margens laterais, um pouco abaixo das extremidades dos lobos do tégmen.

Tégmen quase tão longo quanto o lobo médio e estreitando-se em direção à base. Superfície esclerosada no ventre e nos lados. A área esclerosada alcança as margens laterais do dorso como uma faixa estreita, na metade distal, e como um traço, na metade basal, onde se expande numa área maior e mais clara. Um pouco adiante da metade de seu comprimento, apresenta um fino sulco transversal de cada lado e bem alargado ao meio do ventre, onde se funde à faixa membranosa média longitudinal distal.

Lobos laterais formando extremidade arredondada, voltada para $\sigma$ dorso e avançando lateralmente sobre quase toda metade basal do lobo médio.

Peça basal parecendo quase tão longa quanto os lobos laterais.

MATERIAL ESTUDADO - Vinte e seis exemplares de Minas Gerais. Quatorze machos, três dos quais de uma amostra e onze de outra.

VARIAÇÃo OBSERVADA - Os edeagos não mos. tram diferenças notáveis entre si, a não ser variação na largura da faixa membranosa média longitudinal anterior ventral do tégmen.

Passalus coniferus Eschscholtz, 1829 (Est. IX, fig. 7, 8 e 9; Est. XIX, fig. 3)

Passalus coniferus Eschsch., 1829: 16 (sep. p. 4) Passalus coniferus; Burm., 1847: 482

Passalus torpidus Erich., 1847: 112

Passalus conifer; Kaup, 1869: 31

Neleus coniferus; Kaup, 1871: 86

Neleus Coniferus; Kuwert, 1891: 185

Neleus Crinicicatrix Kuwert, 1891: 185

Ptychotrichus coniferus; Kuwert 1898: 276

Ptvchotrichus brevilabris Kuwert 1898: 276

Ptychotrichus sulciscutellum Kuwert, 1898: 276
Ptychotrichus torpidus; Kuwert, 1898: 276

Ptychotrichus crinicicatrix; Kuwert, 1898: 277

Ptychotrichus crinicicatrix; Rosmini, 1902: 9

Passalus crinicatrix; Pangella, 1905a: 15

Passalus coniferus; Luederw., 1931: 172, 189-191, 206,256

Passalus coniferus; Hincks \& Dibb, 1935: 56-57

Passalus coniferus; Doesburg, 1942: 333

Passalus coniferus; Blackwelder, 1944: 192

Passalus coniferus; Hincks, 1950: 1046

Passalus coniferus; Guérim, 1953: 244

Passalus coniferus; Hincks \& Dibb, 1958: 18

Passalus coniferus; Pereira \& Kloss, 1966: 46, 47, fig. 14 (Intest. post.)

Passalus coniferus; Vulcano \& Pereira, 1967: 544

Passalus coniferus; Reyes-Castillo, 1970: 203, 205, 215

\section{DESCRIÇÃO DO EDEAGO}

Lobo médio globoso, quase tão longo quanto largo e não ultrapassado em largura pelo tégmen. Superfície com as áreas ventro-laterais esclerosadas, claras e pontuadas, na parte distal e lateral. As áreas esclerosadas são longitudinalmente deprimidas e mais escuras junto aos seus limites laterais. Na margem distal do dorso, junto ao meio, aparecem vestígios dos esclerosamentos.

Tégmen mais curto do que o lobo médio. Superfície esclerosada no ventre, parcialmente nos lados e em partes do dorso. A área escle. rosada alcança as margens laterais do dorso na parte distal, onde cobre quase toda a superfície dos lobos laterais e junto à base, onde aparece como uma pequena mancha. Ainda no dorso, há duas áreas esclerosadas lineares e isoladas, junto à margem distal, ao nível da base de cada lobo lateral.

Lobos laterais mostrando-se por pequena convexidade da margem distal lateral e por extremidade apontada no dorso, avançando dorsalmente sobre a metade basal do lobo médio.

Peça basal quase indistinta dos lobos laterais e aparentando ser tão longa quanto eles. É globosa na base.

MATERIAL ESTUDADO - Sete exemplares de São Paulo. Três machos (mesma amostra).

VARIAÇÃo OBSERVADA - Os edeagos não mos. tram diferenças notáveis entre si. 

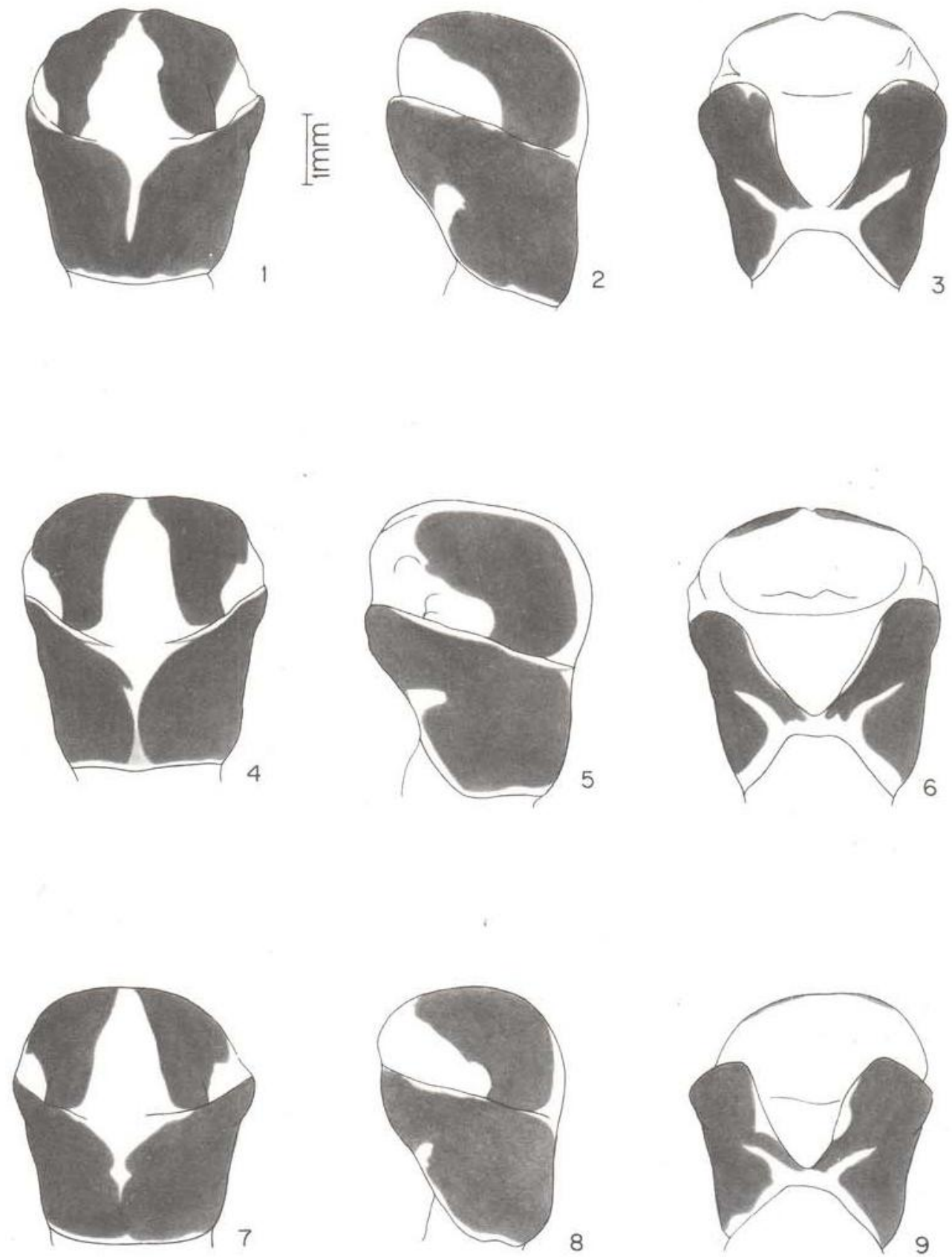

ESTAMPA XI - Passalus interruptus (Lin., 1758): Fig. 1 a 3 - Edeago em vista ventral, lateral e dorsal de indivíduo proveniente do Amazonas. Exemplar IOCZ n. ${ }^{\circ} 14.258$; Fig. 4 a 6 - Edeago em vista ventral lateral e dorsal de indivíduo proveniente do Acre. Exemplar ZUEC n. ${ }^{\circ} 290$; Fig. 7 a 9 - Edeago em vista ventral, lateral e dorsal de indivíduo proveniente da Bahia. Exemplar IOCZ n. ${ }^{\circ} 14.261$. Para todas as figuras: Mesma escala. Areas esclerosadas representadas sem detalhes, apenas aspecto de seus contornos. 
Passalus interruptus (Linnaeus, 1758)

(Est. IX, fig. 10, 11 e 12; Est. X, fig. 1 a 12;

Est. XI, fig. 1 a 9; Est. XIX, fig. 4)

Scarabeus interruptus Linn., 1758: 354

Scarabeus interruptus; Linn., 1764: $33^{*}$

Lucanus interruptus; Linn., 1767: 560*

Lucanus? interruptus; Degeer, 1774; est. XIX, fig. $13^{*}$

Lucanus? interruptus; Fabr., 1781: $3^{*}$

Lucanus? interruptus; Fabr., 1787: 2*

Lucanus? interruptus; Roemer, 1789: 3, 38, est. 2, fig. $2^{*}$

I ucanus interruptus; Oliv., 1789: 24, est. 3, fig. 5 (pars?)*

I ucanus interruptus; Herbst, 1790: 304, est. 34, fig. $4^{*}$

Lucanus interruptus; Voet (ed Panzer), 1791: 31, est. 29 , fig. $1^{*}$

Passalus interruptus; Fabr., 1792: 240
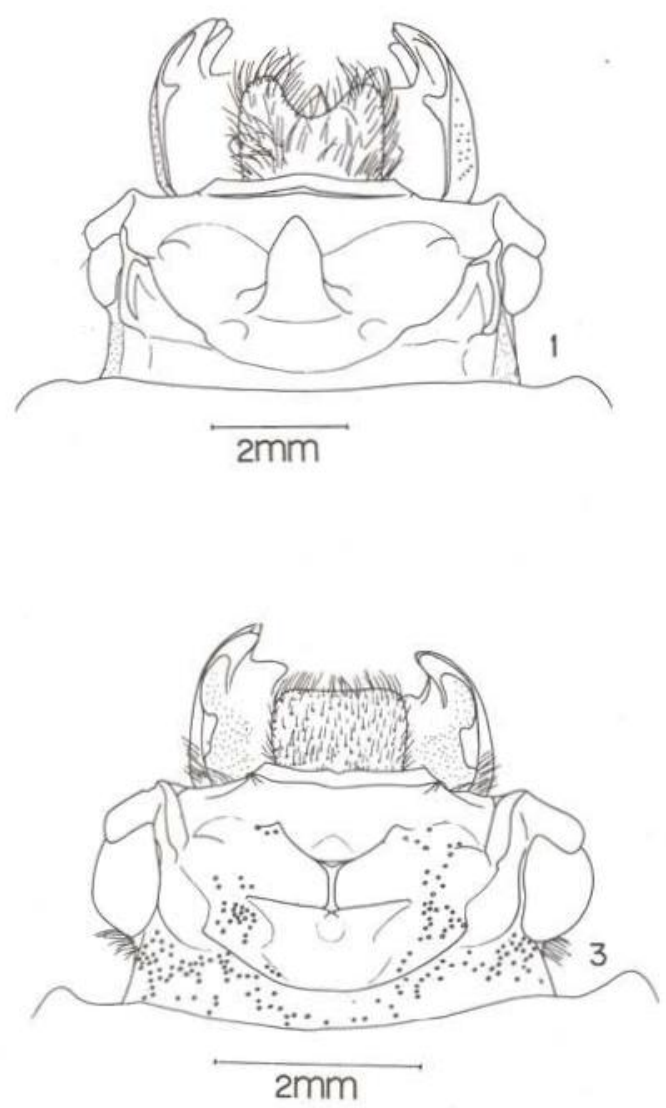

Lucanus interruptus; Panzer (1793?) (sec. Burm.): 11 , est. 2, fig. $6-8^{*}$

Passalus interruptus; Fabr., 1801: 255 Passalus interruptus; Weber, 1801: 78 Passalus interruptus; Illiger, 1802: 248* Passalus interruptus; Latr., 1804: 254* Passalus interruptus; Illiger, 1805: $105^{*}$ Passalus interruptus; Latr., 1807: 136 Passalus interruptus; Latr., 1817: 331 Passalus interruptus; Lamark, 1817: 597* Passalus interruptus; Latr., 1818: 571* Passalus interruptus; Duméril, 1823: 173, est. 5, fig. 2*

Passalus interruptus; Duméril, 1825: $23^{\circ}$

Passalus interruptus; Lepeletier \& Serv., 1825: 19 Passalus interruptus; Eschsch., 1829: 15 (sep. p. 3) Passalus spectabilis Perty, 1830: 55, est. 11, fig. 15 Passalus Interruptus; Perch., 1835: 42, est. 1, fig. 1, 2 Passalus Tlascala Perch., 1835: 45, est. III, fig. 5 Passalus interruptus; Hope, 1837: $115^{*}$

(*) apud Hincks \& Dibb, 1935
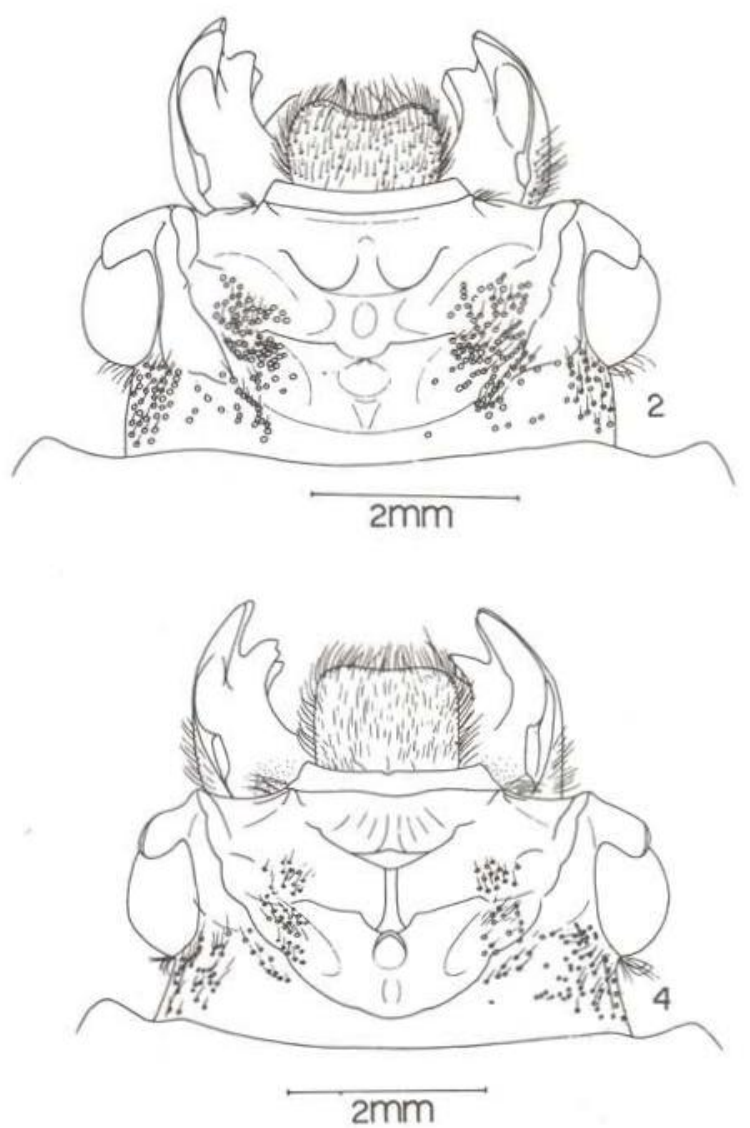

ESTAMPA XII - Odontotaenius disjunctus (Illiger, 1800). Exemplar IOCZ n..$^{\circ}$ 6789: Fig. 1 - Vista dorsal da cabeça, labro e mandibulas. Popilius tetraphyllus (Eschscholtz, 1829). Exemplar MZSP, AM, Manaus, IX/1963: Fig. 2 - Vista dorsal da cabeça, labro e mandibulas. Popilius marginatus (Percheron, 1835). Exemplar MZSP, MT, Utiariti, VII-VIII/1961: Fig 3 - Vista dorsal da cabeça, labro e mandíbulas. Popilius re. fugicornis Bührnheim, 1962. Exemplar IOC n. 9515, Holótipo: Fig. $4-$ Vista dorsal da cabeça, labro e mandíbulas. 

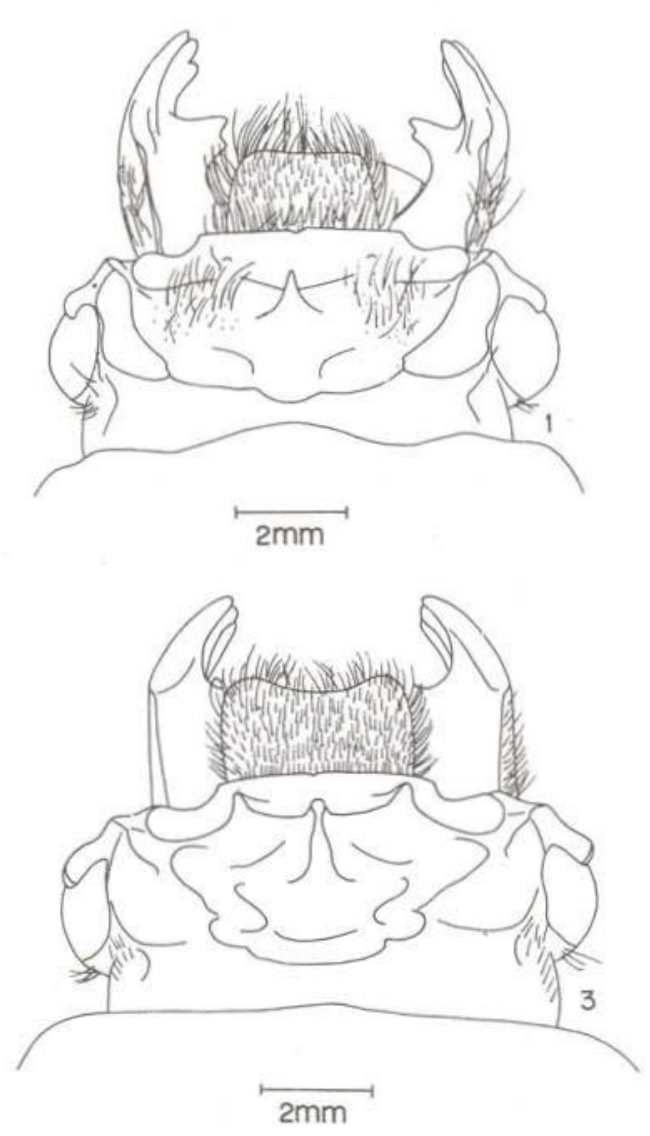
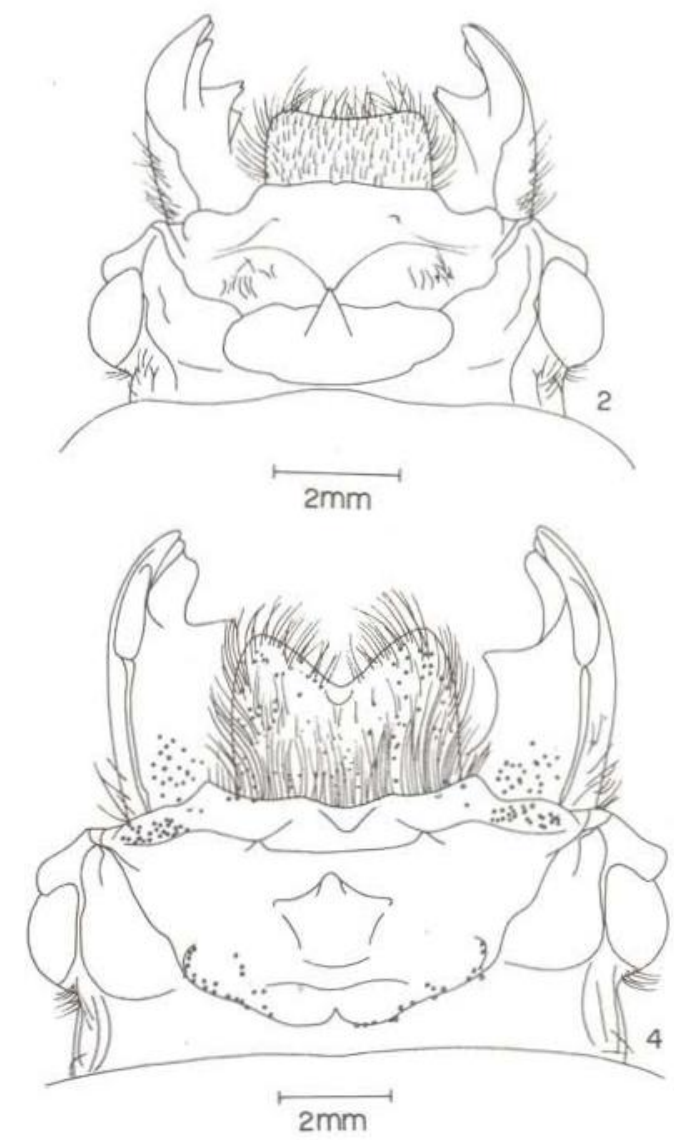

ESTAMPA XIII - Veturius libericornis Kuwert, 1891. Exemplar IOC n. ${ }^{\circ}$ 14.761: Fig. 1 - Vista dorsal da cabeça, labro e mandíbulas.

Veturius assimilis (Weber, 1801). Exemplar ZUEC n.॰ 199: Fig. 2 - Vista dorsal da cabeça, labro e mandibulas.

Veturius punctatostriatus Arrow, 1907. Exemplar IOC n.॰ 14.760: Fig. 3 - Vista dorsal da cabeça, labro e mandibulas. Verres furcilabris (Eschscholtz, 1829). Exemplar IOC n.0 14.758: Fig. 4 - Vista dorsal da cabeça, labro e mandíbulas.

Passalus grandis Dejean, 1837: 194

Passalus interruptus; Audoin \& Brullé, 1837: 439, est. 27 , fig. 5

Passalus interruptus; Guérin-Méneville, 1829-38: est. 27, fig. 8. 8a-c (Partes bucais)

Passalus interruptus; Cast., 1840: 178

Passalus interruptus; Perch., 1841: 11

Passalus tlascala; Perch., 1841: 12

Passalus interruptus; Burm., 1847: 481

Passalus tlascala; Burm., 1847: 482

Passalus tlascala; Truqui, 1857: 264 (sep. p. 7)

Passalus interruptus; Kaup, 1869: 31

Neleus interruptus; Kaup, 1871: 86

Neleus tlascala; Bates, 1886: 14 est. 1, fig. 15, $15 \mathrm{a}$

Neleus Interruptus; Kuwert, 1891: 185

Neleus Praestigiator Kuwert, 1891: 185

Neleus interruptus; Kuwert, 1898: 263

Neleus interruptus ab. latus Kuwert, 1898: 263

Neleus praestigiator; Kuwert, 1898: 263
Neleus tlascala; Kuwert, 1898: 273

Neleus interruptus; Rosmini, 1902: 7

Neleus tlascala; Pangella, 1905: 12

Neleus interruptus; Pangella, 1905a: 8

Neleus interruptus; Arrow, 1906(1907): 451

Neleus interruptus; Heyne \& Taschenberg. 1908: 58, est. 8 , fig. 39 , fig. 38 (nec Passalus assimilis)

Passalus interruptus; Arrow, 1910: fig. 1, 2

Passalus interruptus; Gravely, 1918: 63, 68

Passalus interruptus; Moreira, 1921(1922): 277, 284, fig. 1 , p. 256 , fig. 2 , p. 257

Passalus interruptus; Moreira, 1925: 32, 36 37, fig. 1 , p. 11 , fig. 4,5, p. 14 , fig. 1,4

Passalus interruptus; Luederw., 1931: 172, 191-194, 256 , est. 1 , fig. 5,22

Passalus Tlascala; Luederw., 1931: 194

Passalus interruptus forma a Luederw., 1931: 193

Passalus interruptus; Hincks, 1934: 274 
Passalus interruptus; Hincks \& Dibb, 1935: 57-58 Passalus interruptus; Blackwelder, 1944: 193

Passalus interruptus; Guérin, 1953: 245

Passalus interruptus; Hincks, 1953: 34

Passalus interruptus; Hincks \& Dibb, 1958: 18

Passalus interruptus; Vulcano \& Pereira, 1967: 544

Passalus interruptus; Reyes-Castillo, 1970: 204, 205, 206, 207, 212, 213

Passalus interruptus; Virkki \& Reyes-Castillo, 1972: 52, 55, fig. 29 (Citotaxonomia)

Passalus interruptus; Reyes-Castillo, 1973: 1579-1582

\section{DESCRIÇÃO DO EDEAGO}

Lobo médio mais curto do que largo, distalmente achatado e só ligeiramente ultrapassado em largura pelos lobos laterais. Superfície esclerosada nas áreas latero-ventrais. As áreas esclerosadas são longitudinalmente de.
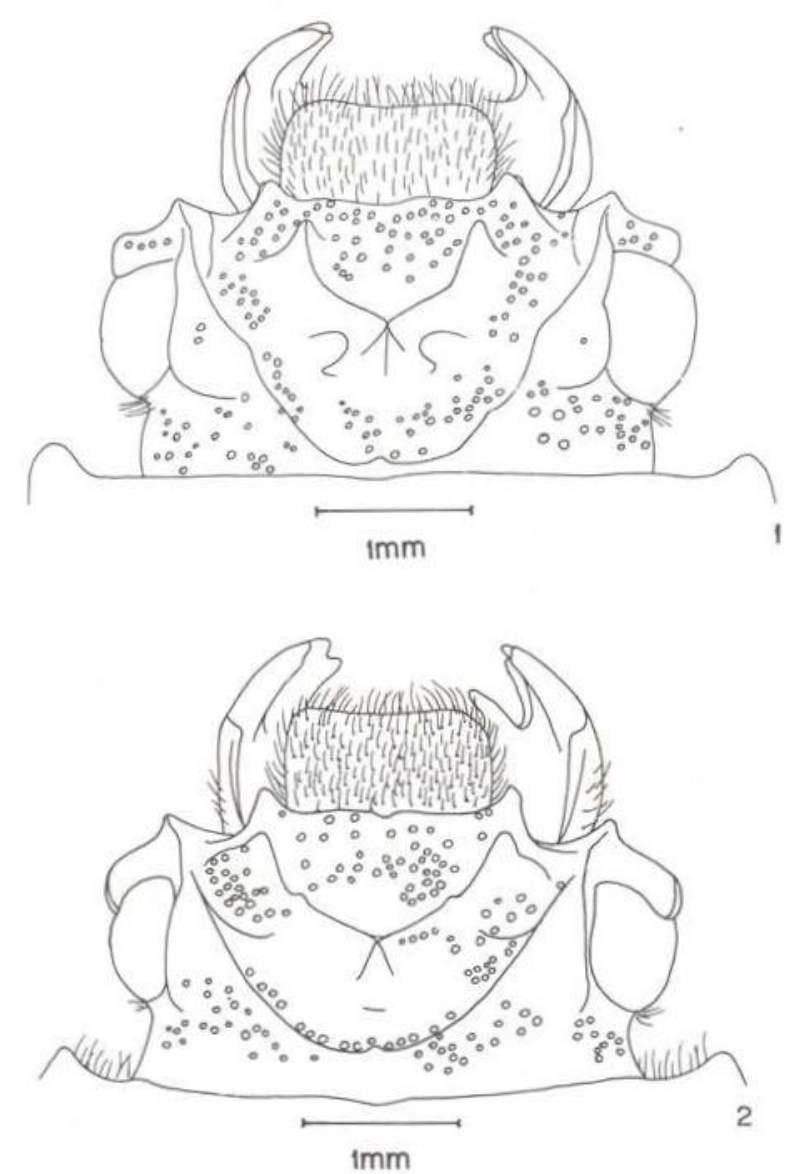

ESTAMPA XIV - Spasalus crenatus (MacLeay, 1819). Exemplar MZSP, AM, Benjamin Constant, 18-28/IX/1962: Fig. 1 - Vista dorsal da cabeça, labro e mandíbulas. Spasalus robustus (Percheron, 1835). Exemplar IOCZ n. 7215: Fig. 2 - Vista dorsal da cabeça, labro e mandíbulas.
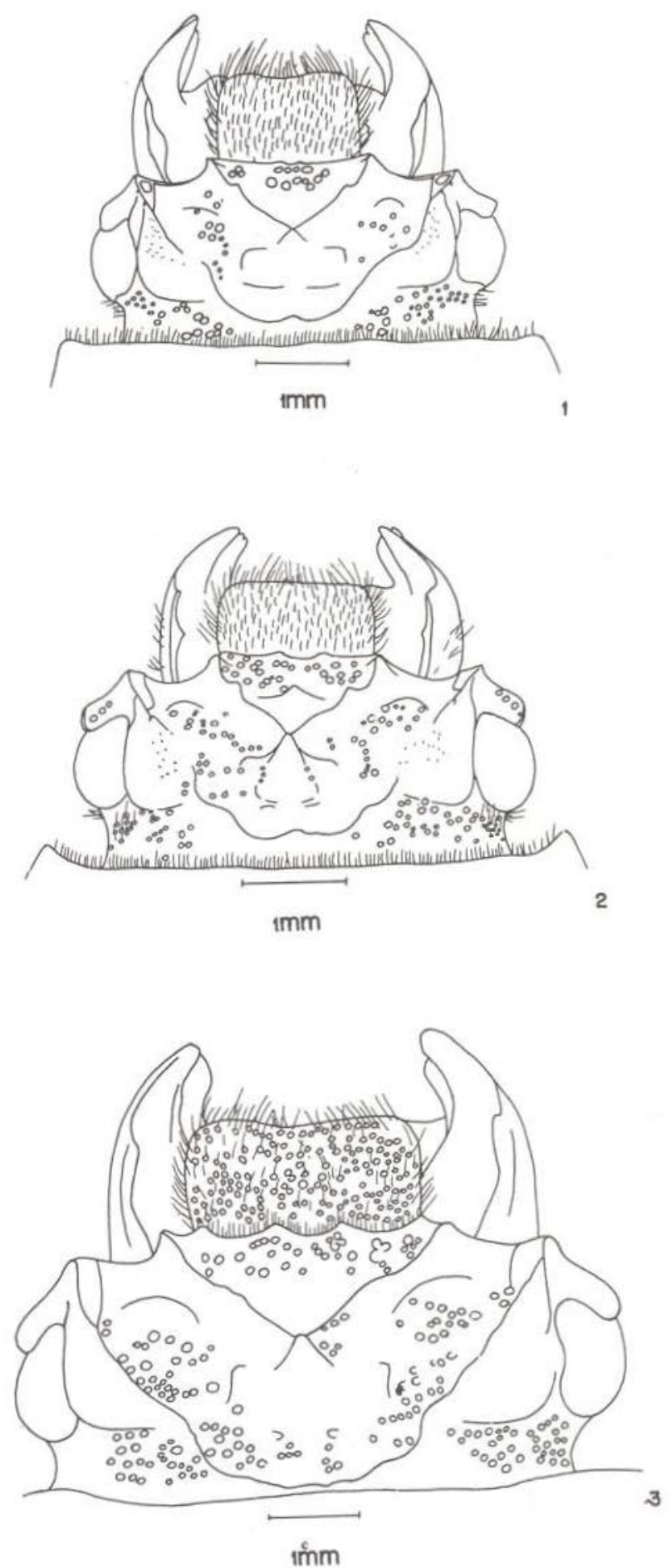

ESTAMPA XV - Paxillus pentaphylloides Luederw., 1931. Exemplar ZUEC n. ${ }^{\circ} 332$ : Fig. 1 - Vista dorsal da cabeça, labro e mandibulas. Paxillus forsteri Luederw., 1927. Exemplar MZSP, GO, Campinas, VIII/1927, Parátipo: Fig. 2 - Vista dorsal da cabeça, labro e mandíbulas. Paxillus lanei Pereira, 1939. Exemplar MZSP, MT, Salobra, 18-29/X/1938, Holótipo: Fig. 3 - Vista dorsal da cabeça, labro e mandibulas. 

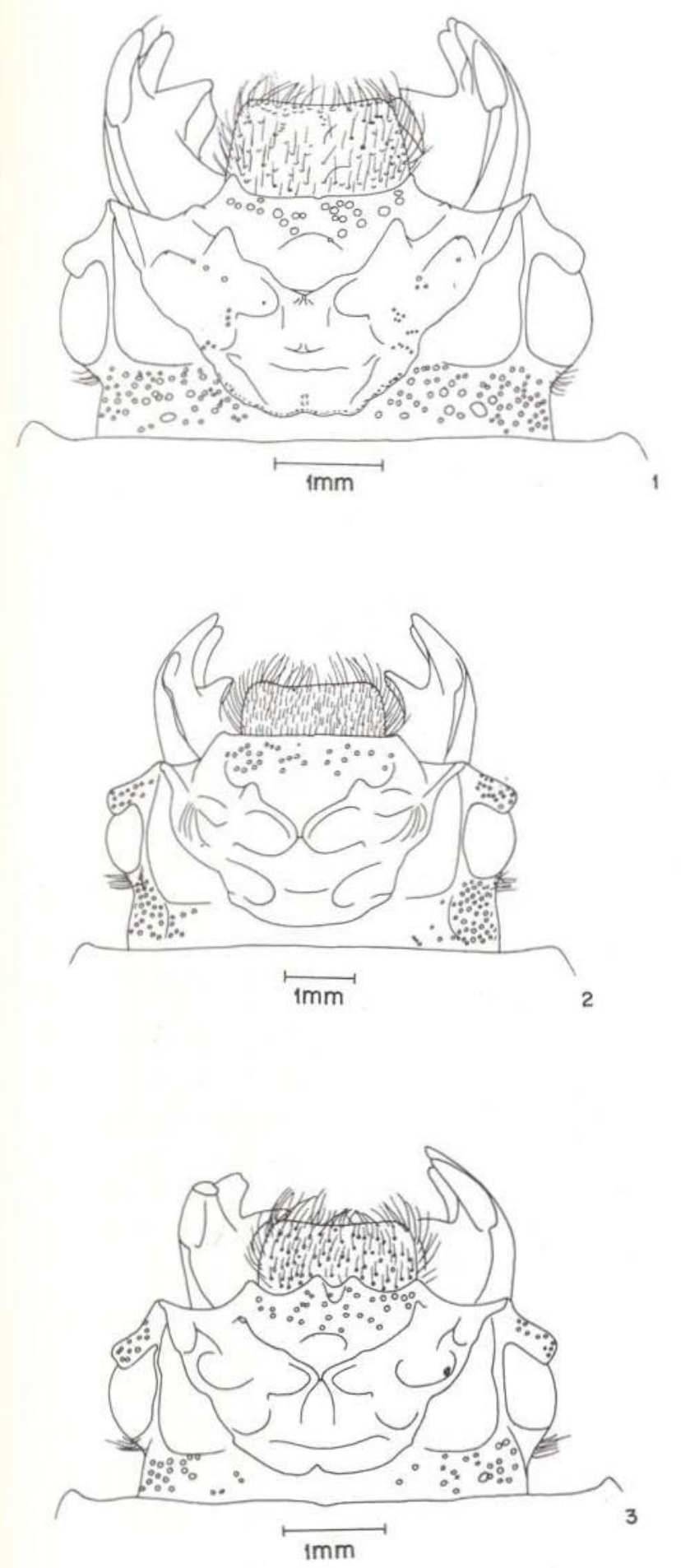

ESTAMPA XVI - Passalus rhodocanthopides (Kuwert, 1891). Exemplar IOC n. ${ }^{\circ}$ 14.780: Fig. 1 - Vista dorsal da cabeça, labro e mandíbulas. Pas. salus morio Percheron, 1835. Exemplar ZUEC n. ${ }^{\circ}$ 340: Fig. 2 - Vista do:sal da cabeça, labro e man. dibulas Passalus punctatostriatus Percheron, 1835. Exemplar ZUEC n. ${ }^{\circ}$ 202: Fig. 3 - Vista dorsal da cabeça, labro e mandíbulas.
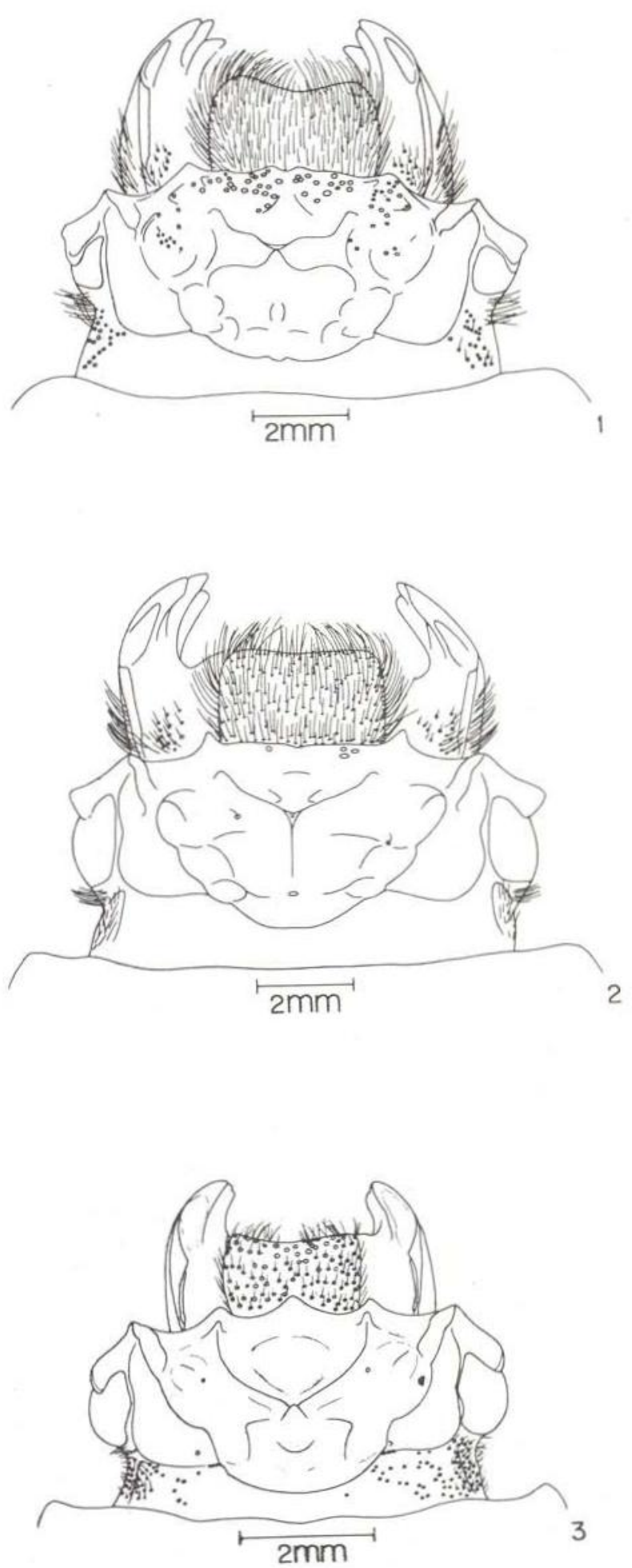

ESTAMPA XVII - Passalus gravelyi Moreira, 1922. Exemplar IOCZ n.॰ 7985: Fig. 1 - Vista dorsal da cabeça labro e mandíbulas. Passalus convexus Dalman, 1817. Exemplar IOC n..$^{\circ}$ 14.771: Fig. $2-$ Vista dorsal da cabeça, labro e mandíbulas. Passalus zikani Luederw., 1929. Exemplar IOCZ n. ${ }^{\circ}$ 7669: Fig. 3 - Vista dorsal da cabeça, labro e mandíbulas. 

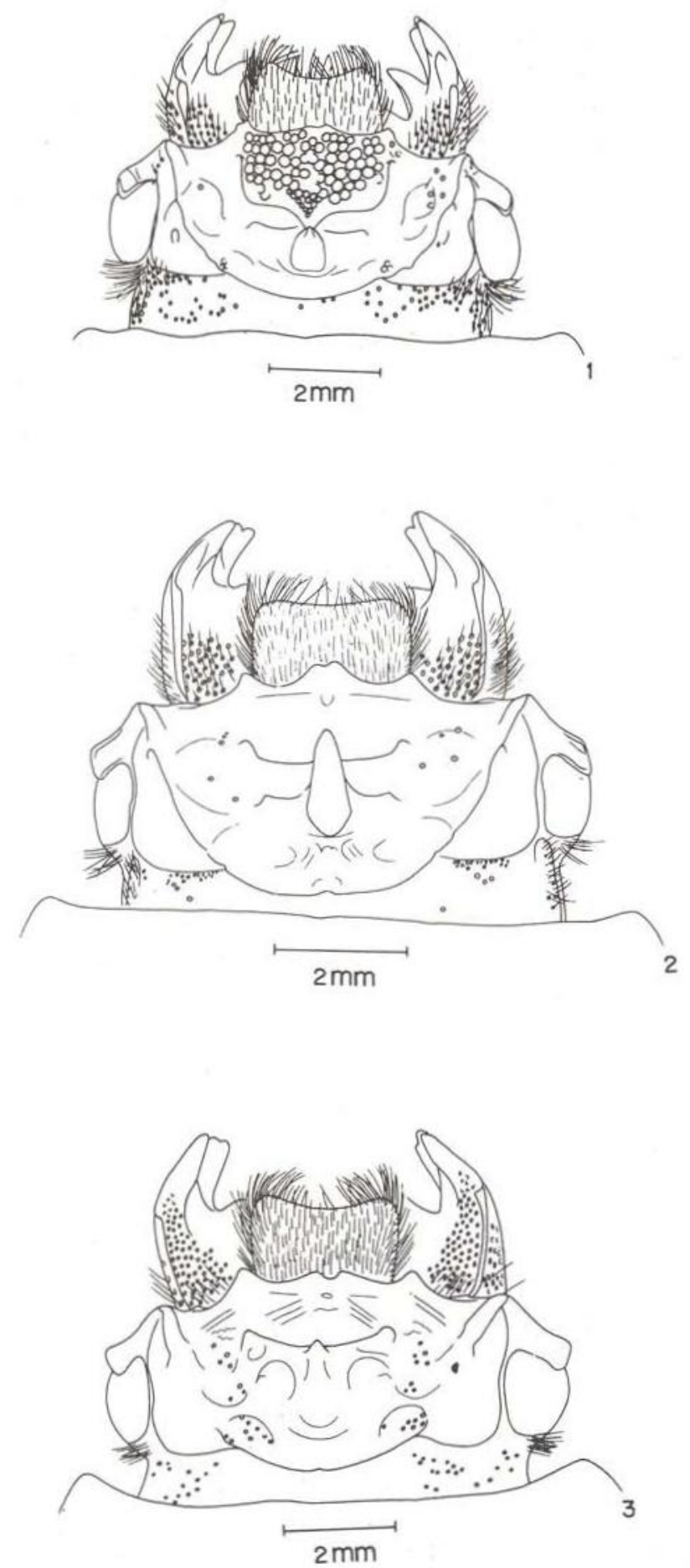

ESTAMPA XVIII - Passalus occipitalis Eschscholtz, 1829. Exemplar IOC n.॰ 14.776: Fig. $1-$ Vista dorsal da cabeça, labro e mandíbulas. Passalus alius (Kuwert, 1898). Exemplar IOC n. 14.779: Fig. 2 - Vista dorsal da cabeça, labro e mandíbulas. Passalus quadricollis Eschscholtz, 1829. Exemplar IOC n.0 14.775: Fig. 3 - Vista dorsal da cabeça, labro e mandíbulas. primidas e mais escuras no meio. No fundo da depressão das áreas esclerosadas, há traços bem escuros, dispostos do meio para os lados. $\mathrm{Na}$ parte antero-dorsal dos lados, junto ao limite das áreas esclerosadas, aparece densa pontuação mais escura.

Tégmen aparentando ser mais comprido que o lobo médio no ventre e nos lados, apesar de ser quase tão longo quanto ele. Superfície esclerosada no ventre e nos lados. A área esclerosada alcança o dorso cobrindo toda a superfície dos lobos laterais, sem chegar a se encontrar no meio, e parte da superfície correspondente à peça basal, sem chegar a tocar a margem basal. Na metade distal, apresenta uma depressão transversal mais escura, que vai desde a margem do dorso, pelos lados, até a margem ventral.

Lobos laterais formando extremidade arredondada no dorso e avançando dorsalmente além da metade basal do lobo médio.

Peça basal mais estreita e mais longa que os lobos laterais. Muito curta ao meio do dorso, onde sua margem basal sofre uma acentuada reentrância, deixando apenas estreita faixa membranosa além da base dos lobos laterais.

MATERIAL ESTUdADO - Dois exemplares do Amapá, cinco do Amazonas, oito do Pará, dois do Acre, um do Mato Grosso, dois da Bahia e um de São Paulo. Um macho da primeira procedência, três da segunda (amostras diversas), três da terceira (amostras diversas) e um de cada uma das demais.

VARIAÇÃo OBSERVADA - Ainda que os edeagos pertençam a indivíduos provenientes de localidades que cobrem uma distribuição ampla, não mostram variação muito grande. A variação desses edeagos será descrita em seguida.

\section{Variação do edeago em Passalus interruptus (Linnaeus, 1758)}

Examinando o edeago de Passalus interruptus provenientes de sete estados brasileiros (Est. IX, fig. 1-9; Est. X, fig. 1-12), cobrindo uma extensão territorial bastante ampla, foi possível verificar variações no tamanho e na forma desta parte da genitália. 
Foi medido o comprimento e a maior lar gura dos tégmens, e o comprimento total dos edeagos, cujos valores encontram-se na TABELA I. Os lobos médios não foram medidos, por terem seus limites basais escondidos sob a borda anterior do tégmen. Também não foi medida a parte exposta do lobo médio, devido aos deslocamentos que pode ter, principalmente no plano longitudinal, em torno de sua articulação com o tégmen.
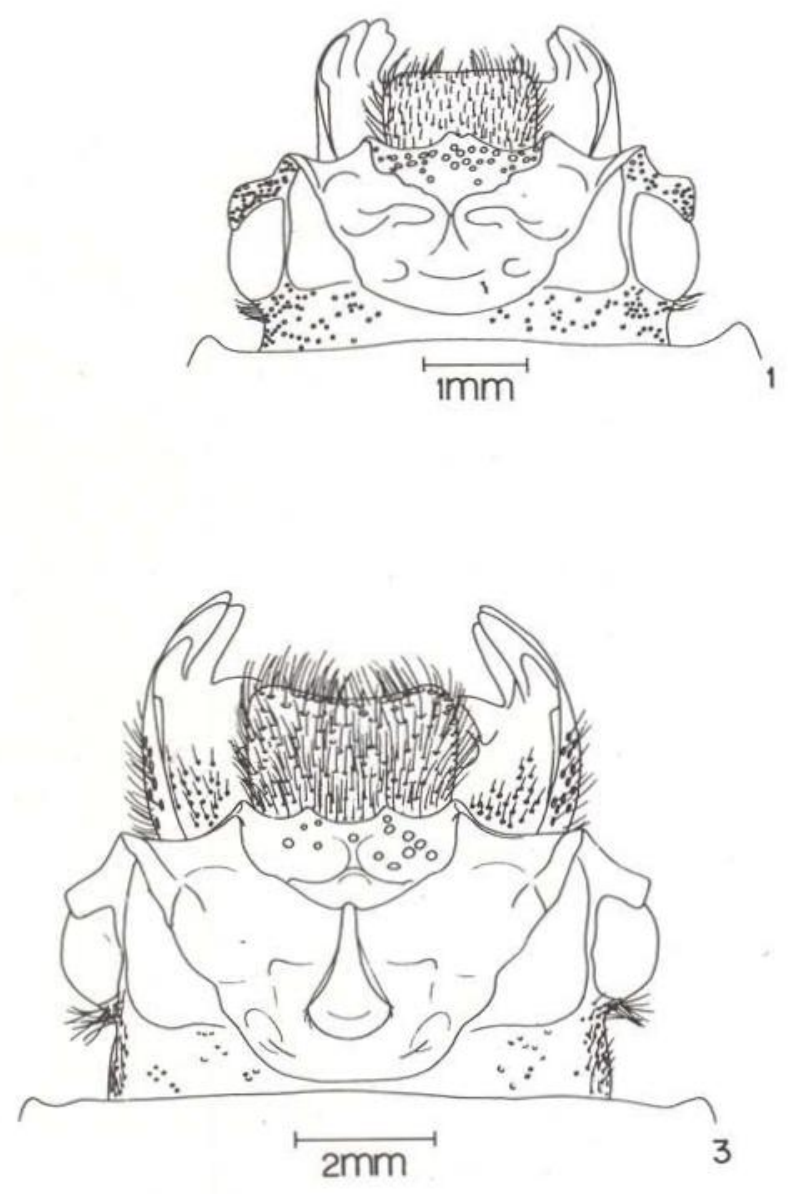

Das medidas dos edeagos de onze exemplares da espécie, resultaram intervalos entre os valores máximo e mínimo encontrados, de $0,5 \mathrm{~mm}$ para o comprimento do tégmen, de $0,1 \mathrm{~mm}$ para a maior largura do tégmen e de $1,2 \mathrm{~mm}$ para o comprimento total do edeago. As medidas obtidas da amostra disponível, que é reduzida mas cobre distribuição ampla, sugerem uma variação pequena nas dimensões do edeago de Passalus interruptus.
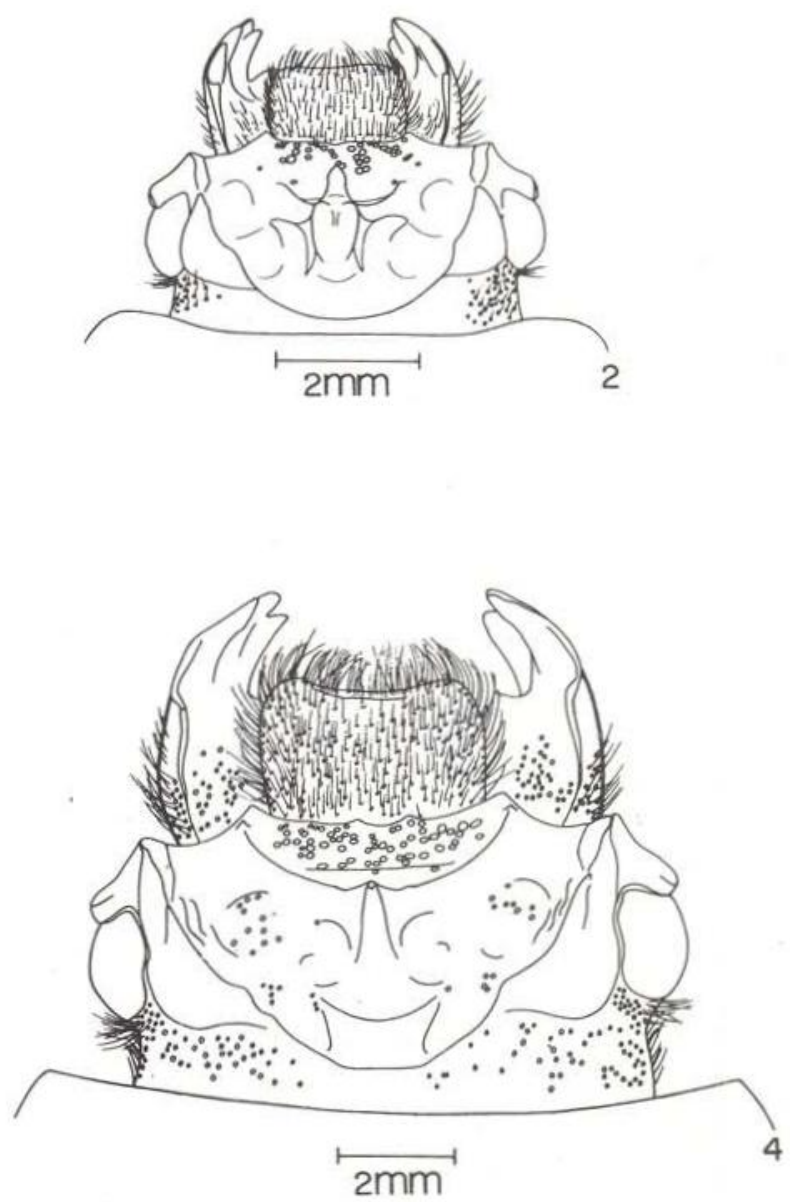

ESTAMPA XIX - Passalus glaberrimus Eschscholtz, 1829. Exemplar IOC n.0 14.773: Fig. 1 - Vista dorsal da cabeça, labro e mandíbulas. Passalus plicatus Percheron, 1835. Exemplar IOC n. 14.778: Fig. 2 - Vista dorsal da cabeça, labro e mandíbulas, Passalus coniferus Eschscholtz, 1829. Exemplar ZUEC n. ${ }^{\circ}$ 01: Fig. 3 - Vista dorsal da cabeça, labro e mandíbulas. Passalus interruptus (Lin., 1758). Exemplar ZUEC n. ${ }^{\circ}$ 290: Fig. 4 - Vista dorsal da cabeça, labro e mandbulas. 
TABELA I

Passalus interruptus (Lin., 1758)

(Medidas em milímetros)

\begin{tabular}{|c|c|c|c|c|c|c|c|c|c|c|c|}
\hline EXEMPLAR & $\begin{array}{c}10 c \\
14.792\end{array}$ & $\begin{array}{c}10 c \\
14.830\end{array}$ & $\begin{array}{c}10 \mathrm{C} \\
14.833\end{array}$ & $\begin{array}{c}10 c \\
14.834\end{array}$ & $\begin{array}{c}10 C \\
14.292\end{array}$ & $\begin{array}{c}\text { ZUEC } \\
194\end{array}$ & $\begin{array}{c}10 \mathrm{C} \\
14.254\end{array}$ & $\begin{array}{c}10 c \\
14.253\end{array}$ & $\begin{array}{c}10 C \\
14.258\end{array}$ & $\begin{array}{r}\text { ZUEC } \\
290\end{array}$ & $\begin{array}{c}10 C \\
14.261\end{array}$ \\
\hline $\begin{array}{l}\text { Procedência } \\
\text { Comprimento }\end{array}$ & $\mathrm{AP}$ & PA & PA & PA & MT & SP & $\mathrm{AM}$ & $\mathrm{AM}$ & $\mathrm{AM}$ & $\mathrm{AC}$ & BA \\
\hline $\begin{array}{l}\text { do tégmen } \\
\text { Maior largura }\end{array}$ & 2,7 & 2,8 & 2,7 & 2,6 & 2,6 & 2,7 & 2,5 & 2,5 & 2,6 & 2,4 & 2,3 \\
\hline $\begin{array}{l}\text { do tégmen } \\
\text { Comprimento }\end{array}$ & 3,4 & 3,4 & 3,4 & 3,3 & 3,3 & 3,3 & 3,3 & 3,3 & 3,4 & 3,4 & 3,4 \\
\hline $\begin{array}{l}\text { do edeago } \\
\text { Comprimento }\end{array}$ & 4,3 & 4,6 & 4,6 & 4,5 & 4,1 & 4,5 & 3,9 & 4,0 & 3,9 & 3,9 & 3,7 \\
\hline do corpo & 44,0 & 45,0 & 44,5 & 47,0 & 43.5 & 46,0 & 44,0 & 44,0 & 44,0 & 45,0 & 41,0 \\
\hline
\end{tabular}

(*) Os comprimentos do corpo foram tomados ao longo da linha média do corpo, desde a borda do clípeo até a extremidade posterior dos élitros.

Os lobos médios mostram variação na amplitude da curvatura de sua margem livre distal. Nos exemplares provenientes do Amapá, Amazonas, Acre e Bahia, a margem livre distal do lobo médio é menos convexa do que nos do Pará, Mato Grosso e São Paulo.

A área membranosa média ventral do tégmen apresenta contornos e extensão variáveis, até em indivíduos de uma mesma população.

Os lobos laterais têm a margem distal lateral sinuosa e voltada, junto ao dorso, para a extremidade apical do edeago, nos indivíduos do Amapá, Pará, Mato Grosso e São Paulo. A margem distal lateral dos lobos laterais é qua. se reta do ventre até o dorso, no material do Amazonas, Acre e Bahia. O ângulo formado pelas margens internas dorsais dos lobos la. terais, varia em todo o material disponível.

Os edeagos que pertencem aos exemplares fixados e conservados por dessecação, e agora reidratados, não mostram particularidades na forma ou no tamanho, que os distingam dos fixados e conservados em álcool $70 \%$ (do Amapá, do Acre e de São Paulo) . 


\section{DISCUSSÃO}

\section{A genitália MASCULINa E SUAS hoMologias}

A não ser pela discordância na interpretação dos últimos segmentos abdominais, o estudo da morfologia da genitália masculina, resultou em achados coincidentes com os de Reyes-Castillo (1970a), único trabalho que comenta a genitália completa dos Passalidae.

Reyes-Castillo (1970a: 61) interpreta o nono segmento abdominal, como sendo um ter. gito em forma de ferradura e esternitos sobre a abertura genital. De modo diverso, nos resultados do presente trabalho, interpretamos o esclerito com aspecto de ferradura, como um uroesternito remanescente do nono segmento, e a esclerito duplo situado sobre a abertura genital, também como um uroesternito, mas remanescente do décimo segmento (Est. I, fig. 2,5 e 6 ) .

$\mathrm{Na}$ ausência de estudos ontogênicos que esclareçam as homologias dos escleritos abdominais dos Passalidae, há mais indícios para justificar uma hipótese de rotação do edeago, do que do segmento genital, como se infere da interpretação de Reyes-Castillo (1970a). Lindroth \& Palmén in Tuxen (1970: 84), não fizeram qualquer menção à possibilidade de rotação do segmento genital nos Coleópteros, mas afirmaram que o edeago de muitos torna-se mais ou menos rotado em torno do seu eixo. Outro aspecto que contradiz a interpretação do esclerito em ferradura como um tergito, é a sua semelhança com o nono uroesternito em U ou Y, descrito por Sharp \& Muir (1912: 603), Snodgrass (1935: 597) e Lindroth \& Palmén in Tuxen (1970: 80), presente em várias familias de Coleópteros, cujas genitálias não parecem ter sofrido rotação em nenhuma de suas partes.

Apesar de nenhum dos autores que se ocuparam do edeago de Passalídeos, haver comentado o fato dele apresentar-se voltado para o dorso, mesmo quando em repouso no interior do abdome, há vários aspectos que levam a crer que sofra uma rotação permanente de $180 .^{\circ}$ em torno do seu eixo longitudinal. O percurso helicoidal do canal deferente dos Passalidae e a semelhança do aspecto ventral de seu edeago com o aspecto dorsal do edeago de Trox omacanthus, em Sharp \& Muir (1912: 577, pl. XLII-fig. 2a), são argumentos reforçados pelo significado que uma torção de meia volta no edeago, poderia ter tido na conquista de um ambiente constituído por canais na madeira cuja altura impossibilita a cópula por cavalgamento.

Quanto à interpretação do segmento representado pelo esclerito duplo situado sobre a abertura genital, parece-nos mais adequado considerá-lo como sendo o décimo, por estar embaixo da abertura anal, a exemplo do plano geral estabelecido para as genitálias masculinas de Coleóptera por Sharp \& Muir (1912: 635, pl. LXXVIII - fig. 239) e adaptado por Jeannel in Grassé (1965: 830, fig. 502). Lindroth \& Palmén in Tuxen (1970: 80, fig. $86 \epsilon$ 87), silenciaram sobre a ocorrência do esclerito subanal nos Coleópteros, referindo-se apenas a um supranal, que consideraram como nono urotergito, o que também não colide com nossa interpretação.

A morfologia geral do edeago e dos dois semi-segmentos que o envolvem, assim como sua posição relativa, são semelhantes nos Passalídeos estudados, aos aspectos que Percheron (1835: 16, pl. I - fig. 11) descreveu e esquematizou para Passalus interruptus, sem haver feito hipóteses sobre suas homologias.

O tipo de edeago "encapsulado" que Jeannel (1955: 40) estabeleceu para os Lamellicornia, com o "tambor" formado pelo tégmen, envolvendo e abrigando um lobo médio pequeno, não é aplicável aos Passalidae. Mesmo o edeago de Pticopus angulatus, que ReyesCastillo (1970a: 60, fig. 50) representou e considerou com estrutura de tipo encapsulado, tem as extremidades dos lobos laterais afastadas e terminando um pouco além dos três 
quartos basais do lobo médio, cuja curvatura apical fica livre. Todos os edeagos da família, tanto os descritos por Sharp \& Muir (1912) e Reyes-Castillo (1970, 1970a e 1973), como os agora estudados e o tipo referido na chave de identificação de Crowson (1968), tem a peça basal curta, os lobos laterais também curtos e o lobo médio globoso, destacado e relativamente livre, apenas acompanhado de cada lado ou latero-dorsalmente, pelos lobos laterais.

\section{O EDEAGo NA SISTEMÁTICA DAS ESPÉCIES ESTUDADAS}

Os edeagos das espécies estudadas mostram-se distintos entre si, não havendo nenhum caso de identidade entre edeagos obtidos de espécies consideradas diferentes. Também não foi verificada qualquer identidade entre nossos achados e os de Reyes-Castillo (1970, 1970a e 1973) para espécies diferentes, ape. nas alguns casos de semelhança, acompanha. dos no entanto, de nítidas diferenças de tamanho.

Das sete espécies estudadas, cujos edeagos também mereceram a atenção de ReyesCastillo (1973), todas confirmaram os resultados deste autor, apesar das diferenças entre os métodos de conservação e representação empregados.

Esta diversidade de edeagos, encontrada até agora em espécies de Passalidae neotropicais, contraria a uniformidade mencionada por Gravely (1918: 5) e confirma a opinião de Reyes-Castillo (1970a: 61) sobre sua importância na separação das espécies da família.

O relato de Sharp \& Muir (1912: 580 ) sobre a existência de dois tipos de edeagos no restrito material que examinaram, nada diz sobre o significado taxonômico do órgão, pois além de envolver gêneros afastados e até de faunas diversas, está baseado na comparação de apenas um representante de cada gênero, no máximo dois em Aulacocyclus. A manifesta preocupação de Gravely (1914: 191; 1918: 5) com a ocorrência dos edeagos de tégmen inteiro e tégmen dividido, em gêneros e numa subfamília, parece tef afastado sua atenção dos demais caracteres do órgão, assim como do seu valor diferencial ao nível de espécie, cujos taxa são os que tem maior probabilidade de serem naturais.

Em virtude dos resultados agora obtidos demonstrarem que podemos ter dentro de um mesmo gênero, espécies com edeagos de tégmen inteiro, parcialmente dividido ou nitidamente dividido em peça basal e lobos laterais, e em virtude da restrição dos dados de Sharp \& Muir (1912) e da abordagem parcial do problema por Gravely (1914, 1918), concluimos pela necessidade do reexame do assunto em relação à fauna Australiana e também da extensão destes estudos às demais faunas de Passalidae.

O edeago de Popilius marginatus (Percheron, 1835) aproxima-se mais do de Popilius tetraphyllus (Eschscholtz, 1829) e de Popilius refugicornis Bührnheim, 1962, por ter o lobo médio maior do que o tégmen e os lobos laterais muito curtos, mas difere claramente de ambos, por ser menor e por ter as áreas escle. rosadas do lobo médio muito menores e mais ventro-laterais. Distingue-se ainda do edeago de $P$. tetraphyllus, pela forma globosa do lobo médio e do de $P$. refugicornis, pela ausência de expansões dorsais de suas áreas esclerosadas e presença de sulco transversal nas áreas laterais do tégmen. Comparado com o edeago descrito por Reyes-Castillo (1973: 1945, fig. 1) para a mesma espécie, confirma os resultados deste autor, com pequenas diferenças resultantes de outros métodos de conservação e representação, além da escala do desenho ter valor passível de dúvida. Estas diferenças estão num achatamento da curvatura distal do lobo médio, provavelmente resultante do fato da peça estar dessecada e no que parece um avanço das áreas esclerosadas do lobo médio para o dorso, consequente à dessecação do órgão ou a um erro nosso de interpretação da figura.

O edeago de $P$. refugicornis aproxima-se mais do de $P$. marginatus e de $P$. tetraphyllus, pelos caracteres já mencionados, mas difere de ambos, por ter suas áreas esclerosadas avançando sobre o dorso, e os sulcos transversais laterais no esclerosamento do tégmen ausentes. Distingue-se ainda do edeago de $P$. tetraphyllus, pelo aspecto globoso do lobo médio e de $P$. marginatus, pela extensão das áreas esclerosadas do lobo médio. 
O ecieago de $P$. tetraphyllus aproxima-se mais do de $P$. marginatus e de $P$. refugicornis, pelos caracteres já mencionados, mas difere claramente de ambos, pelo aspecto ovalado do lobo médio. Distingue-se ainda do edeago de $P$. marginatus, pelas áreas esclerosadas do lobo médio bem mais extensas e de $P$. refugicornis, pela ausência de projeções dorsais dos esclerosamentos e presença de sulco transversal nas áreas laterais do tégmen.

0 edeago de Odontotaenius disjunctus (Illiger, 1800) aproxima-se mais do representado por Reyes-Castillo (1970a: 60, fig. 49) para Odontotaenius zodiacus (Truqui, 1857). pelo lobo médio mais estreito do que o tégmen e por apresentar os lobos laterais com extremidade dorsal esclerosada voltada para a base. mas difere claramente deste, por não ter expansão dorsal extensa das áreas esclerosadas da peça basal, como sugere a figura daquele autor. Comparações de tamanho não podem ser feitas, devido à ausência de escala na figura de $O$. zodiacus.

A proximidade de $O$. disjunctus com $O$. zodiacus pelo edeago, e a existência de carac teres comuns, que os afastam dos Popilius Kaup, 1871 já discutidos, como o lobo médio mais largo que o tégmen e a extremidade dorsal dos lobos laterais voltada para a base, corroboram para confirmar a revalidação por Reyes-Castillo (1970a: 149, 150), do gênero Odontotaenius Kuwert, 1896, para estas e mais cinco espécies que faziam parte de Popilius Kaup, 1871. As afinidades de Odontotaenius com Oileus Kaup, 1869 e Pseudarrox ReyesCastillo, 1970, argüidas por este último autor (1970: 150), com base em caracteres exosqueléticos externos, parecem um bom campo de especulação para a aplicação do edeago na sistemática dos gêneros dos Passalidae.

O edeago de Veturius libericornis Kuwert. 1891 aproxima-se mais do de Veturius assimilis (Weber, 1801) e de Veturius punctatostriatus (Arrow, 1907), pelo aspecto biconvexo de sua vista lateral e pela posição mais latero-basal das áreas esclerosadas do lobo médio, que não alcançam a margem distal dos lados, mas difere claramente de ambos, por ter sulco transversal nas áreas esclerosadas do tégmen. Distingue-se ainda do edeago de $V$. assimilis. por mostrar discretas expansões dorsais das áreas esclerosadas do lobo lateral e do de $V$. punctatostriatus, por ter expansões dorsais das áreas esclerosadas do tégmen apenas nos lobos laterais.

$O$ edeago de $V$. assimilis aproxima-se mais do de $V$. libericornis e de V. punctatostriatus, pelos caracteres já mencionados, mas difere claramente de ambos, por ter reduzido sulco transversal lateral na área esclerosada do tégmen. Distingue-se ainda do edeago de $V$. libe ricornis, por ter expansões dorsais marginais da área esclerosada do tégmen muito estreitas, tanto na altura dos lobos laterais, quanto da peça basal, e do de $V$. punctatostriatus, por ter as expansões dorsais da área esclerosada do tégmen muito mais estreitas, à altura dos lobos laterais.

$O$ edeago de $V$. punctatostriatus aproximase mais do de $V$. libericornis e de $V$. assimilis, pelos caracteres já mencionados, mas difere claramente de ambos, por ter o tégmen inteiro, sem sulco transversal na área esclerosada. Distingue-se de $V$. libericornis, por ter expansões dorsais do esclerosamento do tégmen, ao longo de toda a linha marginal dos lados do dorso e de $V$. assimilis, por ter expansões dorsais do esclerosamento do tégmen, bem mais largas à altura dos lobos laterais.

As espécies estudadas de Veturius Kaup, 1871. tem seus edeagos difíceis de relacionar com o representado por Reyes-Castillo (1973: 1548 - 1549, fig. 3) para Veturius cephalotes (Lepeletier \& Serville, 1825), em virtude do alcance das áreas esclerosadas ventrais do lobo médio e das expansões dorsais do esclerosamento do tégmen não estarem claras, além da ausência de descrição ou figura, que escla. reçam seu aspecto em vista lateral. A mesma dificuldade se apresenta em relação a Veturius charpentierae Reyes-Castillo, 1973.

Os nossos resultados, acrescentados aos de Reyes-Castillo (1973: 1548-1551, fig. 3 e 4), são pouco conclusivos sobre as possiveis características comuns aos edeagos dos Veturius, o que indica a necessidade de estender o presente estudo, a um maior número de espécies deste gênero.

0 edeago de Verres furcilabris (Eschscholtz, 1829) é muito característico e não se 
aproxima de nenhum dos demais agora estu. dados, identificando-se com o descrito por Reyes-Castillo (1973: 1547-1548, fig. 2) para a mesma espécie. A figura deste autor acrescenta aos nossos resultados, a presença de sulco transversal dividindo a área esclerosada do tégmen e deixa dúvidas em relação à reduzida extensão do que parece ser uma das áreas esclerosadas do lobo médio. Aparece ainda uma reentrância nas margens laterais, à altura da peça basal, que não ocorre em nosso material mas parece consequência de um enrugamento da área membranosa do tégmen, ocasionado pela dessecação. A semelhança dos demais caracteres, reforçada pelo fato das medidas do material de Reyes-Castillo, estarem dentro dos limites da variação de tamanho dos nossos exemplares, não deixa dúvidas sobre a identidade dos edeagos agora discutidos. 0 edeago desta espécie, é o único conhecido do gênero Verres Kaup, 1871 e não mostra afinidades com nenhum dos demais gêneros. 0 edeago de Verres cavicollis Bates, 1886, só foi comentado por Reyes-Castillo (1970a: 61) por apresentar um flagelo no saco interno, permanecendo suas demais características desconhecidas.

O edeago de Paxillus pentaphylloides Luederwaldt, 1931 aproxima-se mais do de Paxillus forsteri Luederwaldt, 1927 e de Paxillus lanei Pereira, 1939, pelo aspecto característico dos lobos laterais, que tem a extremidade bem destacada e arredondada, e se estēndem latero-dorsalmente ao lobo médio, mas difere claramente de ambos, por ter os lobos laterais também visíveis ventralmente. Distingue-se ainda do edeago de $P$. forsteri, pela maior extensão das áreas esclerosadas do lobo médio e do de $P$. lanei, por ter o lobo médio quase tão largo quanto longo.

$O$ edeago de $P$. forsteri aproxima-se mais do de $P$. pentaphylloides, e de $P$. lanei pelos caracteres já mencionados, mas difere claramente de ambos por ter os lobos laterais estendendo-se junto aos $2 / 3$ basais do lobo médio. Distingue-se ainda do edeago de $P$. pentaphylfoides, por não ter os lobos laterais bem visíveis ventralmente e do de $P$. lanei, por ser quase tão largo quanto longo.
O edeago de $P$. lanel aproxima-se mais do de $P$. pentaphylloides e de $P$. forsteri, pelos caracteres já mencionados, mas difere claramente de ambos, por ser quase tão largo quanto longo. Distingue-se ainda do edeago de $P$. pentaphylloides, por ter os lobos laterais bem dorsais e pouco visíveis ventralmente, e do de $P$. forsteri, por ter os lobos laterais estendendo-se só um pouco além da metade do comprimento do lobo médio.

$O$ edeago de $P$. leachi descrito por ReyesCastillo (1973: 1553-1556, fig. 6), aproxima-se mais dos edeagos dos Paxillus agora estudados, pelo aspecto característico dos lobos laterais com a extremidade arredondada, destacada e estendendo-se latero-dorsalmente ao lobo médio, mas distingue-se do de $P$. pentaphylloides e de $P$. forsteri, por ter o lobo médio mais largo do que longo, de $P$. forsteri e de $P$. lanei, por ser mais longo do que largo e de $P$. forsteri. por ter os lobos laterais terminando antes da metade do lobo médio, sem considerar as áreas esclerosadas do lobo médio, por não estarem claras no desenho.

O edeago de Spasalus crenatus (Mac Leay, 1819) mostra-se idêntico ao descrito por Reyes-Castillo (1973: 1557-1558, fig. 7) apesar de menor, e aproxima-se mais do de Spasalus robustus (Percheron, 1835) e de Spasalus ba. lachowskyi Reyes-Castillo, 1973, descrito pelo mesmo autor (1973: 1558-1559, fig. 9), pelos lobos laterais curtos, apesar de destacados por reentrância ventro-lateral da margem distal do tégmen, mas diferindo claramente de ambos por ter a distância entre os lobos laterais mais larga do que o lobo médio. Difere ainda do edeago de $S$. robustus, por ter as áreas esclerosadas do lobo médio bem menos extensas e do de $S$. balachowskyi, por ter o lobo médio quase tão longo quanto o tégmen.

$S$. robustus aproxima-se mais de $S$. crenatus e $S$. balachowskyi, pelos caracteres já mencionados, mas difere claramente de $S$. crenatus, por ter a distância entre os lobos laterais quase tão larga quanto o lobo médio e de S. balachowskyi, por ter o lobo médio quase tão longo quanto o tégmen.

A proximidade de $P$. leachi, $P$. pentaphylloides, $P$. forsteri e $P$. lanei, pelo edeago e a existência de caracteres sob este aspecto que os 
separam de S. crenatus, S. robustus e S. balachowskyi, também próximos entre si, corroboram para confirmar a revalidação do gênero Spasalus Kaup, 1869, por Reyes-Castillo (1973: 1556-1557) .

$\mathrm{O}$ edeago de Ptichopus angulatus (Percheron, 1835) representado e comentado por Reyes-Castillo (1970a: 61, fig. 50a-b), é o único conhecido do gênero Ptichopus Kaup, 1869, mas é muito característico pelo lobo médio bem reduzido em relação ao tégmen, não mostrando afinidade com nenhum dos demais gêneros.

$O$ edeago de Passalus rhodocanthopoides (Kuwert, 1891) mostra-se idêntico ao descrito por Reyes-Castillo (1973: 1569, fig. 15) para a mesma espécie. O desenho deste autor apresenta pequenas diferenças no contorno, que parecem consequência do estado de dessecação do material estudado, mas tem medidas dentro dos limites da variação que verificamos em nossos exemplares. Parece mais fácil relacioná-lo com os edeagos dos Paxillus estudados do que com os demais Passalus Fabr., 1792, pois tem lobos laterais de extremi. dade arredondada e destacada, que se estendem latero-dorsalmente ao lobo médio, apesar de seu tégmen ser mais curto do que o lobo médio.

O edeago de Passalus morio Percheron. 1835 é muito característico e não mostra afini. dades claras com os demais já conhecidos. Difere do descrito por Reyes-Castillo (1973: 1566-1569, fig. 14) para Passalus latifrons Percheron, 1841, principalmente por ter lobos laterais mais estreitos do que o lobo médio, cujo quinto basal não ultrapassam. Esta dife. rença confirma a revalidação de $P$. latifrons por Reyes-Castillo (1973).

$\mathrm{O}$ edeago de Passalus punctatostriatus Percheron, 1835 é muito característico e não mostra afinidades claras com os demais conhecidos. Pelo lobo médio mais largo que o tégmen lembra o de P. morio, mas pelo aspecto e posição dos lobos laterais, afasta-se muito dele.

O edeago de Passalus convexus Dalman, $1817^{\circ}$ é muito característico e não mostra afinidades com nenhum dos demais conhecidos. Confirma os resultados de Reyes-Castillo
(1973: 1561-1562, fig. 10) para a mesma espécie, apesar de mostrar-se cerca de um terço maior e, por não estar dessecado, como toda a parte membranosa aparente.

O edeago de Passalus gravelyi Moreira, 1922 é muito característico e não mostra afinidades claras com os demais conhecidos. Pelo aspecto e posição dos lobos laterais lembra o de $P$. morio, mas pelo lobo médio ligeiramente mais estreito do que o tégmen, afasta-se dele.

O edeago de Passalus epiphanoides (Kuwert, 1891) descrito por Reyes-Castillo (1973: 1562-1566, fig. 12), também é muito característico e não mostra afinidades claras com os demais conhecidos.

O edeago de Passalus zikani Luederwaldt 1929 aproxima-se apenas do descrito por ReyesCastillo (1973: 1571-1572, fig. 16) para Passalus spinifer Percheron, 1841, pelos lobos laterais de posição latero-dorsal ao lobo médio, mais dorsal no material dessecado, mas com o mesmo aspecto, e separados da peça basal por reentrâncias laterais do tégmen. Os edea. gos das duas espécies são difíceis de distinguir, tanto pela descrição de Reyes-Castillo (1973). quanto pela figura, cuja escala indica medidas e proporções bem próximas para ambas, nada se podendo concluir no entanto, em vista do aspecto e dos limites das áreas esclerosadas em $P$. spinifer não estarem claros, nem sabermos qual é seu aspecto em vista lateral.

A torção no sentido horário, que deforma principalmente o lobo médio, mas também o tégmen do edeago de $P$. zikani, poderia ser un caráter diferencial em relação a $P$. spinifer, se tivéssemos dados que indicassem sua constância na espécie, o que é dificultado por haver poucos exemplares disponiveis nas coleções. Esta mesma torção no edeago foi encontrada por Reyes-Castillo (comunicação pessoal) em espécies do gênero Paxillus. Os reduzidos dados com que contamos, ainda não permitem qualquer conclusão sobre o assunto.

O edeago de Passalus occipitalis Eschscholtz, 1829 aproxima-se apenas do de Passalus glaberrimus Eschscholtz, 1829, pelo tégmen afunilado em direção à peça basal e pelos lobos 
laterais curtos, voltados para o dorso e embutidos no quinto basal do lobo médio, mas difere desta espécie, pelo menor tamanho e pelas áreas esclerosadas do lobo médio menos extensas.

O edeago de Passalus alius (Kuwert, 1898) aproxima-se apenas do de Passalus quadricollis Eschscholtz, 1829, por ser bem mais Iongo do que largo, ter o lobo médio mais estreito do que o tégmen, com aspecto ventral elíptico e os lobos laterais estendendo-se mais laterodorsalmente ao lobo médio, mas distingue-se claramente desta espécie, por ter os limites ventrais internos das áreas esclerosadas do lobo médio regulares, apresentar vestígios laterais de sulco tranversal na área esclerosada do tégmen e lobos laterais menos dorsais.

$\mathrm{O}$ edeago de Passalus glaberrimus Eschscholtz, 1829 concorda com o descrito por Reyes-Castillo (1973: 1574, fig. 18) para a mesma espécie, apesar das medidas dos nossos exemplares serem um pouco maiores. Aproxima-se apenas do de $P$. occipitalis, pelos caracteres já mencionados.

O edeago de Passalus abortivus Percheron, 1835 descrito por Reyes-Castillo (1973: 1573, fig. 17) é muito característico, sendo o único dos Passalus conhecido com os lobos laterais tão reduzidos.

O edeago de Passalus plicatus Percheron. 1835, é muito característico e não mostra afinidades claras com os demais conhecidos. Pelo aspecto do lobo médio, pelo tégmen dividido por sulco transversal bem evidente, e pela forma e largura dos lobos laterais, lembra $P$. gravelyi, mas pela posição mais lateral dos lobos laterais, afasta-se dele.

O edeago de Passalus coniferus Eschscholtz, 1829 aproxima-se mais do edeago de Passalus interstitialis Eschscholtz, 1829 descrito por Reyes-Castillo (1973: 1582, fig. 23) e de Passalus interruptus (Linnaeus, 1758), por ser quase tão largo quanto longo e ter os lobos laterais dirigidos no sentido ventro-dorsal e estendendo-se dorsalmente ao lobo médio, mas distingue-se de ambos, pelo aspecto de sua vista lateral "(de $P$. interstitialis, comunicação pessoal de Reyes-Castillo). $O$ edeago de $P$. coniferus distingue-se ainda do de $\boldsymbol{P}$. intersti- tialis, pelo tamanho e de $P$. interruptus, pelo aspecto globoso do lobo médio. Confirma ainda os resultados de Reyes-Castillo (1973. 1577-1579, fig. 21) para a mesma espécie, tanto pelas medidas e proporções, quanto pela forma, que parece só não ser mais coincidente, em virtude das técnicas diferentes usadas na fixação do material.

O edeago de $P$. interruptus é muito parecido com o descrito por Reyes-Castillo (1973: 1582-1584, fig. 24) para Passalus punctiger Lepeletier \& Serville, 1825. Este edeago no entanto, tem medidas bem inferiores às do menor de $P$. interruptus que estudamos. A grande proximidade de $P$. interruptus e $P$. punctiger, pelos caracteres exosqueléticos de uso tradicional, já tem sido responsável por aparecerem confundidos ou como sinônimos na literatura. Esta semelhança repete-se nos edeagos, que também só podem ser distinguidos pelo tamanho. A uniformidade aí verificada e o resultado do exame dos edeagos em algumas populações afastadas de $P$. interruptus (Estam. pas $\mathrm{X}$ e XI), indicam a necessidade de efetuar estudos mais extensos sobre a variação de caracteres ao longo de transectos, para um meIhor entendimento do significado que o complexo interruptus-punctiger-P. tlascala Perch., 1835 , possa ter na história evolutiva dos Passa. lidae.

O edeago de $P$. interruptus ainda mostra afinidades com o de Passalus bucki Luederwaldt, 1931 e de Passalus elfridae Luederwaldt, 1931, descritos por Reyes-Castillo (1973: 1576-1577, fig. 20; 1579, fig. 22), pelos mesmos caracteres que o aproximam dos de $P$. coniferus, $P$. interstitialis e $P$. punctiger.

Os nossos resultados acrescentados aos de Reyes-Castillo (1973), apesar de abrangerem um total de 21 espécies, são pouco conclusivos sobre os possíveis caracteres comuns aos edeagos de Passalus como um todo. Mesmo considerando seus subgêneros e seções, só constatamos afinidades mais claras entre espécies de Mithrorhinus Kaup, 1871 ( $P$. spinifer e $P$. zikani) $\in$ entre espécies dentro de seções de Passalus Hincks \& Dibb, 1933 s. str., como em "Phoroneus" ( $P$. alius com $P$. quadricollis, $P$. occipitalis com $P$. glaberrimus) e em "Neleus" ( $P$. bucki, P. elfridae, $P$. coniferus, 
$P$. interruptus, $P$. interstitialis e $P$. punctiger) . Estes fatos indicam claramente a necessidade de revisão do gênero Passalus, para apurar pos. síveis grupos mais naturais de espécies, que no momento, devem estar nele reunidos.

A tentativa de verificar o significado taxonômico do edeago dos Passalidae, produziu interessantes resultados no que toca à sua diversidade entre as espécies de certos gêneros e à sua uniformidade, até muito grande em outros, como a verificada na seção "Neleus" de Passalus s. str., demonstrando o quanto poderá ser útil ampliar estes estudos e estendêlos aos demais caracteres, para que possamos melhor perceber as afinidades entre as espécies da família, agrupando-as numa sistemática mais natural.

\section{VARIAÇÃo INTRA-ESPECÍFICA DO EDEAGO}

Em quinze das espécies agora estudadas, dispusemos de exemplares de localidades diferentes, cobrindo áreas geográficas mais ou menos extensas, que permitiram uma verificação prévia da variação intra-específica dos caracteres do edeago.

A variação intra-específica da forma e das dimensões dos edeagos examinados, ampliada pelas descrições e figuras do material de Reyes-Castillo (1973), mostra-se pequena e mantem-se dentro dos limites das espécies ccnhecidas, mesmo nos casos em que foram examinados exemplares cobrindo uma distribuição ampla, como em P. interruptus (Tabela I) .

Comparando nossos resultados com os de Reyes-Castillo (1973), verificamos que para Verres furcilabris, Passalus rodocanthopoides e Passalus coniferus, as medidas calculadas pelas escalas dos desenhos daquele autor acham-se dentro dos limites da variação que observamos. O edeago de Popilius marginatus, representado por Reyes-Castillo (1973: 1945. fig. 1), é bem maior do que os agora estudados, provavelmente por incorreção na escala do desenho, que indica um edeago com cerca de $1 / 3$ do comprimento total do corpo dos exemplares. O edeago de Spasalus crenatus, repressentado por Reyes-Castillo (1973: 1557, 1558, fig. 7), mostra-se maior do que os dos dois exemplares estudados, ampliando bastan. te seu intervalo de variação. Os edeagos de Passalus convexus e Passalus glaberrimus, representados por Reyes-Castillo (1973: 15611562, fig. 10; 1574, fig. 18), são menores que os dos nossos exemplares, talvez em consequência do estado de dessecação do material daquele autor.

Em várias das espécies estudadas, dispusemos de amostras com mais de uma dezena de machos da mesma localidade, permitindo apurar casos de variação intrapopulacional do edeago. A área média ventral não esclerosada do tégmen mostrou contornos e extensão variáveis em Popilius marginatus, Verres furcilabris, Paxillus pentaphylloides (mesma população), Spasalus robustus, Passalus rodocanthopoides (mesma população), Passalus plicatus (mesma população) e Passalus interruptus (mesma população). Este aspecto do edeago não tem portanto, qualquer valor diferencial.

A torção que deforma o lobo médio e o tégmen no sentido horário em Passalus zikani, varia de intensidade dentro da mesma população.

O sulco transversal médio da área esclerosada do tégmen, em Popilius marginatus mostra-se mais extenso num exemplar do que noutro de localidade diferente, em Verres furcilabris é ausente no nosso material e parece existir no de Reyes-Castillo (1973: 1547, fig. 2) e em Passalus alius existe nos exemplares de uma localidade e falta nos de outra. Apesar das reduzidas amostras examinadas, pode tratar-se de uma variação interpopulacional. Esta variação prejudica o valor diferencial do carácter ao nível de espécie.

Verres furcilabris ainda apresentou diferenças entre os exemplares provenientes do Mato Grosso, cujo edeago é mais curto, com - lobo médio embutido no tégmen, e os exemplares do Amapá e do Amazonas, cujo edeago é mais longo, com o lobo médio mais livre, o que poderá se definir como uma variação interpopulacional, se amostras maiores daquelas localidades mostrarem as mesmas caracteristicas.

Em Passalus interruptus apareceram variações do edeago com maior probabilidade de serem interpopulacionais, sugerindo a possibilidade do seu uso no estudo da história da dis- 
tribuição das espécies de Passalidae. Passalus interruptus mostrou um edeago com a margem lateral distal dos lobos laterais sinuosa, em exemplares provenientes do Amapá, Mato Grosso, São Paulo e diferentes localidades do Pará, e outro com a margem lateral distal dos lobos laterais quase reta, em exemplares provenientes do Acre, Bahia e diferentes localidades do Amazonas.

TÉCNICAS DE PREPARO E REPRESENTAÇÃO DO EDEAGO DOS PASSALIDAE PARA ESTUDOS TAXONÔMICOS

A potencialidade demonstrada pelo edeago dos Passalídeos para estudos de sistemática e as dificuldades encontradas na comparação de nossos resultados com os de Reyes-Castillo (1970. 1970a e 1973), indicam a necessidade de uniformização das técnicas de preparo e representação do material.

O estudo de amostras de uma mesma espécie, como em Passalus interruptus, demonstrou que os resultados obtidos com edeagos de insetos fixados em líquido, aparentemente não diferem, tanto na forma quanto nas dimensões dos obtidos com edeagos de insetos dessecados e bem reidratados. Como o material dessecado e não inteiramente reidratado de ReyesCastillo (1973) apresenta indícios de deforma- ção, sugerimos que estudos futuros se desenvolvam preferencialmente com material fixado e conservado em líquido, e quando necessário, com material fixado e conservado por dessecação, mas demoradamente reidratado e passado para conservação em Ilquido.

Como os lobos laterais, por sua forma e posição, parecem caracterizar populações, várias espécies e até gêneros, recomenda-se, portanto sua descrição e representação em vista lateral, pois as vistas ventral e dorsal nem sempre esclarecem sua forma.

A importância dos esclerosamentos e outros acidentes superficiais do edeago como caracteres diferenciais, obriga sua descrição e representação de agora em diante e contraindica o uso de técnicas de diafanização.

O saco interno pode ser extraído para estudo de sua morfologia, com auxílio de uma incisão circular na área membranosa dorsal do lobo médio, sem preuízo de nenhum dos caracteres agora estudados.

A articulação do lobo médio cơm o tégmen no sentido ventro-dorsal, torna a medida de comprimento do edeago (Tabela I) um dado de pouca confiança para comparações, restando o comprimento e a maior largura da projeção de topo do tégmen, como as dimensões menos sujeitas às deformações que o edeago inteiro possa sofrer nos processos de fixação. 


\section{CONCLUSÓES}

A genitália masculina dos Passalidae compõe-se do edeago e um anel que o envolve. Este anel é constituído dorsalmente pelo décimo uroesternito e ventralmente pelo nono uroesternito em forma de ferradura.

$O$ edeago dos Passalidae mostra-se voltado para o dorso, mesmo quando em repouso no interior do abdome, com fortes indícios de ha. ver sofrido uma rotaçäo permanente de $180^{\circ}$ em torno do seu eixo longitudinal.

Todos os edeagos conhecidos de Passalidae têm a peça basal curta, os lobos laterais também curtos e o lobo médio globoso, destacado e relativamente livre, apenas acompanhado de cada lado ou latero-dorsalmente, pelos lobos laterais.

Todos os edeagos conhecidos de Passalidae são característicos para as espécies a que pertencem, ocorrendo apenas casos de seme Ihança entre os de Passalus punctiger e Passa. lus interruptus, Passalus interstitialis e Passalus coniferus, acompanhados no entanto de nítidas diferenças de tamanho.

As espécies estudadas do gênero Popilius aproximam-se pelo lobo médio maior que o tégmen e pelos lobos laterais muito curtos, caracteres que também as afastam dos demais gêneros.

As espécies estudadas do gênero Odonto. taenius aproximam-se pelo lobo médio mais estreito que o tégmen e pelos lobos laterais com a extremidade dorsal esclerosada e voltada para a base, caracteres que também as afastam dos demais gêneros, reforçando a re. validação deste gênero por Reyes-Castillo (1970a: 149, 150).

As espécies estudadas do gênero Paxillus aproximam-se pelo aspecto característico dos lobos laterais, com a extremidade bem destacada, arredondada e estendida latero-dorsalmente ao lobo médio, caracteres que também as afastam dos demais gêneros.
As espécies estudadas do gênero Spasalus, aproximam-se pelos lobos laterais curtos e destacados por reentrância ventro-lateral da margem distal do tégmen, caracteres que também as afastam dos demais gêneros, reforçan. do a revalidação deste gênero por Reyes-Castillo (1973: 1556-1557).

Apesar do gênero Verres ter apenas uma de suas espécies com o edeago conhecido, este é muito característico e se afasta de todos os dos demais gêneros, por ter o lobo médio muito maior que o tégmen, os lobos laterais curtos e ventro-laterais.

Apesar do gênero Ptichopus ter apenas uma de suas espécies com edeago conhecido, representado por Reyes-Castillo (1970a: 61). apresenta este órgão muito característico e distinto de todos os demais gêneros, por ter o tégmen muito longo em relação ao lobo médio.

As espécies do gênero Passalus, cujo edeago é conhecido, não apresentam caracteres nesse órgão que permitam correlacioná-las todas entre si. Duas espécies consideradas como do subgênero Mithrorhinus, mostram-se afins pelos edeagos com lobos laterais laterodorsais e separados da peça basal por reentrâncias laterais do tégmen. As espécies do subgênero Passalus s. str. seção "Phoroneus", mostram-se afins pelos edeagos com o tégmen longo e afunilado em direção à base, e os lobos laterais apontados latero-dorsalmente. As espécies do subgênero Passalus s. str. seção "Neleus", mostram-se afins pelos edeagos quase tão longos quanto largos e com os lobos laterais de posição dorsal ao lobo médio.

As espécies estudadas do gênero Veturius, não apresentam afinidades claras pelo edeago.

As conclusões prévias sobre a possível significado dos caracteres do edeago ao nível de gênero, indicam a conveniência de estender estes estudos a um maior número de espécies, principalmente em Veturius e Passalus, que 
merecem uma minuciosa revisão à luz de todos os caracteres de comprovado significado taxo. nômico.

A variação da forma e das dimensões dos edeagos estudados, mesmo nos casos em que foram examinados exemplares cobrindo uma distribuição ampla, mostra-se pequena e mantem-se dentro dos limites conhecidos para as espécies.

A ocorrência de caracteres do edeago com provável significado populacional, constatada principalmente em Passalus interruptus, sugere a possibilidade de seu uso no estudo da história da distribuição das espécies.
Os resultados obtidos com o estudo de edeagos de exemplares fixados em líquido, são muito próximos dos obtidos com material dessecado reidratado e passado para conservação em líquido.

Técnicas de diafanização não devem ser utilizadas no edeago para estudos taxonômicos. uma vez que seus esclerosamentos e outros acidentes superficiais revelaram-se bons caracteres diferenciais.

O comprimento e a largura da projeção de topo do tégmen, mostraram-se as medidas menos sujeitas às deformações que o edeago inteiro possa sofrer nos processos de fixação. 


\section{SUMMARY}

Studies of the male genitalia of the Passalidae (Coleoptera), giving special attention to structural homologies in the terminal abdominal somite, have revealed that the aedaeagus has probably undergone a permanent rotation of $180^{\circ}$ around its longitudinal axis. The investigation, based on detailed examinations of 26 species (14 from Amazonian Brazil) representing 7 genera (Odontotaenius, Popilius, Veturius, Verres, Paxillus, Spasalus and Passalus) provided data for an evaluation of the taxonomic significance of the aedaeagus and demonstrated that the structure adequately characterizes individual species and the majority of the genera studied. Intraspecific variation, although considerable in some cases, did not reduce the taxonomic usefulness of the aedaegus, but rather revealed possible interpopulational patterns which may take on additional significance in distributional studies. To facilitate future comparative analyses, suggestions have been presented for a standardized methodology in the preparation and representation of the aedaeagus in taxonomic investigations. 
AlleE, W.C.; PARK, O.; EMERSON, A.E.; PARK, T. \& SCHMIDT, K.P.

1949 - Principles of animal ecology. W. B. Saunders Co., London, XII + 837 pp., 263 figs.

ARRow, G.J

1907 - A contribution to the classification of the coleopterous family Passalidae. Trans. Ent. Soc. London, 1906: 441-469.

1951 - Horned beetles. A study of the fantastic in nature. W. Junk ed., The Hague. 154 pp., 15 ests.

AudoIn, J.V. \& Brullé, A.

1837 - Histoire Naturelle des Insectes. V.G. Coléoptères. Paris, III, $436 \mathrm{pp}$.

BABB, G.F.

1904 - On the stridulation of Passalus cornutus Fab. Ent. News, 12:279-281, fig.

BATES, H.W.

1886 - Biologia Centrali-Americana. Coleoptera Pectinicornia, 2(2):1-24, est. 1.

BLACKWELDER, R.E.

1944 - Checklist of the coleopterous insects of Mexico, Central America, the West Indies, and South America, Part 2. Bull. U.S. Nat. Mus., 185: 189-341.

BLATCHLEY, W.S.

1910 - The Coleoptera or beetles known to occur in Indiana, Bull. Ind. Dept. Geol. Nat. Res., (1): 1-1386, figs (apud Reyes-Castillo, 1970).

BÜHRNHEIM, P.F.

1961 - Redescrição de Passalus zikani Luederwaldt, 1929 (Coleoptera, Passalidae). Mems Inst. Oswaldo Cruz, 59 (3) : 251258, 29 figs.

1962 - Um novo Popilius Kaup, 1871 do leste meridional brasileiro (Coleoptera, Passalidae)). Mems Inst. Oswaldo Cruz, 60 (3): 303-309, 4 figs.

1963 - Redescrição dos tipos de Passalus gra velyi Moreira, 1922 e Passalus striatissimus Luederwaldt, 1934 (Coleoptera, Passalidae). Mems Inst. Oswaldo Cruz, 61 (2): 313-320, 2 figs.

1964 - Nota sobre anomalias em antenas de Passalus glaberrimus Eschsch., 1829 (Coleoptera, Passalidae). Atas Soc. Biol. Rio de Janeiro, 8(5): 56-58, 6 figs
BURMEISTER, H.C.

1847 - Handbuch der entomologie, vol. V, Coleoptera Lamellicornia et Pectinicornia. Eslim, Berlim, VIII +584 pp

CASEY, T.L.

1896-1897 (1897) - Coleopterological notices VII, Annals N.Y. Acad. Sci., 9: 285-684.

1914 - Miscellaneous notes and new species. Mem. Col., 5: 355-378.

Crowson, R.A.

1960 - The phylogeny of Coleoptera. Ann. Rev. Ent. 5: 111-134.

1967 - The natural classification of the families of Coleoptera, Nathaniel Lloyd Co., Ltd., London, $187 \mathrm{pp}$.

DALMAN, J.W.

1817 - In: C.J. SCHOENHERR, Signonymia insectorum oder Versuch einer synonymie aller bisher bekannten Insecten; nach Fabricii Systema Eleutheratorum geordnet, I, Eleutherata oder Käfer. Upsala, pt. 3: 1-506. (apud Reyes-Castillo, 1973).

DEJEAN, P.F.M.A.

1837 - Catalogue des Coléoptères de la Collection de M. le Comte Dejean. Paris, 3 ed.: 194-195. (apud Luederwaldt, 1931).

DOEsBuro, P.H. VAN.

1942 - Passalidae (Col. I) In: Beiträge zur Fauna Perus. Bd. I: 329-335.

DRAPIEZ

1819 - Ann. Geo. Sci. Physiol. Brux., I:50, est. IV, fig. 4 (apud Gravely, 1918).

ERICHSON, W.F.

1847 - Naturgeschichte der Coleopterorum quae in Republica Peruana observatae sunt. Arch. Naturgesch., 13: 67-185. (apud Reyes-Castillo, 1970).

ESCHSCHOLTZ, J.F.

1829 - Dissertatio de Coleopterorum genere Passalus. Mem. Soc. Imp. Nat., Moscou, 7: 13-28, (apud Reyes-Castillo, 1973); Sep.: 1-16.

1831 - Dissertation sur les coléoptères du genre Passale. Annls Sci. Nat. Paris, 22: 332-336 (apud Vulcano \& Pereira, 1967).

FABRICIUS, J.C.

1792 - Entomologia systematica emendatae et auctae. Hafniae, p. 2: 240-241. (apud Luederwaldt, 1931). 
1801 - Systema Eleutheratorum. Kiliae, II, 687 pp. (apud Reyes-Castillo, 1970).

GEMMIGER, M. \& HAROLD, E. von

1868 - Catalogus coleopterorum huscusque descriptorum synonymicus et systematicus. Monnachil, 3: 753-978. (apud Reyes-Castillo, 1970).

GRAVELY, F.H.

1914 - An account of the oriental Passalidae (Coleoptera), based primarily on the collection in the Indian Museum. Mem. Indian Mus., 3:177-353, est.

1918 - A contribution towards the revision of the Passalidae of the world. Mem. Indian Mus., 7(1):1-143, 16 figs.

GRAY, I.E.

1946 - Observations on the life history of the horned Passalus. Amer. Midl. Nat., 35(3): 728-746, 3 figs, 1 est.

GUERIN, C.

1953 - Coleopteros do Brasil. São Paulo, pp. 244-245.

Heynne, A. \& TASHeNBerg, O.

1908 - Die exotishen Käfer in Wort und Bild. J.F. Schereiber, Esslingen \& München, 310 pp., 39 ests.

Hincks, W.D.

1934 - Notes on the Passalidae (Coleoptera). n. 5. Synonymic notes, with the description of a new genus and new species. Entomologists mon. Mag., 70: 151-157 e $270-274$.

1949 - Systematic and synonymic notes on Passalidae (Col.), Ann. Mag. Nat. Hist., 12(2): $56-64, \mathrm{pl} . \mathrm{V}$.

1950 - XCVI. Systematic and faunistic notes on american Passalidae (Col.). Ann. Mag. Nat. Hist., 12(3): 1033-1047, 5 figs.

1953 - The Passalidae (Ins., Col.) of El Salvador. Senckenbergiana, 34(1-3): 29-35, fig.

HincKs, W.D. \& DIBB, J.R.

1935 - Coleopterorum Catalogus. Pars. 142: Passalidae. W. Junk., s'Gravenhage, 118 pp.

1958 - Coleopterorum Catalogus. Suplementa Pars 142: Passalidae. Uitgevery Dr. W. Junk., s'Gravenhage, $32 \mathrm{pp}$.

ILLIGER, J.C.W

1800 - In: Oliver, Entomologie oder Naturgeschichte der Insecten mit ihren Gattungen-undArt- Merkmalen, iher Beschreibung und Synonymie, übersetzt mit Anmerkun gen. Braunschweig, 1. 309 pp. (apud Reyes-Castiilo, 1970)

JEANNEL, $R$.

1955 - L'edéage. Publ. Mus. Nat. Hist., Paris, 16, 155 pp., 94 figs.
1965 - In: GRASSE, P.-P., Traité de Zoologie. Paris, IX,: 771-1077.

JEANNEL, R. \& PAULIAN, R.

1944 - Morphologie abdominale des coléoptères et systématique de l'ordre. Rev. Franc. d'Ent., 11: 66-110.

KaUP, J.J.

1868 - Prodomus zur einer Monographie der Passaliden. Coleopterologische Hefte, 3: 4-32.

1868 - Prodomus zur einer Monographie der Passaliden. Coleopterologische Hefte, 4: 1-31.

1869 - Prodomus zur einer Monographie der Passaliden. Coleopterologische Hefte, 5: $1-40$.

1871 - Monographie der Passaliden. Berl. ent. Z. 15: 1-126, 5 ests.

Krause, J.B.

1946 - The structure of the gonads of the woodeating beetle, Passalus cornutus Fabricius. Annls Ent. Soc. Amer., 39: 193-206, 4 ests, 17 figs.

Krause, J.B. \& Ryan

1953 - Annls ent. Soc. Amer., 41(1): 1-20, 4 ests.

KUWERT, A

1890 - Einige neue Passaliden. Dt. ent. Z., 1: 97-104.

1891 - Systematiche Uebersicht der Passaliden-Arten und Gattungen. Dt. ent. Z., 1: 161-192.

1896 - Die Passaliden Dichotomisch Bearbeitet. Nov. Zool., 3: 209-235, V-VII.

1897 - Die Passaliden Dichotomisch Bearbeitet. 2 ter. Theil-Die Arten, Nox. Zool., 4: 274-306.

1898 - Die Passaliden Dichotomisch Bearbeitet. 2 ter. Theil-Die Arten, Nov. Zool., 5: 137-205.

1898 - Die Passaliden Dichotomisch Bearbeitet. 2 ter. Theil-Die Arten, Nov. Zool., 5(3); 259-349.

LAporte, F. (Comte. de Castelnau)

1840 - Histoire naturelle des animaux articules. Paris, Vol. 1, 324 pp. (apud Reyes-Castillo, 1970).

LATREILle, P.D

1807 - Genera crustaceorum et insectorum secundum ordinem naturalem, in familiae disposita, iconibus exemplisque plurimus explicata. Paris, vol. 2, 280 pp. (apud Reyes-Castillo, 1970).

1817 - Insectes, In: CUVIER, Régne animal. Paris, vol. 3, 653 pp., (apud Reyes-Castillo, 1970).

LECONTE, J.L. \& HORN, G.H.

1833 - Classification of the Coleoptera of North America. Prepared for the Smith- 
sonian Institution. Smithson, Misc. Coll., 26(4): 235-236

Lepeletier de SAINT Fargeau \& Audinet-Servilu.e, J.G. 1825 - Passale. In: Encyclopédie méthodique Histoire naturelle. Paris, X: 19-21. (apud Reyes-Castillo, 1973).

LEWIS, H.C.

1956 - The alimentary canal of Passalus. Ohio J. Sci., 26(1): 11-24, 14 figs.

LINDROTH, C.H. \& PALMÉN, E.

1970 - In: TUXEN, S.L., (Ed.), Taxonomists glossary of genitalia in insects. Copenhagen, Munksgaard, 2nd ed.

LiNNAEUS, C.

1758 - Sistema naturae per regna tria naturae secundum classes, ordines, genera, species, cun characteribus differentiis, synonymis, locis. Holmiae, ed. 10, vol. $1,833 \mathrm{pp}$.

1764 - Museum Ludovicae Ulricae Reginae. Stockholm (apud Gravely, 1918).

1767 - Systema Naturae, Stockholm, I(2), ed. XII. (apud Gravely, 1918).

LUEDERWALDT, $\mathrm{H}$.

1927 - Cinco novas espécies da família dos Passalídeos (Col. 1), Bolm Mus. Nac., Rio de Janeiro, (2): 37-38.

1927(a) - Passalus tetraphyllus Eschscholtz, é um Popilius. Bolm Mus. Nac., Rio de Janeiro, (3): 65-66.

1929 - Passalus zikani n. sp. (Col. Lamellia, Passalidae), Bolm Mus, Nac., Rio de Janeiro, (2): 31 .

1931 - Monographia dos Passalídeos do Bra sil (Col.) Revta Mus. paul., 17(1): 1-262, 2 pls.

1931(a) - Notas sobre passalídeos americanos (Col. Lamell.) Revta Ent., Rio de Janeiro, (1): 62-65, fig.

1934 - O gênero Publius com uma chave para classificação dos gêneros da subfamília Proculinae (Col. Lam., Passalidae), Revta Mus. paul, 18(1): 1-15 (sep.)

1934(a) - Revisão do gênero Paxillus. (Col. Lamell. Passalidae). Revta Mus. paul., 18(5): 1.15 (sep.)

1934(b) - Corrigenda e Suplemento à Monographia dos Passalídeos no Brasil. Revta Mus. paul., 18(6): 1-5 (sep.).

1934(c) - Novos passalídeos americanos (Coleoptera), Bolm Biol,, São Paulo, 2(1): 19-21.

1941 - Passalídeos americanos. Arq. Zool. S. Paulo, 3: 75-91, 8 figs.

MACLEAY, W.S.

1819 - Horae entomologicae or essays on the annulose animals. Richard and Arthur, London, vol. I(1), 524 pp., 3 ests. (apud Reyes-Castillo, 1973).
Metcalf, M.E.

1932 - The structure and development of the reproductive system in Coleoptera with notes on its homologies. Quart. J. Micr. Sci., 75: 49-129, ests 7-10.

MoreIrA, C.

1921(1922) - Coléoptères passalides du Brésil. Annls Soc. Ent. Fr., 90: 255-294, 26 figs.

1925 - Insetos coleópteros passalídeos do Brasil. Fauna bras., n. ser., 1: 5-52, figs.

OHaUs, F.

1909 - Bericht über eine entomologische Studienreise in Südamerika. Stett. Ent. Ztg., 70: 3-139. (apud Luederwaldt, 1931).

OLIVIER, A.G

1789 - Entomologie ou Histoire Naturelle des Insectes. Paris. (apud Vulcano \& $\mathrm{Pe}$ reira, 1967).

Pangella, G.

1905 - Passalidi di Costa Rica. Boll. Musei Zool. Anat. Comp. R. Univ. Torino, 20(498): $1-12$.

1905(a) - Viaggio del Dr. Alfredo Borelli nel Paraguay e nella Republica Argentina. Passalidi. Boll. Musei Zool. Anat. Comp. R. Univ. Torino, 20(508): 1-16.

PARK, O.

1937 - Studies in nocturnal ecology. Further analysis of activity in the beetle, Passalus cornutus, and description of audio frequency recording apparatus, J. Anim. Ecol., 6(2):239-253, figs.

PATTERSON, M.T.

1937 - The cellular structure of the digestive tract of the beetle Passalus cornutus Fabricius. Annls Ent. Soc. Amer., 30(4): $619-640,25$ figs.

PAULIAN, R.

1947 - Scarabaeoidea. Coléoptères des Antilles, vol. I., Fn. Emp. Français VII: pp. 17.23, figs. 1-8.

Pearse, A. S.; Patterson, M. T.; Rankin, J. S. \& WHARTON, G.W.

1936 - The ecology of Passalus cornutus Fabricius, a beetle which live in rotting logs, Ecol. Monogr., 6(4): 455-490, 43 figs., 8 ests.

PERCHERON, A.

1835 - Monographie des passales, et des genres qui en ont été séparés; accompagnés de planches dessinées par l'auteur, ou toutes les espèces on été figurées, Libr. de J. Albert Marcklein, Paris, 108 pp. VII pls.

1841 - Révision critique et supplément a la monographie du genre Passale; première partie, Mag. Zool., 253: 11-48, ests 77-79. 
PEREIRA, F.S.

1939 - Duas espécies novas de passalídeos. Bolm Biol., (n. ser.), São Paulo, 4(1): 79-81.

1941 - Contribuição para o conhecimento dos Pseudacanthinae (Col. Passalidae). Arq. Zool. S. Paulo, 3: 93-111, 6 figs.

1944 - Lucanidae, Passalidae e Scarabaeidae de Monte Alegre. Papéis avulsos Zool. S. Paulo, 6(8): 81-92.

PEREIRA, F.S. \& KLoss, G.R.

1966 - Observações sobre o intestino posterior de alguns Passalidae (Col.) americanos. Papéis avulsos Zool. S. Paulo, 19(3): 43-52, 24 figs.

PERTY, J.A.M.

1830 - Insecta Brasiliensia. In: Delectus animalium articulatorum, fasc. 1: 1-60 (apud Reyes-Castillo, 1973).

Reyes-Castillo, P.

1970 - A new species of Neotropical Passalidae (Coleoptera, Lamellicornia) Ent. Arb. Mus. Frey, 21: 3-12.

1970(a) - Coleoptera, Passalidae; Morfologia y División en Grandes Grupos; Géneros Americanos, Folia Ent. mexicana, (20-22): $1-240$, figs, 3 fots.

1973 - Passalidae de la Guyana Francesa (Coleoptera, Lamellicornia). Bull. Mus. natn. Hist. Nat., Paris, 3a série, 197, Zoologie 129: 1541-1587.

REYes-CASTILLO, P. \& RICHTER, P.O

1973 - Ovariole number in Passalidae (Coleoptera), Proc. Ent. Soc. Wash., 75(4): 478-479.

ROBERTSON, J.G.

1961 - Ovariole numbers in Coleoptera, Canad. J. Zool., 39: 245-263.

ROSMINI, O.

1902 - Viaggio del Dr. Enrico Festa nella Republica dell'Ecuador e regioni vicine. Bol. Musei Zool. Anat. Comp., Torino, 17(428): 1-10.

SCHAFFER, E.L.

1917 - Mitochondria and other cytoplasmic structures in the spermatogenesis of Passalus cornutus. Biol. Bull. Wood's Hole, 32: 407-434.

SCHOENHERR, C.J.

1817 - Synonymia Insectorum. Paris, Appendix, I, Pars 3. (apud Luecierwaldt, 1931).

SCUDDER, G.G.E.

1971 - Comparative morfology of insect genitalia, Ann. Rev. Ent., 16: 379-406.

SHARP, D. \& MUIR, F.

1912 - The comparative anatomy of the male genital tube in Coleoptera. Trans. Ent. Soc. London: 477-642, est. 42-78.
SMTTH, F.

1852 - Nomenclature of Coleopterous Insects in the Collection of the British Museum. London, Part IV. Passalidae, 24 pp. 1 est. (apud Reyes-Castillo, 1970).

SNODGRASS, R.E.

1935 - Principles of Insect Morphology . McGraw-Hill, N.Y., IX + 667 pp.

Trueui, M.E.

1857 - Enumeration des espèces mexicaines du genre Passalus, avec um tableau synoptique de toutes les espèces et la description de celles qui sont nouvelles. Rev. Zool., 2a Ser., 9: 258-269 e 308-317.

TUXEN, S.L. (Ed.)

1970 - ver LINDROTH \& PALMÉN.

Virkki, N. \& Reyes-Castillo, P

1972 - Citotaxonomy of Passalidae (Coleoptera). An. Esc. Nac. Cienc. Biol. Méx., 19: 49-83.

Vulcano, M.A. \& Pereira, F.S.

1967 - Sinopse dos Passalidee e Scarabaeidae s. str. da Região Amazônica (Insecta, Coleoptera). Atas do Simpósio sobre a Biota Amazônica, 5 (Zoologia): 533-603 $+3 \mathrm{pp}$. errata.

WEBER, F.

1801 - Observationes Entomologicae, Kiliae (apud Luederwaldt, 1931).

WESTWOOD, J.O.

1845 - A catalogue of the Lucanoid Coleoptera in the collection of the rev. F.W. Hope, M. A., F. R.S. \& C., President of the Entomological Society of London. Together with description of new species therein contained. London, 29 pp. (apud Reyes-Castillo, 1970).

WYTSMANN, P.

1844 - Catalogue Svstématique des Passalides. Annls Cir. Mus. Genova, (2a) I (XXI): 236-348 (apud Gravely, 1918).

ZANG, R.

1903 - Bemerkungen zur aelteren Passaliden-Literatur. Dt. Ent. Z.: 417 (apud Pereira, 1941).

1904 - Ueber einige Passaliden, Tydscht. v. Ent., XLVII: 181-185.

1905 - Neotropiche und indo-australiche Passaliden. Dt. Ent. Z., 1: 164-167.

1905(a) - Dreizehn neuen Passaliden. Dt. Ent. Z., 2: 225-245.

1905(b) - Diagnosen neuer Passaliden, Dt. Ent. Z., 2: 315-316.

1905(c) - Note XX. Passalidarum Synonymia. Kristiche Revision der von Kuwert und anderen autoren aufgestellten Gattungen und Arten. Not. Leyden Mus., 25: 221-232 (apud Reyes-Castillo, 1970). 


\section{APENDICE}

\section{MATERIAL EXAMINADO}

Todos os exemplares dissecados para estudo do edeago, seguem abaixo relacionados pelo nome, autor e data da espécie, número de exemplares examinados, Estado do Brasil ou país de procedência, dados de localidade e data de coleta, sigla da coleção a que pertencem e número de registro, sexo, indicação do indivíduo cujo edeago foi desenhado e o método pelo qual se encontrava conservado. O coletor ou coletores, só estão citados em exemplares que pertencem a coleções não numeradas.

Dentre os 213 indivíduos examinados pertencentes a 26 espécies diferentes, foram encontrados 110 machos, cujos edeagos serviram ao presente estudo.

Popilius marginatus (Percheron, 1835) -3 , PA, Belém, $\mathrm{Km} 90$ Belém-Brasília, Faz. Canđiru, P. Waldyr col., 27/VIII/1972. MPEG (um macho e duas fêmeas), dessecados reidratados; $-2, \mathrm{MT}$, Utiariti, rio Papagaio, VII-VIII/1961, K. Lenko col., MZSP (um macho des. e uma fêmea), desseca. dos reidratados.

Popilius refugicornis Bührnheim, 1962 -5, ES, Linhares, Sooretama, 23-28/III/1959, IOC 9.515 (des.) e 9.517 (machos), $9.514,9.516$ e 9.518 (fêmeas), dessecados reidratados; -1, RJ, Petrópolis, Parque São Vicente, $4 / \mathrm{XII} / 1960$, IOC 9.519 (macho), dessecado reidratado; -2 , RJ, São Fidelis, Alvarenga col., VII/1956, MZSP (fêmea), dessecados reidratados; $-1, \mathrm{RJ}$, Rio de Janeiro, Grajaú, 2/VI/1956, IOC 9.513 (macho), dessecado reidratado; -1 , SP, Tremembé, J. Halik, XII/1939, MZSP (fêmea), dessecado reidratado.

Popilius tetraphyllus (Eschescholtz, 1829) -2, AM, Manaus, K. Lenko col., IX/1963, MZSP (macho des.), dessecados reidratados.

Odontotaenius disjunctus (Illiger, 1800) -4 , EUA, Michigan, Allegan, 12/VI/1912, IOCZ 6.789 (des.) e 6.794 (machos), 6.788 e 6.795 (fêmeas), dessecados reidratados; -2, EUA, N. Carolina, Ascheville, 20/IV/1913, IOCZ 6.796 (macho), 6.790 (fêmea), dessecados reidratados; -2, EUA, Illinois, Willowspring, 15/VI/1930, IOCZ 6.792 (macho), 6.790 (fêmea), dessecados reidratados.

Veturius libericornis Kuwert, 1891 -5, PA, Belém, Utinga, 22/IX/1968, IOC 14.761 (des.) e 14.840 (machos), 14.762, 14.841 e 14.842 (fêmeas) álcool.
Veturius assimilis (Weber, 1801) -2, MG, Barreira do Piquete, Serra da Mantiqueira, 6-11/I/1961, IOC 14.755 (macho), 14.765 (fêmea), álcool; -3, SP, Paranapiacaba, 7/IV/1972, ZUEC 199 (macho des.), 200 e 201 (fêmeas), álcool; -1, SP, Represa Barra Bonita, 18/XI/1972, ZUEC 271 (macho), álcool

Veturius punctatostriatus Arrow, 1907 -3, AP, Serra do Navio, $27 / \mathrm{X} / 1968$, IOC 14.760 (macho des.), 14.925 e 14.926 (fêmeas), álcool.

Verres furcilabris (Eschscholtz, 1829) -2, AP, Serra do Navio, $27 / \mathrm{X} / 1968$, IOC 14.758 (macho des.) e 14.828 (fêmea), álcool; -1, AM, Manaus, Res. Ducke, $3 / \mathrm{X} / 1968$, IOC 14.827 (macho), álcool; 4, MT, Alto Araguaia, Faz. Morro do Fogo, $1-10 / \mathrm{VII} / 1972$, ZUEC, 255, 256 e 257 (machos), 258 (fêmea), álcool.

Paxillus pentaphylloides Luederwaldt, 1931 -30, SP, Campinas, diversas datas, ZUEC 32,53 a 62,96 , $97,315,331$ e 332 (des.) (machos), 33, 63 a 71 , 94, 95, 305 e 330 (fêmeas), álcool; -1, ES, Faz. Jerusalém 2/II/1913, IOCZ 7306 (macho), des. secado reidratado.

Paxillus forsteri Luederwaldt, 1927 -1, GO, Campi. nas, VIII/1927, P. Forster col, Parátipo, MZSP (macho des.), dessecado reidratado; -2 , GO, DF, Brasilia, I/1961, IOC 14.757 (macho) e 14.756 (fêmea), dessecados reidratados.

Paxillus lanei Pereira, 1939 -1, MT, Salobra, EFNB, 18-29/X/1938, Comissão IOC col., Holótipo, MZSP (macho des.), dessecado reidratado.

Spasalus crenatus (MacLeay, 1819) -1, AM, Manicoré, rio Madeira, IOCZ 7.213 (macho), dessecacado reidratado; -1 , AM, Benjamin Constant 18-28/IX/1962, K. Lenko col., MZSP (macho des.), dessecado reidratado.

Spasalus robustus (Percheron, 1835) -1, SP, Săo Paulo, Alto da Serra, XI/1925, IOCZ 7.215 (macho des.), dessecado reidratado; -1, SP, Apiaf, IOC 14.855 (macho), álcool; 1, RJ, Itatiaia, Est. Biológica, 1/VIII/1933, IOCZ 7.233 (macho), dessecado reidratado.

Passalus rhodocanthopoides (Kuwert, 1891) -27, AP, Serra do Navio, 27/X/1968, IOC 14.780 (des.) e 14.801 a 14.810 (machos), 14.811 a 14.826 (fêmeas), álcool.

Passalus morio Percheron, 1835 -6, MG, Jaboticatubas, Serra do Cipó, diversas datas, ZUEC 409 (macho), 368, 369, 370, 407 e 408 (fêmeas), ál- 
cool; -1, RJ, Rio de Ianeiro, Grajaú, 15/XI/1960, IOC 14.877 (macho), álcool; -4 , SP, Campinas, diversas datas, ZUEC 340 (des.), 341 e 342 (machos), 270 (fêmea), álcool.

Passalus punctatostriatus Percheron, $1835-5$, SP, Mogi das Cruzes, Taiaçupeba, 25/VI/1972, ZUEC, 202 (des.), 203 e 204 (machos), 205 e 206 (fêmeas), álcool.

Passalus convexus Dalman, 1817 -5, PA, Belém, IAN, $25 / \mathrm{IX} / 1968$, IOC 14.771 (des.) e 14.797 (machos), 14.798 a 14.800 (fêmeas), álcool; -5 , RJ, Rio de Janeiro, Tijuca, $7 / \mathrm{X} / 1972$, IOC 14.774 e 14.777 (machos), $14.782,14.785$ e 14.787 (fêmeas), álcool.

Passalus gravelyi Moreira, 1922 -1, RJ, Itatiaia, Macieiras, 21/VII/1933, IOCZ 7.985 (macho des.), dessecado reidratado.

Passalus zikani Luederwaldt, 1929 -2, RJ, Itatiaia, Maromba, 1/IV/1937, IOCZ 7.669 (des.) e 7.671 (machos), dessecados reidratados.

Passalus occipitalis Eschscholtz, 1829 -2, RJ, Rio de Janeiro, Paineiras, 22/I/1961, IOC 14.776 (des.) e 14.796 (machos), álcool; -3 , RJ, Rio de Janeiro, Tijuca, $4 / \mathrm{XI} / 1962$, IOC 14.835 e 14.836 (machos) e 14.837 (fômeas), álcool.

Passalus alius (Kuwert, 1898) -2, MG, Barreira do Piquete, 06-11/I/1961, IOC 14.779 (des.) e 14.791 (machos); -3, MG, Jaboticatubas, Serra do Cipó, 12/II/1974, ZUEC 392 e 393 (machos) e 410 (fêmea), álcool; -1, MG, Jaboticatubas, Serra do Cipó, 1/XI/1973, ZUEC 367 (fêmea), álcool.

Passalus quadricollis Eschscholtz, $1829-2$, RJ, Rio de Janeiro, Tijuca, 2-3/XI/1962, IOC 14.775 (des.) e 14.789 (machos), álcool.

Passalus glaberrimus Eschscholtz, 1829 -2, AM, Manaus, Reserva Ducke, $3 / \mathrm{X} / 1968$, IOC 14.773 (macho des.), 14.784 (fêmea), álcool.
Passalus plicatus Percheron, $1835-4$, MG, Barreira do Piquete, 6-11/I/1961, IOC 14.778 (des.), 14.794 e 14.795 (machos), 14.793 (fêmea), álcool; -22, MG, Jaboticatubas. Serra do Cipó, 1973 e 1974, ZUEC $371,372,374,394,397$ a 400 e 411 a 413 (machos), 373, 395, 396, 401 a 406,414 e 415 (fêmeas), álcool.

Passalus coniferus Eschscholtz, 1829 -7, SP, Campinas, 12/X/1969, ZUEC 01 (des.), 02 e 03 (machos), 04, 05, 06 e 07 (fêmeas), álcool.

Passalus interruptus (Lin., 1758) -2, AP, Serra do Navio, 29/X/1968, IOC 14.792 (macho des.) e 14.829 (fêmea), álcool; -3 , AM, São Paulo de Olivença, 10/VII/1935, IOCZ 14.254 e 14.255 (machos), 14.303 (fêmea), dessecados reidratados; -2, AM, Itacoatiara, III/1936, IOCZ 14.258 (macho des.) e 14.259 (fêmea), dessecados reidratados; -2, PA, Cachimbo, 14-21/IX/1955, IOC 14.839 e 14.844 (fêmeas), dessecados reidratados; -1 , PA, Cachimbo, 25-9/X/1956, IOC 14.858 (fêmea), dessecado reidratado; -3 , PA, Mosqueiro, $15 / \mathrm{XI} / 1956$, IOC 14.830 (macho des.), 14.831 e 14.832 (fêmeas), dessecados reidratados; -1, PA, Belém, 4/IX/1959, IOC 14.834 (macho), dessecado reidratado; -2, AC, Porto Walter, Faz. São Geraldo, 3/II/1973, ZUEC 290 (macho des.) e 291 (fêmea), álcool; -1, MT, Colonia Terenos, 10/XII/1936, IOC 14.292 (macho des.), dessecado reidratado; -1 , GO, Campinas, 11-19/II/1945, IOC 14.279 (fêmea), dessecado reidratado; -2, BA, Agua Preta, sem data, IOCZ 14.261 (macho des.) e 14.283 (fêmea), dessecados reidratados; -1, SP, Campinas, 9/XI/1971, ZUEC 194 (macho des.), álcool; -1, Paraguai, Chaco, Rio Confuso, II/1940, IOC 14.838 (fêmea), dessecado reidratado. 


\section{INDICE DAS ESPÉCIES ESTUDADAS QUE OCORREM NA AMAZONNIA}

Popilius marginatus (Percheron, 1835) ............ 10

Popilius tetraphyllus (Eschscholtz, 1829) ........... 12

Veturius libericornis Kuwert, $1891 \ldots \ldots \ldots \ldots \ldots \ldots .15$

Veturius punctatostriatus (Arrow, 1907) .......... 16

Verres furcilabris (Eschscholtz, 1829) ........... 16

Paxillus pentaphylloides Luederwaldt, 1931* ........ 18

Spasalus crenatus (MacLeay, 1819) ............. 20

Passalus rhodocanthopoides (Kuwert, 1891) ........ 22

Passalus morio Percheron, $1835^{*} \ldots \ldots \ldots \ldots \ldots \ldots .23$

Passalus punctatostriatus Percheron, $1835^{*} \ldots \ldots \ldots \ldots .24$

Passalus convexus Dalman, $1817 \ldots \ldots \ldots \ldots \ldots \ldots .26$

Passalus glaberrimus Eschscholtz, 1829 ........... 32

Passalus coniferus Eschscholtz, $1829^{*} \ldots \ldots \ldots \ldots \ldots .34$

Passalus interruptus (Lin., 1758) ............... 36

(•) - (Estudadas em material não Amazônico).

(Aceito para publicação em 22/11/77) 


\section{INDICE DAS ESPÉCIES ESTUDADAS QUE OCORREM NA AMAZONNIA}

Popilius marginatus (Percheron, 1835) ............ 10

Popilius tetraphyllus (Eschscholtz, 1829) ........... 12

Veturius libericornis Kuwert, $1891 \ldots \ldots \ldots \ldots \ldots \ldots . \ldots$

Veturius punctatostriatus (Arrow, 1907) ........... 16

Verres furcilabris (Eschscholtz, 1829) ............. 16

Paxillus pentaphylloides Luederwaldt, 1931* ........ 18

Spasalus crenatus (MacLeay, 1819) ............. 20

Passalus rhodocanthopoides (Kuwert, 1891) ......... 22

Passalus morio Percheron, $1835^{*} \ldots \ldots \ldots \ldots \ldots \ldots .23$

Passalus punctatostriatus Percheron, $1835^{*} \ldots \ldots \ldots \ldots .24$

Passalus convexus Dalman, $1817 \ldots \ldots \ldots \ldots \ldots \ldots .26$

Passalus glaberrimus Eschscholtz, 1829 .......... 32

Passalus coniferus Eschscholtz, $1829^{\circ} \ldots \ldots \ldots \ldots \ldots .34$

Passalus interruptus (Lin., 1758) ............... 36

(•) - (Estudadas em material não Amazônico). 